NBER WORKING PAPER SERIES

\title{
SMALL HIGH SCHOOLS AND STUDENT ACHIEVEMENT: LOTTERY-BASED EVIDENCE FROM NEW YORK CITY
}

\author{
Atila Abdulkadiroğlu \\ Weiwei Hu \\ Parag A. Pathak \\ Working Paper 19576 \\ http://www.nber.org/papers/w19576
}

\author{
NATIONAL BUREAU OF ECONOMIC RESEARCH \\ 1050 Massachusetts Avenue \\ Cambridge, MA 02138 \\ October 2013
}

We thank Jennifer Bell-Ellwanger, Neil Dorosin, Stacey Gillett, Saskia Levy-Thompson, Jesse Margolis, Michelle Paladino, and officials at the New York City Department of Education for providing access to the data used in this study. We are grateful to Elizabeth Kelly and school officials at The Urban Assembly and MAK Mitchell for helpful discussions. A special thanks to Dick Murnane for encouraging us to pursue this work. Josh Angrist, Annice Correira, Sameer H. Doshi, Esther Duflo, and Peter Hull provided helpful comments. Pathak is grateful for the hospitality of Graduate School of Business at Stanford University where parts of this work were completed and the National Science Foundation for research support. The views expressed herein are those of the authors and do not necessarily reflect the views of the National Bureau of Economic Research.

At least one co-author has disclosed a financial relationship of potential relevance for this research. Further information is available online at http://www.nber.org/papers/w19576.ack

NBER working papers are circulated for discussion and comment purposes. They have not been peerreviewed or been subject to the review by the NBER Board of Directors that accompanies official NBER publications.

(C) 2013 by Atila Abdulkadiroğlu, Weiwei Hu, and Parag A. Pathak. All rights reserved. Short sections of text, not to exceed two paragraphs, may be quoted without explicit permission provided that full credit, including (C) notice, is given to the source. 
Small High Schools and Student Achievement: Lottery-Based Evidence from New York City Atila Abdulkadiroğlu, Weiwei Hu, and Parag A. Pathak

NBER Working Paper No. 19576

October 2013

JEL No. H52,I21,I28,J24

\begin{abstract}
One of the most wide-ranging reforms in public education in the last decade has been the reorganization of large comprehensive high schools into small schools with roughly 100 students per grade. We use assignment lotteries embedded in New York City's high school match to estimate the effects of attendance at a new small high school on student achievement. More than 150 unselective small high schools created between 2002 and 2008 have enhanced autonomy, but operate within-district with traditional public school teachers, principals, and collectively-bargained work rules. Lottery estimates show positive score gains in Mathematics, English, Science, and History, more credit accumulation, and higher graduation rates. Small school attendance causes a substantial increase in college enrollment, with a marked shift to CUNY institutions. Students are also less likely to require remediation in reading and writing when at college. Detailed school surveys indicate that students at small schools are more engaged and closely monitored, despite fewer course offerings and activities. Teachers report greater feedback, increased safety, and improved collaboration. The results show that school size is an important factor in education production and highlight the potential for within-district reform strategies to substantially improve student achievement.
\end{abstract}

$\begin{array}{ll}\text { Atila Abdulkadiroğlu } & \text { Parag A. Pathak } \\ \text { Duke University } & \text { Department of Economics, E17-240 } \\ \text { Department of Economics } & \text { MIT } \\ \text { Durham, NC 27708 } & 77 \text { Massachusetts Avenue } \\ \text { atila.abdulkadiroglu@duke.edu } & \text { Cambridge, MA 02139 } \\ \text { and NBER } & \text { ppathak@mit.edu } \\ \text { Weiwei Hu } & \\ \text { Department of Economics } & \\ \text { Duke University, NC 27708, USA } & \\ \text { weiwei.hu@duke.edu } & \end{array}$

Parag A. Pathak

Department of Economics, E17-240

Cambridge, MA 02139

and NBER

ppathak@mit.edu 


\section{Introduction}

One of the most significant trends in US public education in the last half-century has been the emergence of large comprehensive high schools, which teach a range of students a wide variety of curricula. In 1950, there were about 24,500 high schools educating 5.7 million students across the United States. Even though the total high school population increased more than 2.3 times, by 2000 there were only about 1,900 more high schools, implying that average high school size increased from about 230 to just over 500. In the past fifty years, the percent of high schools enrolling more than 1,000 students grew from 7 to 25 percent and from 1990 to 2000, the number with more than 1,500 students doubled (Lawrence, 2002; NCES, 2010). The postwar consolidation and growth in high school size represents the culmination of aggressive efforts by advocates including Harvard University's President James Conant who called for the "elimination of the small high school" and for the extension of the high school curriculum beyond traditional academic areas (Conant, 1959; Toch, 2003).

Proponents of school consolidation see large comprehensive high schools as realizing scale economies by educating more students with the same facilities, staff, and resources. They also point to a greater diversity of curricular and extra-curricular offerings and the potential for interaction across a range of socioeconomic groups. At the same time, in large schools, there may be challenges in monitoring students. Resources spent maintaining order and discipline could otherwise be used to educate students. Moreover, teachers may face difficulties providing personalized instruction and developing long-term relationships with students. More individualized attention and frequent interaction may improve students' sense of belonging and provide focus in schools' curricula and culture (Toch, 2003; Iatarola, Schwartz, Stiefel and Chellman, 2008).

In the last decade, perhaps the most wide-ranging reform in public K-12 education involved the restructuring of large, underperforming high schools into small schools. Since the 200102 school year, about 1,600 new small schools have been created in the United States (Toch, 2010). More than half of the nation's largest urban school districts have transformed some large high schools into smaller ones and the Gates Foundation has pushed small school efforts in 275 districts nationwide (Brynes, 2003; Robelen, 2005). Some are entirely new schools, while others involve the conversion of formerly large high schools into several small schools. The most significant changes have taken place in New York City (NYC), the nation's largest school district where more than 150 new unselective small high schools with 9th grade have opened since 2002.

The purpose of this paper is to assess the causal effects of attendance at new small high schools in New York City on student achievement, graduation, and college. Aside from size, the common features of NYC's small schools are "academic rigor, personalized learning environments, and partnerships with non-profit organizations, cultural institutions, and businesses that 
bring additional resources to enhance learning" (Klein, 2005). Schools formed as part of the New Century High School Initiative commit to educational principals, but are free to make choices about curricula and principals operate with more autonomy (Hemphill and Nauer, 2009). Many have specific themes or career focus, including science and technology, arts and humanities, career and professional training, or leadership and service. A unique feature of the New York City's small school initiative is that it has been implemented in partnership with the NYC's Department of Education (DOE), the United Federation of Teachers, and the Council of Supervisors and Administrators (NVPS, 2006). In particular, teachers and principals at small schools have their salaries and benefits set based on district-wide collective bargaining agreements. Therefore, our study not only provides evidence of the role of school size in education production, but also whether effective secondary school reform can take place within the existing traditional public school system.

The evaluation of small schools is made difficult by the fact that the schools may select motivated students with involved parents, by giving preference to those who attend information sessions or open houses (see, e.g., Gootman (2006b)). As a result, just as in any study of school models, selection bias is the major empirical challenge in studying the effects of the new small high schools. To obtain a seat at a small high school a student must apply via the New York City high school match, a centralized process that assigns all entering high school students to city schools (Abdulkadiroğlu, Pathak and Roth, 2005; Abdulkadiroğlu, Pathak and Roth, 2009). Unlike other NYC public high schools (many of which screen applicants), if there are more applicants than seats, then assignment to an unselective small school involves a random component. If two students rank a particular school as their most preferred choice and are in the same school priority group, then the student with the more favorable lottery number will be offered the seat before the student with a less favorable lottery number. Using this random variation, we are able estimate causal effects free of selection bias for 108 out of 151 new, small unselective high school programs.

Students who attend the schools in our study would otherwise attend traditional New York City public high schools, though predominantly in the Bronx and Brooklyn neighborhoods where small schools were created. NYC public schools serve a disproportionately black and Hispanic student population. Like many urban school districts, NYC students have lower test scores and high school graduation rates, and are less likely to go to college than students from nearby districts. Relative to this group, NYC small schools serve an even higher fraction of black and Hispanic students, with below-average baseline scores. Though our paper focuses on more than $70 \%$ of oversubscribed schools, it's worth noting that we cannot use our methodology to study schools that are not oversubscribed. We therefore see our lottery estimates as providing unusually clean evidence about possibilities for urban small schools reform, rather than an 
overall small school treatment effect. The effects of small schools in urban populations are of special interest given the paucity of examples of successful interventions for this population, in particular for outcomes related to college choice and enrollment. ${ }^{1}$

Lottery-based estimates show large and consistent score gains for students who attend a small high school on New York State Regents tests, statewide high-stakes exams required for graduation. Students score higher on all five of the major Regents tests: Mathematics, English, Living Environment, Global History, and United States History. Small school attendance causes an increase in credit accumulation, attendance, and graduation rates. Though small school students perform no better on the PSAT or SAT, they are considerably more likely to enroll in college and are less likely to require remediation in reading and writing. A significant fraction of small school students are pushed to four-year public institutions and those within the City University of New York (CUNY) system. The evidence, so far, indicates that they are more likely to matriculate for at least two academic semesters.

New York City's Department of Education enlisted the support of several intermediary organizations in designing and supporting new small schools. Although they were established around a common set of principals set by the Gates Foundation, the intermediaries differed in their implementation of those principals. Seven out of the 18 intermediaries - New Visions, Replications, Urban Assembly, NYC Academies, Institute for Student Achievement, College Board, and Outward Bound - established more than 90 percent of the schools during the time of our study. We also report on an investigation of achievement differences across these intermediaries. With a few exceptions, we find broadly consistent effects for the main outcomes though usually with reduced statistical precision. This pattern suggests that idiosyncratic implementation details introduced by intermediaries are trumped by larger changes associated with significantly smaller school size.

After documenting small school effects, we turn to an investigation of school practices using detailed information from the NYC Learning Environment Survey, the nation's largest annual school survey. This survey has unusually widespread coverage; it is completed by roughly threequarters of students and teachers, and upwards of $45 \%$ of eligible parents during our time period. Following other studies that use survey information to complement quasi-experimental school evaluations (see, e.g., Angrist, Pathak and Walters (2013a), Dobbie and Fryer (2013a), PopEleches and Urquiola (2013)), we utilize survey responses to investigate mechanisms for the small school effects. Students in our small schools experiment are at schools associated with

\footnotetext{
${ }^{1}$ Cullen, Levitt, Robertson and Sadoff (2013) provide a recent review of high school reform. Although lauding the effects of high-performing "No Excuses" charter schools studied by Abdulkadiroğlu, Angrist, Dynarski, Kane and Pathak (2011b) and Dobbie and Fryer (2011), they remain skeptical that such "Herculean" (quoted in original) efforts can be scaled.
} 
higher levels of engagement, safety and respect, academic expectations, and communications compared to those who do not obtain offers. In particular, students report that they are more closely monitored and have more frequent interactions with teachers. On the other hand, small schools have substantially fewer activities and course offerings. Teachers report greater feedback, increased safety, and improved collaboration at the schools in our experiment.

New York City's experience with small schools stands out not only because it was a signature part of Bloomberg-era reforms, but also because it involved the largest number of new small high schools created in any district. Between 2002 and 2008, the number of high schools in NYC increased from just over 250 to nearly 450 (shown in Figure 1). Gates Foundation-funded policy reports and briefs by MDRC (Bloom, Thompson and Unterman (2010), Bloom and Unterman (2012), and Bloom and Unterman (2013)) also study the effects of small high schools on progression towards graduation and high school graduation using the high school match, though with a different econometric approach and sample. ${ }^{2}$ Other studies of small school efforts that do not use lotteries in NYC and elsewhere generally find positive results. Foley and Reisner (2009) present an observational analysis of the New Century High Schools, while Schwartz, Stiefel and Wiswall (2013) use an instrumental variables strategy based on proximity. Both papers report positive graduation results for new small schools. Similarly, Barrow, Claessens and Schanzenbach (2013) also use distance as an instrument to study Chicago's new small high schools and find that students are more likely to graduate. Kuziemko (2006) uses shocks to school enrollment to study Indiana's small schools and finds positive math and attendance effects. ${ }^{3}$ This paper also contributes to a growing literature exploiting random variation in student assignment processes to study school effects (see, e.g., Angrist, Dynarski, Kane, Pathak and Walters (2012), Angrist et al. (2013a), Cullen, Jacob and Levitt (2006), Deming, Hastings, Kane and Staiger (2011)), though lottery-based studies tracking student to college choice and enrollment are still relatively rare. ${ }^{4}$

The next section describes New York City's small schools in more detail and schools in our study. Section III describes our lottery-based estimation framework based on the centralized

\footnotetext{
${ }^{2}$ Other reports that study NYC's small high schools include Hemphill and Nauer (2009), which provides a descriptive account of the expansion of small schools and choice in NYC, Foley, Arcaira, Coleman, Reisner, Scott, Turner and Woods (2010), which describes intermediary organizations, and Shear, Means, Mitchell, House, Gorges, Joshi, Smerdon and Shkolnik (2008), which reports on surveys of implementation issues with Gates Foundation supported small schools.

${ }^{3}$ While small schools have fewer students per grade, they do not necessarily have smaller class sizes. Studies of class size reductions generally report positive achievement effects (Angrist and Lavy, 1999; Krueger, 1999; Dynarski, Hyman and Schanzenbach, 2011; Fredriksson, Öckert and Oosterbeek, 2013).

${ }^{4}$ Deming et al. (2011) show that attending a higher value-added school in Charlotte increases college enrollment for girls, while Angrist, Cohodes, Dynarski, Pathak and Walters (2013b) and Dobbie and Fryer (2013b) find that high-performing charter schools significantly increase college enrollment.
} 
high school match, while Section IV presents data and descriptive statistics. Section V presents the lottery estimates for Regents, credits, attendance, and high school graduation. Section

VI presents results for college enrollment and choice. Section VII reports on results split by student groups and by school intermediaries, while Section VIII contains further information on differences in the small school learning environment. Section IX examines what can be learned more generally about the role of school size in education production from our analysis. The paper concludes in Section X.

\section{Small Schools in New York City}

\section{II.1 Background}

There has been experimentation with small high schools in New York City for a number of decades. An important antecedent to the large-scale changes in the 2000s that we study here took place in the 1980s, when Chancellor Anthony Alvarado reorganized East Harlem's District 4 and empowered Deborah Meier, an education reformer often described as the founder of the modern small schools movement, to establish 15 small schools in New York City (Toch, 2003). In 1994, the Annenberg Foundation gave a $\$ 25$ million grant to encourage small school creation, but these schools were not seen as central to Chancellor Rudy Crew's reform agenda (UFT, 2005; Gootman, 2006a). Small school reform rose to the top of the reform agenda with the 2001 election of Michael Bloomberg as Mayor of New York City, the imposition of mayoral control, and the subsequent appointment of Joel Klein as Chancellor in 2002. The DOE, together with the United Federation of Teachers and Council of Supervisors and Administrators, launched the New Century High School Initiative with $\$ 31$ million in financial support from the Bill and Melinda Gates Foundation, Carnegie Corporation, and the Open Society Institute.

At the beginning, there was a fertile landscape for school development with the DOE hosting workshops on school design, budgeting, hiring, and building partnerships with local organizations. Intermediary organizations submitted applications to the DOE to start new schools describing their vision, curriculum and instructional model, teacher evaluation practices, leadership and governance structure, and proposed budget. The Gates Foundation identified rigor, relevance, and relationships ("the three Rs") as the key to high school reform. They envisioned small schools as allowing teachers and staff to create an environment where students could be more easily monitored and feel safer; this would in turn increase motivation and attendance, and ultimately high school graduation and college enrollment rates. Underserved low-income and minority students, in particular, were expected to benefit from the personalized academic and social support at small schools (Gates, 2005). The New Visions for Public Schools, an education reform organization in NYC, played a major role in directing new school creation. They 
identified ten principles of school design: a rigorous instructional program, personalized instructional relationships, a clear focus on teaching and learning, instructional leadership, school-based teacher-driven professional development and collaboration, meaningful continuous assessment, community partners, family/caregiver involvement, youth participation and development, and the effective use of technology (Foley et al., 2010).

To supervise new school creation, the DOE established a designated development/advocacy office with direct reporting to the chancellor (Bloomfield, 2006; Foley and Reisner, 2009). The strongest proposals were granted, and Gates distributed planning grants to new school organizers of $\$ 400,000$ over four years and $\$ 200,000$ to assist with school implementation (Foley et al., 2010). Approved schools typically started in 9th grade with 100 students and grades were added as classes were promoted. To focus on struggling students, many small schools opened in economically disadvantaged areas of New York City. Figure 2 shows that Bronx and Brooklyn were home to the greatest number of new small high schools. A total of 61 new small high schools with 9th grade entry opened in the Bronx, 44 in Brooklyn, 22 in Manhattan, 15 in Queens, and 1 in Staten Island.

By 2003, the Gates Foundation granted an additional $\$ 58$ million to New Visions and other intermediary organizations. Mayor Bloomberg and the DOE announced ambitious plans to expand the New Century initiative and create numerous additional small schools. The new centralized high school admissions process also allowed students to access the increased number of school options (Abdulkadiroğlu et al., 2005). The peak year of Gates-supported small high school creation was 2004, when 49 new unselective small high schools opened, with 18 in the Bronx and 17 in Brooklyn. Figure 3 shows that new small school creation tapered afterwards. In 2007, there were 12 newly created small schools, while in 2008, there were only 4 . At least 60,000 students enrolled in a new small high school in our study between school years 2004-05 through 2009-10.

After jumpstarting small school creation in New York City, the Gates Foundation has since turned its attention away from small schools. Foundation president Bill Gates concluded that small schools did not have the effect on college readiness and graduation rates that he expected (Gates, 2009). However, since high small school creation peaked in 2004, it has only recently become possible to systematically examine these outcomes in NYC. Even without the Gates Foundation's on-going support, New York's dramatic and unprecedented small school reform continues to leave a large imprint throughout city's public schools. As of 2013, 13 new high small school programs have been closed and the new small schools continue to be an integral part of the district's school portfolio strategy (DOE, 2012a).

Aside from initial foundation support, another important ingredient for small school expansion was a collaborative partnership between the DOE, the United Federation of Teachers 
(UFT), the union representing most NYC teachers, and the Council of School Supervisors, a collective bargaining unit for school administrators. For instance, a 2005 UFT Taskforce report expressed support for the creation of small schools, seeing them as a "chance for innovation and experimentation" and way to provide "opportunities for teacher voice in a personalized, collegial, collaborative and professional work space" (UFT, 2005).

The UFT also played a role in hiring teachers by serving on personnel committees at all new or redesigned schools (DOE, 2007b). Labor agreements required that if new school creation impacted another school, then $50 \%$ of the teaching staff at the impacted school should be selected among the "appropriately licensed most senior applicants from the impacted school staff who meet the new school's qualifications" (DOE, 2007b). To be hired, small school principals asked teachers to present teaching portfolios, demonstrate lessons, and often have small school teaching experience. Given each school's unique requirements, the definition of qualified staff set by personnel committees could differ by school, and the $50 \%$ requirement did not imply that half of the phased-out school's staff was necessarily rehired at the new school. As soon as a phase-out was completed, teachers were hired in the same way as at all other NYC public high schools using the "Open Market System." Throughout, teacher work schedules and salaries were determined according to the collective bargaining agreement.

The growth in New York City's small schools took place during a period of system-wide changes in governance at the DOE. All schools could elect for a "school-based option" in their labor agreement, which involved deviations from UFT requirements on staffing, class sizes, and rotations; these proposals must be approved by $55 \%$ of the staff and predominantly were used to increase learning time for students. Goertz, Loeb and Wyckoff (2011) state that from 2004 to $2006,35 \%$ of all schools adopted a school-based option. In 2005, the DOE launched the Empowerment Zone, where schools (small or not) signed contracts exchanging deviation from city-wide curriculum requirements and rules governing the allotment of some district-level funding for performance-based accountability (Nadelstern, 2005). As of September 2005, 30 schools joined the zone, 14 of which were new small schools and by the following year, 331 schools throughout the district became empowerment schools (Nadelstern, 2005; Klein, 2006). While maintaining union contracts, principals had more authority over educational decisions and budgets, greater voice in the selection and evaluation of administrative teams, and fewer reporting requirements (DOE, 2007a). Around this time, progress reports with letter grades began playing an important role in accountability decisions and lower performing schools could be subject to leadership changes or closure. By 2007-08, principals were able to chose among three classes of school support organization and empowerment zones were the most popular choice (Hemphill and Nauer, 2010). Even with these district-wide changes in governance, the auxiliary organizations mostly provided instructional support and oversight. All employment decisions remained with 
the DOE and the collective bargaining agreement, which was renegotiated for 2007, continued to apply (DOE, 2009).

\section{II.2 Small Schools Studied}

We compile the list of new small high schools created between 2002-2008 from several sources. First, we use NYC's Supplementary High School Directory for New Schools. Second, we append any schools listed in the 2005 DOE Guide to NYC's Small Schools. Third, we add any schools listed in New Visions from Public Schools reports. Fourth, we use the list of small school intermediary organizations contained in Foley et al. (2010) and collect the names of small schools from intermediary websites. Finally, we include any small schools listed in Bloom et al. (2010). Our sample of small schools includes all new unselective small high schools created between 2002 and 2008 with 9th grade entry. The data appendix provides additional details on the construction of the eligible small high school list.

Table 1 shows that 151 high school programs meet our eligibility criteria. To be in our lottery study, a school must be oversubscribed for at least one year between application years 2003-04 and 2007-08, and there must be a set of applicants who are subject to a lottery in New York City's high school match. Of the 151 eligible school programs, 108 are in our lottery sample. Occasionally, there is more than one program at a high school. For example, at the Bronx Theatre High School, a New Visions performing arts school, there is a separate theatre design and technology program and a performance and production program, each of which is ranked separately by applicants. The 151 eligible school programs correspond to 143 eligible schools, of which 101 schools are in the lottery sample.

Table 1 also reports the coverage of school programs by intermediary organizations, where a school may be placed into more than one category if it supported by multiple groups. New Visions affiliated schools represent $62 \%$ of eligible small schools, with Institute for Student Achievement, Urban Assembly, and Replications forming the three next largest intermediaries. We have near complete coverage for Urban Assembly and NYC Academies in our lottery study, and we cover more than half of the schools for all other intermediaries except for the Institute for Student Achievement. 13 newly created small high school programs eligible for our study have been closed, and among those currently open, $72 \%$ are in the lottery study. Table A1 provides a complete list of school programs, schools, intermediaries, years in the lottery sample for the eligible schools in study. Table A2 reports the breakdown of applicants by application cohort and the grades we can observe. Variation in coverage reflects year-to-year fluctuations in student demand and school capacities. 


\section{Empirical Framework}

\section{III.1 Estimating Equations}

We are interested in the causal effect of attending a new small high school on student achievement. We fit equations for educational outcomes, $y_{i g t}$, of student $i$ in grade $g$, tested in year $t$, of the following form:

$$
y_{i g t}=\alpha_{t}+\beta_{g}+\sum_{j} \delta_{j} d_{i j}+\gamma^{\prime} X_{i}+\rho S_{i g t}+\epsilon_{i g t},
$$

where $S_{i g t}$ is our measure of exposure to small schools. The terms $\alpha_{t}$ and $\beta_{g}$ are year-oftest and grade-of-test effects, $X_{i}$ is a vector of demographic controls such as gender and race indicators and baseline test scores with coefficient $\gamma$, and $\epsilon_{i g t}$ is an error term that reflects random fluctuation in test scores. We cluster standard errors by school-test year for Regents test outcomes. For outcomes involving repeat observations per student like credits and attendance, we additionally cluster by student. The dummies $d_{i j}$ are indicators for lottery-specific "risk sets," which will be described in Section III.2. The coefficient of interest is $\rho$.

For Regents test outcomes, the variable $S_{i g t}$ is the years spent in a small school as of test date, counting any repeat grades and any time in a small school listed in Table A1 (not just those subject to lottery). This means if a student transferred to another small school after an initial assignment, we count time spent at both schools. For each test, we compute the implied years of small school attendance based on the test date and enrollment status. We assume the enrollment date is September 1st of each year and count how many days students stay in a small school from the application date to the test date. Since students can determine when they take a Regents exam, scaling small school exposure by years allows us to interpret estimates as peryear effects. For outcomes such as graduation and college attendance, we measure small school exposure by whether a student attends a small school following application in 9th grade. We focus on attendance as the endogenous variable for these outcomes to avoid confronting issues related to timing and reverse causality.

Ordinary least squares (OLS) estimates of equation (1) would capture the average causal effect of years or enrollment at a small school in the sample if $S_{i g t}$ were randomly assigned. However, students selectively choose schools, and their choices may be related to unobserved variables such as family characteristics and motivation, which potentially bias OLS estimates. Our econometric approach is based on an instrumental variables (IV) strategy that exploits the partial random assignment of $S_{i g t}$ embedded in the NYC high school match.

The first stage equation for the IV estimation of $\rho$ is given by

$$
S_{i g t}=\lambda_{t}+\kappa_{g}+\sum_{j} \mu_{j} d_{i j}+\Gamma^{\prime} X_{i}+\pi Z_{i}+v_{i g t}
$$


where $\lambda_{t}$ and $\kappa_{g}$ are year-of-test and grade effects. The excluded instrument is the random offer indicator $Z_{i}$. The coefficient $\pi$ captures the effect of the instrument on either time spent or enrollment at an eligible small high school. IV estimates of $\rho$ in equation (1) adjust for differences between offers and enrollments for those offered and not, and capture the causal effect for those who comply with (that is, enroll in a small school) with an offer (Imbens and Angrist, 1994). For Regents outcomes, the IV estimates of $\rho$ can be interpreted as the weighted-average causal response of each year at a small school.

In practice, the use of a lottery instrument is complicated by the fact that students obtain school offers through a centralized mechanism where their choices interact with their school priority and the choices of other students. To implement our IV strategy, it is necessary to determine how random offers are generated by the high school match.

\section{III.2 Extracting Assignment Lotteries from the High School Match}

Admissions to New York City high schools are administered centrally by the NYC DOE. Every eighth-grader submits up to 12 schools in order of preferences. At schools, students can also be explicitly ranked in a strict order or ranked within coarser priority groups where a lottery number breaks ties. The student-proposing deferred acceptance algorithm (DA) then computes assignments taking student preferences, school priorities, and lottery numbers into account (Abdulkadiroğlu et al., 2005; Abdulkadiroğlu et al., 2009). When two students apply to a school program for which they are in the same priority group, the lottery number determines which student is offered. After DA has been run, if a student prefers another school to her assignment, it must be the case that all of the seats at the other school are assigned to students with higher priority or with the same priority, but better lottery numbers. Therefore, whether a student is rationed by lottery at school $s$ is determined by whether she ranks school $s$ above or below the school she is assigned, her priority at school $s$, where other applicants rank school $s$ compared to their assignments, and other applicants' priorities at school $s$. To operationalize our econometric strategy, it is necessary to identify groups of students who, conditional on information contained in their preferences and priorities, face the same risk of assignment.

Figure 4 illustrates the steps we use to identify applicants subject to lottery at a given school program. We first identify students who rank a small high school program anywhere on their preference form. For many of these students, the decision to rank a small school does not play any role in the assignment under the student-proposing deferred acceptance algorithm. For instance, a student who ranks a small school second, but has a guaranteed priority at her first choice will not be considered for her second choice because she'll obtain an offer at her first choice. To focus on students for whom the small school choice is relevant, we identify applicants who did not receive an assignment more preferred to the highest ranked small school on their 
preference list. Applicants who are admitted at schools preferred to their highest ranked small school (shaded in Figure 4) do not contribute to the lottery sample.

The remaining marginal applicants can differ in the priority group they receive at the school. Many small schools give priority to students who live in particular geographic regions or who express interest by visiting high school fairs or open houses. The random number orders the marginal applicants students within these priority groups lexicographically. For instance, at the Bronx Theatre High School, there are four priority groups:

1) Priority to Bronx students or residents who attend an information session,

2) Then to New York City residents who attend an information session,

3) Then to Bronx students or residents,

4) Then to New York City residents,

and the random number orders students within each priority group. Among the marginal applicants, we identify the lowest priority group for which some students are offered and other students are not. In the Figure 4 example, every marginal applicant in the first priority group is admitted and no applicant in third priority group is admitted. Lottery-based rationing therefore takes place only among applicants in the second priority group. If there is no priority group where marginal applicants are offered and others are not, then the school is not oversubscribed. An oversubscribed school contributes applicants to our lottery study in a given year if there are marginal applicants and among the marginal applicants in the lowest priority group, some are offered and some are not. ${ }^{5}$ The random offer indicator $Z_{i}$ is 1 for students who are offered a seat at that small school program choice, and 0 otherwise.

The assignment of a student to a small school not ranked first depends on the student preferences and priorities at higher-ranked schools in a complex way. ${ }^{6}$ For this reason, we focus only on students who rank a small school as their top choice, as in other studies using data

\footnotetext{
${ }^{5}$ In principle, every marginal applicant with a priority higher than the lowest priority to obtain an offer should obtain an offer. There are some school program-years where this property does not hold, and we do not include these school program-years in the lottery sample. Based on conversations with the NYC DOE, some of these schools may have slot-specific priorities, where priorities apply for a certain fraction of school seats. For more on slot-specific priorities, see Kominers and Sönmez (2012) and Dur, Kominers, Pathak and Sönmez (2013).

${ }^{6}$ Bloom et al. (2010) consider all preferences ranked by students, and for their sample, 24 percent of students are in more than one lottery. They acknowledge that the possibility a student could face non-zero probability of assignment at a higher choice school creates complications, and therefore pursue an alternative approach. They state that "the probability of prior assignment can vary from just above 0 to just below 1, and this variation can pose a threat to randomization" (italics in original, page 76), but later argue that this may not be an issue in their setting. Abdulkadiroğlu, Angrist, Narita and Pathak (2013) analyze econometric issues associated with efficiently extracting random assignment from centralized matching mechanisms.
} 
from centralized assignment mechanisms (Abdulkadiroğlu et al., 2011b; Deming et al., 2011). Small school risk sets are defined by the identity of the first choice small school program and the application year. The restriction to first choices creates two possible drawbacks. First, if a student ranks multiple small schools and is assigned to a lower ranked small school, we'd code the instrument as zero, since the student did not obtain an offer at her first choice. This potentially weakens the power of the instrument, but does not compromise our research design. ${ }^{7}$ Second, the exclusion of students who do not rank a small school first, but rank it second or lower results in a potentially smaller lottery sample size, though the number of possible additional students in our application is relatively small. ${ }^{8}$

\section{Data and Descriptive Statistics}

\section{IV.1 Sources}

We obtained registration and demographic information for New York City from 2002-03 through 2009-10. Registration data are used to determine whether and for how many years a student is enrolled at a small high school. Demographic information in the NYC file includes borough of residence, race, sex, subsidized lunch, limited English proficiency, and special education status. Baseline (i.e., pre-treatment) test scores are based on 8th grade standardized exams in Math and English Language Arts. Baseline scores are normalized by grade and year to have mean zero and unit variance in the population of New York City students.

NYC demographic and registration information were merged with Regents test scores using student identification numbers. Regents exams are mandatory state examinations where performance determines whether a student is eligible for a high school diploma in New York. There are Regents examinations in English, Global History, US History, and multiple exams in Mathematics and Science. ${ }^{9}$ A Regents exam typically has a multiple choice section and a long

\footnotetext{
${ }^{7}$ In contrast, in the context of DA without school priorities, Abdulkadiroğlu, Angrist and Pathak (2011a) identify a "sharp sample" where offers are a deterministic function of preferences and school rankings.

${ }^{8}$ Among students who did not rank a small school first, but ranked an oversubscribed school second, if we require that students have the same choices and priorities at their first choice, we'd add at most 1,404 students in 326 additional risk sets, for an average about 4.3 students per risk set. Among students who only rank an oversubscribed small school third, the requirement that students have the same first and second choice with the same priorities results in 99 additional students in 40 additional risk sets. Virtually no students are added if we continue further down rank order lists with these restrictions.

${ }^{9}$ Starting in 2005, the Board of Regents started to modify the Mathematics exams. At the beginning of our sample, the two Mathematics examinations were Elementary Algebra and Planar Geometry (Math A) and Intermediate Algebra and Trigonometry (Math B). Two new mathematics examinations, Integrated Algebra I (Math E) and Geometry (Math G), have since been phased in. Since students typically either take Math A or Math E, we focus on the score on the test taken first, taking the Math A score when both are contemporaneous.
} 
answer or essay components and each exam usually lasts for three hours. The English exam, however, consists of two three-hour pieces over two days. Regents scores are standardized to the city score distribution by grade, test-date, year, and subject.

Most Regents exams are offered in January, June, and August, and June is the most common test date. Our file only indicates the term of test taking, and not the exact month. Using the DOE's translation of terms to dates, we compute years assuming the exam date is January 31st or June 1st. Some students retake Regents tests, and in those cases, we use the first-time score. Table B2 presents the number of students who take each exam more than once among the lottery sample as well as the fraction of tests taken on the most common test date.

Other outcomes including credits, grade progression, attendance, and high school graduation are all provided by the DOE. Data on Preliminary SAT (PSAT), SAT Reasoning, and Advanced Placement (AP) tests come from the College Board via the DOE. Data on college enrollment come from the National Student Clearinghouse, as reported to the DOE for their students. Different outcomes generate different follow-up horizons, depending on the point at which they are collected for students. Table B3 provides a complete account.

Our analysis file combines student registration, test scores, credit, attendance, and graduation outcomes, and college outcome files with the NYC small school applicant file. The small school applicant file records grade, year, applicants' preference ranking in the high school match, and each student's priority at each ranked school. Our analysis sample includes students who applied for small school seats in one of the five school years between 2003-04 through 2007-08 for fall 9th grade enrollment. We focus on applicants enrolled in NYC at the time of application because we're interested in how an small high school education compares to a NYC public fallback.

\section{IV.2 Student Characteristics}

Table 2 reports descriptive statistics for New York City 8th graders and for students enrolled at small schools. Small school students are more likely to be black or Hispanic and somewhat more likely to qualify for a subsidized school lunch than NYC's 8th graders. The fraction of students at small schools in the Bronx is higher than the fraction of NYC 8th graders from the Bronx. There are relatively fewer students from Queens and Staten Island. Small school students have significantly lower baseline scores than New York City students. The difference is roughly one quarter of a standard deviation (hereafter, $\sigma$ ).

Since our research design is based on the high school match, we also tabulate student at-

There are Regents science exams in Earth Science, Living Environment, Chemistry, and Physics. The science outcome we focus on is Living Environment because it is the most common Regents science exam taken by students. 
tributes based on their preferences. Table 2 reports on students who apply to small schools by ranking them anywhere on their preference form, students who rank small schools and were not offered a higher choice, students who rank a small school as a first choice, and students subject to lottery at a small school. Across these columns, the make-up of applicants expressing a preference for small schools is more similar to those enrolled at small schools than to the NYC 8th grade population. Comparing the lotteried applicants to students enrolled at small schools, there is a higher fraction from the Bronx and relatively more black and Hispanic students (more than $90 \%$ of the students we study). The baseline scores of lottery applicants are also lower, averaging about $0.19 \sigma$ below the city population for Math and $0.10 \sigma$ below for English. The baseline score difference between lotteried applicants and enrolled students emerges when we compare those ranking small schools first to applicants subject to lottery (in column (5) and (6)), and may be due to the fact that higher priority is given to students who attend small school open houses or information sessions.

Because small high schools did not have resources needed to serve special education students requiring self-contained classes and English-language learners adequately, they were allowed to be added over a three-year time span when the new small schools opened (Bloomfield, 2006; Gewertz, 2006b; Gewertz, 2006a). Students who were special education and limited English proficient were manually placed into programs that could accommodate them and were therefore not always subject to assignment based on lotteries. As a result, no students who are special education and limited English proficient are in the lottery sample.

As a measure of our ability to construct randomly generated offers, in columns (7) and (8), we report on differences in demographic characteristics and baseline scores between students who were offered and not offered a seat. If offers are randomly generated, then they should be independent of student demographics or baseline scores within risk sets. The numbers reported are regression-adjusted differences by offer status within risk set. The regressions only control for application year-first choice dummies. If we are able to successfully extract random assignment, offers should be randomly assigned conditional on these covariates. The differences across demographic characteristics and baseline scores are small and none are statistically significant. This conclusion is supported by high p-values in a joint test of the hypothesis that all differences in demographic characteristics and baseline scores are equal to zero. These findings give us confidence that we have successfully isolated the random variation embedded in the NYC high school match.

\section{IV.3 Small School Environment}

Before presenting our main estimates, we first present an investigation of objective measures of the school environment experienced by students who are in our experiment. Section VIII 
contains additional information about school environments based on reports of students, parents, and teachers from New York City's Learning Environment Surveys.

Table 3 reports estimates of school enrollment rates by borough, per-pupil expenditure from city-level school budget data, school and teacher characteristics from New York State school report cards, and peer characteristics for the relevant group of compliers. Loosely speaking, compliers are the subpopulation of students who are induced to enroll in a small school given the random offer. More formally, let $D_{1 i}$ denote small school enrollment status when the instrument $Z_{i}$ is switched on and $D_{0 i}$ denote small school enrollment status when the instrument $Z_{i}$ is switched off. Compliers are defined as those where $D_{1 i}=1$ and $D_{0 i}=0$. Although the compliant population cannot be enumerated, their characteristics are non-parametrically identified, and estimated using the IV strategy described in Abadie (2003). We focus on differences as experienced by compliers to precisely describe the variation induced by our experiment.

Offered and non-offered compliers are similar along many dimensions, and in many cases their differences are swamped by differences with non-enrollees. Panel A shows that only $15 \%$ of students not enrolled in a small school are at other Bronx high schools, while roughly $40 \%$ of the students in our experiment enroll in a Bronx school. This fact is consistent with fallback schools being located in neighborhoods similar to those where new small schools were created. Panel B shows that the level and composition of average per-pupil expenditure for both offered and non-offered compliers is similar. The absence of expenditure differences may be somewhat surprising given that small schools had access to additional funds in start up years. Start up grants on the order of $\$ 400,000$ are relatively small compared to the total expenditure on direct services of $\$ 6.2$ million at schools attended by offered compliers. It's also worth noting that some aspects of school resources are not captured by information in school budgets, such as auxiliary support donated by outside organizations.

Panel C illustrates important differences in school size and teacher characteristics between offered and non-offered compliers. Non-offered compliers attend schools with 863 9th grade classmates and 2,249 students across all high school grades. These numbers are similar to those not enrolled at small schools, suggesting that in terms of size, the counterfactual fallback for those in our experiment is like a typical NYC high school. Offered small school compliers are at considerably smaller schools, with just over 161 9th grade classmates and 443 students across all high school grades. That is, small school compliers attend schools that have five times fewer classmates both in 9th grade and across all high school grades. This sharp difference in school size motivates the analysis in Section IX, which uses our experiment to estimate the role of school size in education production. Consistent with reduced school size, fewer core classes are taught at small schools. However, the class sizes experienced by the two complier groups are similar to one another and to those faced by non-enrollees. 
Small school size is also associated with fewer teachers, assistant principals, and non-teaching staff. DOE officials encouraged the new small schools to create cross-functional interdisciplinary teams responsible for cohorts of students, rather than the traditional high school with teachers organized into subject area departments (Nadelstern, 2005). Goertz et al. (2011) report that in 2003-04, 34\% of NYC's newly hired teachers were from the New York City Teaching Fellows program, an alternative certification program where teachers take graduate classes at night, and about 5\% were Teach for America (TFA) members. Hemphill and Nauer (2009) state that many teachers at the new small high schools came from these two sources. Consistent with these claims, offered compliers' teachers have less experience and are less likely to be highly educated, as measured by having a master's degree plus 30 hours or a doctorate. Small school teachers often had to take on administrative roles given the reduced staffing at small schools, and additional work requirements may have lead to higher turnover rates (Hemphill and Nauer, 2009). The estimate in Table 3 implies that $28 \%$ of teachers were not teaching at schools attended by offered complies in the following year, while $19 \%$ of teachers were not teaching at schools attended by non-offered compliers in the following year.

Panel D shows that the study body for those offered and not in our small school experiment is similar in terms of minority status, subsidized lunch eligibility, and gender. Both non-offered and offered compliers attend schools with more minorities than students who are not at small schools. The proportion of peers who are special education or limited English proficient is somewhat lower for offered compliers, but the differences are relatively small given what might have been expected with the discretion associated with enrolling these two groups in small school start-up years. For instance, the proportion special education at schools attended by offered compliers is 0.08 , for non-offered compliers it is 0.11 , and for non-enrollees it is 0.10 .

The fallback peer environment as measured by achievement for those in our experiment is well below the typical NYC high school. Non-offered compliers attend schools where the average baseline peer math score is $-0.28 \sigma$, while non-enrollees are at schools with average peer baseline math score of $0.11 \sigma$, a difference of $0.39 \sigma$. The differential when we compare the peer environment for those in our experiment is not as large. Offered compliers attend school where the average peer math baseline score is $-0.07 \sigma$, which is a difference of $0.21 \sigma$ compared to nonoffered compliers. Given that small schools were established to replace underperforming high schools in disadvantaged areas of New York City, it is perhaps not surprising that both offered and non-offered compliers attend schools with weaker peers than those at other NYC schools. The difference in peer baseline scores among the two groups of compliers may also be related to school closure efforts and the consequent shifts of remaining students to the extant high schools in neighborhoods where small schools were established. 


\section{Lottery Estimates}

\section{V.1 Regents}

Applicants spend 0.46 years longer in a small school if they were randomly offered a seat than those who do not before taking Regents Math, an exam typically taken in 9th or 10th grade. This fact can be seen in column (1) of Table 4, which shows the "first stage." The first stage indicates the relationship between lottery offers and years at a small school before test-taking. The size of the first stage depends in part on whether offered applicants accept their offer or opt for other schools. Moreover, some students who do not receive an offer end up at small schools either by re-applying in 9th grade or via the Appeals round of the HS match, which occasionally allowed unassigned students to transfer to small schools after the main round. Regents Living Environment is typically taken around the same time as Regents Math and therefore has a similar first stage size. English and US History are usually taken in 11th grade and have correspondingly larger first stage estimates. The size of the first stage is similar to those reported for other urban high school populations participating in school lotteries, such as Abdulkadiroğlu et al. (2011b)'s study of Boston's charter high schools. ${ }^{10}$

The reduced form effects of winning an offer at a small high school, reported in column (2), indicate that those randomly offered score higher in all major subject areas: $0.06 \sigma$ in Math, $0.08 \sigma$ in English, $0.08 \sigma$ in Living Environment, $0.07 \sigma$ for Global History and $0.07 \sigma$ for US History. The two-stage least squares (2SLS) estimate of the effect of an incremental year in a small school, in column (3), is the ratio of the reduced form estimate to the first stage estimate. The 2SLS estimates show per-year gains on the order of $0.14 \sigma$ for Math, $0.11 \sigma$ for English, $0.18 \sigma$ for Living Environment, $0.11 \sigma$ for Global History, and $0.09 \sigma$ for US History. The addition of controls for demographic characteristics and baseline scores does little to change the estimates, as can be seen in columns (4) and (5), except for some small changes in precision.

Though these estimates are based on randomized lotteries, a potential threat to our study design is that we are more likely to observe follow-up scores for some students than others. In our sample, over $70 \%$ of students take Regents Math, and the follow-up rates hover around $65 \%$ for the other Regents exams, shown in Table A4. However, if the tendency to drop out differs by lottery status, it is possible that selective attrition biases our estimates. Table A4 reports on follow-up differentials by offer status estimated using regression models that parallel the reduced form estimates in Table 4. Positive estimates indicate that lottery winners are more likely to

\footnotetext{
${ }^{10}$ For example, in Table IV of Abdulkadiroğlu et al. (2011b), the first stage estimate on the 10th grade mathematics examination is 0.54. In general, the size of first stages must be judged relative to the fact that the urban high school population is highly mobile. See Angrist et al. (2013b) for further discussion of these issues for Boston's charter high schools.
} 
have valid outcome test scores post-assignment. The estimates in column (2) show that there are no statistically significant differences in Regents Math follow up. There are some statistically significant, but small differences, on the order of 2.3-4.6 percentage points for the other Regents test outcomes. The addition of controls for demographic characteristics and baseline scores does little to change on these estimates.

Motivated by concerns on differential attrition, we report on a simple approach to see whether selective attrition is responsible for the positive Regents estimates in Table 4 . Since we have pre-treatment test scores for applicants, we simply treat the baseline score as the outcome score for students for whom it is missing. The baseline tests are taken in 8th grade statewide, like the Regents, and are used to decide in middle school grade promotion decisions. This approach assumes that the test score for both missing treated and untreated students is unaffected by school assignment. While likely unrealistic, it provides a convenient benchmark to investigate the role of attrition. As expected, the estimates are somewhat smaller in column (6) than in column (5), but are similar overall.

Regents is a focal outcome for New York City's high schoolers because it is taken widely and is required for graduation. However, the Regents outcome is not necessarily ideal because of allegations that it may have been compromised by selective re-grading at certain schools. Dee, Jacob, McCrary and Rockoff (2011), for instance, identify clumping of Regents test scores at 65, with very few students scoring just below 65. These issues led to recent system-wide data audits across schools, including a report by the Auditor General (Fleischer, 2012). This report examined academic data for 460 high schools and identified 60 with the most troubling patterns on Regents scoring and credits. Table A1 shows that 19 of the high schools in our eligible school list were on the audit list, and 12 of these schools are part of the lottery sample. To identify whether selective regrading is driving our results, in Table A6, we report on Regents Math and English estimates excluding these audited schools. The Regents Math estimate remains statistically significant at $0.11 \sigma$, while the English result is an insignificant $0.05 \sigma .{ }^{11}$

\section{V.2 Credits, Grade Repetition, and Attendance}

To graduate, students must meet credit requirements in addition to passing Regents thresholds. Credits can be earned from either Regents course-taking or from courses without Regents assessments such as Economics, Participation in Government, Visual Art, Music, Dance and Theatre, and Health and Physical Education. Students entering 9th grade in our sample period must earn at least 44 credits to graduate (NYSED, 2010; DOE, 2012c).

Small school attendance causes students to earn more credits and progress more rapidly

\footnotetext{
${ }^{11}$ Although not reported in the table, the Living Environment estimate is $0.165 \sigma$ (with se $=0.057$ ), the Global History estimate is $0.076 \sigma$ (with $\mathrm{se}=0.049$ ), and the US History estimate is $0.059 \sigma$ (with se $=0.030$ ).
} 
through high school. The estimates in Panel A of Table 5 show that small school students earn an additional 1.37 credits per year. Students are considered "on track" for graduation if they earn at least 10 credits per year or "on track for four-year graduation" if they earn at least 11 credits per year. $56 \%$ of non-offered students earn 10 or more credits per year, while $50 \%$ earn 11 or more credits per year. On-time progression, measured either way, increases due to small school attendance. Students are 10 percentage points more likely to either earn 10 or more or 11 or more credits per year. Another way to measure on-time progression is by grade repetition. Panel B reports on the effects of small schools on starting grade 10, 11, and 12 on time. For each measure, small schools substantially increase the proportion of students who start their sophomore, junior, or senior years on time.

In recent years, data on credits have come under some scrutiny amidst charges that not all credits are equal. Students typically earn credits by taking (or retaking) courses or via summer school. Gootman and Coutts (2008) report anecdotes from several New York City school administrators suggesting students are increasingly obtaining or "recovering" credits outside of these two main routes, and Epstein (2013) alleges the practice was particularly widespread at some small schools. Students are allowed to recover credits by doing extra work or supplementary projects at the discretion of school administration. It is possible that credits accumulated this way are poor substitutes for credits obtained via more traditional routes, making the effects on credit accumulation hard to interpret. On the other hand, some DOE officials argued that credit recovery is an important way for students to learn outside of traditional routes. ${ }^{12}$ Credit recovery may be valuable in particular for students who have become homeless, pregnant, or experienced other schooling interruptions.

Aside from some anecdotes, there is no systematic evidence that credit recovery is more widespread at small high schools than at traditional high schools. In the Auditor General's report, 19 out of the 60 suspicious high schools are small schools (Fleischer, 2012). If credit recovery efforts were more commonplace outside of small schools, we'd expect our estimates of credit effects to understate the true effect of small schools. We investigate whether our results on credit are driven by the scrutinized schools that may have engaged more aggressively in credit recovery efforts. In Table A6, we report estimates on credits excluding any applicants to the 12 audited small schools that contribute lottery cohorts. The results confirm the findings in Table 5 , and suggest that our results on credit accumulation are not driven by systematically more credit recovery at small schools.

\footnotetext{
${ }^{12}$ For instance, Chancellor Klein defended credit recovery as a "legitimate and important strategy for working with high school students" (Gootman and Coutts, 2008). Nadelstern (2005) viewed giving schools the "greatest possible flexibility to grant credit for project-based work and non-seat time school experiences" as an important component of school autonomy.
} 
Small school proponents argued that increased interaction and engagement at school would reduce truancy. Panel $\mathrm{C}$ of Table 5 reports on the effect of small schools on absenteeism. The number of days a student is absent is relatively high for this population. Students who are not offered miss a total of 27 days on average. Consistent with the engagement hypothesis, small schools decrease days absent by a statistically significant 4 days.

Finally, we report on PSAT and SAT outcomes from the College Board in Appendix Table A4. Though these outcomes are often important college yardsticks nationwide, students in our population can meet admissions requirements for many of New York City's local colleges, including those in the CUNY system, without taking the SAT. Nearly two-thirds of New York high schoolers in our sample take the PSAT, and small school attendance increases this rate by significant 13 points. However, there is relatively little evidence that PSAT scores increase among test-takers, though this result may reflect a change in the composition of test-takers. About a third of NYC's high schoolers take the SAT, but small schools neither increase taking rates, nor do they increase SAT scores among test-takers. Roughly $9 \%$ of students take an Advanced Placement exam, which are supposed to allow students exposure to college-level material courses and even earn college credit. Here, too, small school attendance has little effect on AP testtaking. However, it's worth noting that the taking rate on SATs and APs is relatively small for students in our sample. By comparison, in the Angrist et al. (2013b) sample of Boston charter high schools, nearly two-thirds of students take the SAT and more than a quarter of students take an AP exam.

\section{V.3 Graduation}

Creators of small schools emphasized a college-preparatory curriculum for all students, which most interpreted as meeting high school diploma requirements (Foley et al., 2010). Given that small schools increase Regents scores and credit accumulation, we'd expect that small schools increase high school graduation rates. However, this is not immediate because during our sample period credit requirements for graduation stayed the same, but Regents requirements did not. For students entering 9th grade in 2004, the minimum graduation requirement was to score 55 or higher on at least five Regents exams. Each year, the Regents requirements became more stringent. For entering 9th graders in 2007, students needed to score 65 or higher on four Regents exams and also score 55 or higher on another Regents test (DOE, 2012b).

In Table 6, we consider the effects of small school attendance on high school graduation. Just over half of the students in our study receive a high school diploma. During our sample period, students in New York City were eligible for three different levels of diplomas. Local 
diplomas are offered for students who do not pass Regents diploma requirements. ${ }^{13}$ Regents diplomas require passing at least five Regents exams, while Advanced Regents require passing at least eight Regents exams (DOE, 2012c). The Regents diploma is the most common diploma type for students in our sample.

Table 6 shows that small schools increase the high school graduation rate by over 9 percentage points, an effect almost entirely driven by an increase in the fraction of students awarded Regents diplomas for which the effect is 10 percentage points. Relative to the mean proportion for nonoffered, the 10 point increase in Regents diplomas represents nearly a 30\% increase. Small schools do not have any effect on the awarding of either local or Advanced Regents diplomas. When we exclude audited high schools in Table A6, the effects on graduation are, if anything, higher. The overall graduation rate increases by 10 percentage points and the fraction who obtain Regents diplomas increases by 12 percentage points.

Though the Table 6 estimates show that small schools caused graduation rates to increase, the overall graduation rate in New York City also increased during our study's time period. As a result, there is a concern that increased graduation does not mean students are in fact college-ready. In particular, the city's local colleges have seen increases in the size of their remedial classes and some view this as a consequence of a relaxation of graduation requirements (Foderaro, 2011). A criticism like this would impact all high schools, and not necessarily only the new small high schools. However, we can employ our lottery design to study whether small school students are meeting the requirements to avoid remediation once they arrive at college

Our definition of remediation is based on requirements at CUNY institutions, which enroll the largest fraction of students in our study. CUNY students can avoid remedial coursework either by taking the CUNY Assessment Test (CAT) or by scoring above certain thresholds on the SAT, ACT, or Regents exams. These requirements differ across CUNY campuses. For instance, at CUNY Baruch, a student who scores 510 or higher on SAT Math, 21 or higher on the ACT, or 75 or higher on Regents Math to skip mathematics remediation, while at CUNY Queensborough a student needs a 480 on the SAT, 20 on the ACT, or 75 or higher on Regents Math. There are similar thresholds for reading and writing. During our sample period, the CUNY remediation thresholds have changed over time. ${ }^{14}$

Even though we do not have access to either CAT or ACT scores, we code a student as not remedial if they score above a 75 on the Regents or above a 510 on the SAT portion. We use Regents English for both reading and writing. If students do not take either exam, then under

\footnotetext{
${ }^{13}$ Local diplomas have since been phased out by the New York State Department of Education.

${ }^{14}$ Starting in Fall 2012, students are required to score at least 80 on any of the new Regents examinations and for Mathematics, they must complete Algebra $2 \&$ Trigonometry or a higher-level course. These thresholds do not apply to our sample period. For additional details, see http://www.cuny.edu/academics/testing/cunyassessment-tests/faqs.html, last accessed: September 2013.
} 
this definition, they are coded as remedial. Table 6 shows that in our sample, only about $20 \%$ of students are not remedial for Math while about $30 \%$ of students are not remedial for English. These numbers are low partly because they include students for whom we do not have either Regents or SAT outcomes. Even absent this consideration, the low numbers are perhaps not surprising given that small school students enter high school with substantially lower baseline scores than other NYC 8th graders. Small schools do reduce remediation for writing and reading, but not for math. The effect size is a statistically significant 9 percentage points, which is relatively large compared to the 31 percentage point mean for non-offered students.

\section{College Enrollment and Choice}

Small school advocates conjectured that personalized attention and frequent interaction would increase student motivation, encouraging them to stay in school, and ultimately graduate and go to college. Increasing college attendance was an explicit goal of the Gates Foundation, and this was reflected in intermediaries' intense focus on college-going expectations and supplementary student advising (Foley et al., 2010). Even though more than half of the students in our sample graduate high school, $28 \%$ of our non-offered applicants enroll in college four years after starting 9th grade and about $37 \%$ enroll within six years. ${ }^{15}$

Small schools have a large and significant effect on college enrollment. Table 7 shows that students are 7 percentage points more likely to attend college, which represents nearly a $20 \%$ increase relative to the attendance rate for non-offered students. Some interventions which successfully reduce dropout rates no longer have significant effects when outcomes are measured over a longer window (see, e.g., Rodriguez-Planas (2012)). Here, the effect on college attendance within four years after starting high school is similar to the estimate for attendance within six years, suggesting that non-offered students are not simply delaying college enrollment and catching up to offered students. Table 7 also reports estimates on attendance at two- or four-year colleges, using the classifications in the National Student Clearinghouse. It's worth noting that attending a four-year college does not necessarily imply that a student is in a four-year degree program, because schools which offer both two- and four-year degrees are coded as four-year institutions. In our sample, the fraction who attend a two-year college is about the same as the fraction who attend a four-year college (if a student attends both a two-year college and a four-year college, they are counted twice in this calculation).

Small schools boost attendance at four-year institutions by a statistically significant 6 percentage points, while leaving the effect on two-year colleges unchanged. Gains at four-year

\footnotetext{
${ }^{15}$ The six-year enrollment rate is greater than the fraction who ever attend college reported in the first row of Table 7 because we only report on attendance within six years for cohorts we can follow six years post-assignment.
} 
colleges are almost entirely driven by gains at four-year public colleges. Moreover, the largest college gains come from a shift of the fraction of students attending CUNY institutions. The most commonly attended CUNY colleges are Borough of Manhattan, Bronx Community College, New York City College of Technology, and Lehman College. There is no evidence of increases at four-year private colleges.

Data from the National Student Clearinghouse also allow us to investigate college persistence. Persistence is measured by the likelihood of attempting at least 2 or 4 academic semesters in college. ${ }^{16}$ Looking further out in a student's schooling career reduces the size of the persistence sample compared to the sample use to study college enrollment. Small school attendance increases the fraction of students who attempt college for at least 2 academic years by 5 percentage points, an effect which is marginally significant. The estimates for at least academic 4 semesters are positive, but not precise enough to rule out a zero effect.

\section{Other Results}

\section{VII.1 Subgroups}

The new small schools were launched with the goal of serving struggling students across all demographic groups (Foley et al., 2010). While the students who enroll are more likely to belong to a minority group, are poorer, and have lower baseline scores than typical NYC 8th graders, the fact that applicants obtain priority for some small schools by attending high school fairs generates some important differences between small school enrollees and the lottery applicants, as shown in Table 2. Therefore, it is natural to study whether certain student subgroups benefit more or less from small school attendance.

Table 8 reports estimates for subgroups based on student demographic characteristics and baseline achievement levels for several of our key outcomes of interest. Test score results tend to be higher for girls than boys, but graduation and college results are similar for both groups. The similar effects by sex on four-year college enrollment are noteworthy given evidence that girls usually outperform boys in other related studies (Anderson, 2008; Deming et al., 2011).

Across racial groups, there is a large $0.34 \sigma$ effect on Regents Math for black students, which is much larger than the corresponding estimate for Hispanics. On the other hand, there is no difference in the estimates between blacks and Hispanics for Regents English, both of which are positive but relatively imprecise. The effects for high school graduation, Regents diplomas, and college attendance are similar in magnitude for blacks and Hispanics, though as expected given smaller sample sizes, the estimates are no longer statistically significant in many cases. One

\footnotetext{
${ }^{16}$ We treat an academic semester as enrollment in January-May or August-December.
} 
interesting pattern is that black students are 8 percentage points more likely to attend four-year public colleges; this effect is larger than our overall effect and has the same significance level.

The effects for students who obtain a subsidized lunch are similar to the effects from our overall population, which is perhaps unsurprising given than more than $70 \%$ of our sample is eligible. However, small schools push these students to attend four-year public colleges, a notable finding given evidence that poor students often do not matriculate at four-year institutions (Deming and Dynarski, 2010; Bowen, Chingos and McPherson, 2009; Hoxby and Avery, 2012).

Small school critics allege that the new schools did not serve students who were harder to educate (see, e.g., Bloomfield (2006)). They point to the fact that some small schools were allowed to exclude some special education and limited English proficient students for their first three years. To investigate differences by students' prior levels of achievement, we split our sample into two groups based on having a baseline score above or below the median among lottery applicants, which is already a lower-scoring population. For Regents outcomes and graduation, there is no evidence that small schools were less effective with low baseline students. The high school graduation effect for low baseline students is 7 percentage points, it is not statistically significant, while the effect for high baseline students is a significant 11 percentage points. However, we cannot reject that these two estimates are different given our precision levels. Small schools cause high baseline students to earn more Regents diplomas, but not low baseline students. The difference here is statistically significant.

The flip side of the argument that small schools are ineffective for hard-to-educate students is that their focus on these students detracts from those entering with higher achievement levels. For instance, Hemphill and Nauer (2009) write that "small schools, by pouring resources into helping needy students catch up, may shortchange students who have stronger academic skills." At least for outcomes related to college, Table 8 presents evidence for the exact opposite pattern since the effects are larger for students with higher baseline scores. High-baseline students are 9 percentage points more likely to attend college and 10 percentage points more likely to attend four-year public colleges. The effects on college enrollment outcomes for low-baseline students are positive, but are not precise enough to rule out zero effects.

\section{VII.2 Schools Over Time and Closed Schools}

Given changes in the school landscape after the initial big push for small school creation, it is natural to ask whether schools opened after the last pledge of major support from the Gates foundation in 2005 perform differently than schools opened beforehand. In particular, some have worried that after small schools became more established, their student population changed and this reduced achievement levels (Ravitch, 2011). In Table A6, we report estimates where we sample into two groups: schools opened between 2002-05 and those opened between 2006-08. 
Our lottery design allows us to consider 95 our of 118 programs opened from 2002-2005 and 13 out of 33 programs opened from 2006-2008. We see a consistent pattern of effects across these two groups of schools, and in many cases the effects are larger for schools opened in 2006-2008, even though the coverage of the lottery sample is considerably smaller for 2006-2008, so it's possible that new undersubscribed schools fare differently.

While establishing new schools, the NYC DOE also phased out or closed schools during our time period citing lackluster performance. Through 2012, 13 small high school programs eligible for our study have been closed, 9 of which are in the lottery sample. In Table A6, we also report our main estimates excluding these schools. Each point estimate for Regents, graduation, and college is larger when we exclude closed schools, though given that only a handful of schools have been closed, we do not have the precision to confidently assert these estimates are statistically different from those including the closed schools.

\section{VII.3 Intermediaries}

Each small school model can be seen as a set of preferred practices and features that affect school performance. Intermediaries, typically nonprofit organizations that operate between policymakers, funders, and entities charged with implementing new programs and practices, played an important and continuing role in small school development. Intermediaries often distributed grant funds to schools and provide advice on creating, incubating, and operating small schools (Foley et al., 2010). Eight intermediaries- New Visions, Urban Assembly, Replications, NYC Academies, Institute for Student Achievement, College Board, Outward Bound - were involved in creating and supporting more than $90 \%$ of the schools in our study. The customization provided by these intermediaries is at the heart of the small school reform idea.

To provide examples of the heterogeneity across intermediaries, we describe a few patterns. New Visions supports the largest number of schools, each of which focuses on college-readiness and support for individualized instruction. Urban Assembly's themes range from law and government, media, and the arts to wildlife conservation, maritime studies and green careers. Replications scales up small schools, by identifying the essential features of successful schools and supporting new school leaders during start up. NYC Academies are career academies supported by the National Academy Foundation. These schools train students for careers in industries with strong growth and employment potential. The Institute for Student Achievement specializes in turnaround efforts in New York City and elsewhere. They have their own college preparatory program, which features a trademarked "distributed counseling" system of personalized instruction. College Board has a proprietary curriculum aimed at increasing diversity of students in Advanced Placement courses that focus on inquiry, problem solving, collaboration and persuasive writing. NYC Outward Bound schools emphasize hands-on activities and expeditions; all 
students go on a weeklong wilderness trip intended to teach teamwork and perseverance. The schools also have a "crew" system where a group of students have daily meetings with one teacher throughout high school.

Another motivation for studying effects by intermediaries is to examine whether some small school models are more effective than others. Cullen et al. (2013) conjecture that career and technically-focused high schools may be more successful than other thematic schools. It is also worth noting that the trajectory of expansion and contraction has differed by intermediary. For instance, 3 new Urban Assembly high schools were opened between 2006-08, while only 1 school in the Replications and NYC Academies network opened during the same time period. In 2011, the NYC DOE terminated their contract with Replications, stating that while they were successful in launching schools, they were not as successful in managing them afterwards (Phillips, 2011).

While small school operators have been seen as pursuing a diverse array of school visions, some expressed skepticism about the resulting heterogeneity in the small school portfolio. For instance, Ravitch (2011, p. 81) writes:

"Most of the new small schools were theme schools, centered on a specific profession or speciality. This produced some offbeat results, such as a high school for future firefighters; a school for the hospitality industry; a school for urban planners; a school for architecture; a school for the business of sports; a school for the violin; several schools for social justice, peace, and diversity; and other schools for the health professions, writers, leaders, the arts, law, technology, communications, journalism, and media. Adults like the idea of themes, but few children starting ninth grade are prepared to select a profession or career speciality."

On the other hand, the Department of Education did not place firm requirements on how themes were fulfilled, and adherence to theme does not seem to have played a role in accountability decisions (Gootman, 2005).

The non-offered and offered complier school environments, for the variables examined in Table 3, are similar on many dimensions when split by intermediary. Table A5 shows that offered small school compliers face significant differences in school sizes relative to the untreated. Teachers at their schools are also somewhat less experienced and less highly educated, while baseline peer achievement is higher.

Table 9 reports on lottery estimates by intermediaries. The estimates come from models like equation (1), but estimated separately for schools classified by intermediary. (Table A2 presents information on application patterns by intermediary.) With this approach, some students who are not treated at a particular intermediary nonetheless enroll in a small high school in our study. 
This can be seen in Table A5, which shows complier small school enrollment rates for each of the intermediaries. For instance, $46 \%$ of non-offered Urban Assembly compliers enroll at another small school outside the Urban Assembly family. That table also shows that this exercise not only captures the effect of different intermediaries, but it also captures the consequence of different fallback positions. For instance, non-offered compliers at schools supported by Replications attend schools with peer achievement levels about $0.2 \sigma$ below New York City's average in math, while students who attend schools supported by the NYC Academies attend schools more than $0.4 \sigma$ below. Finally, the sample size shrinks, especially at Institute for Student Achievement, College Board, and Outward Bound, making any conclusions for these intermediaries tentative.

There are large and significant effects on Regents Math for five intermediaries: New Visions, Urban Assembly, Replications, NYC Academies, and College Board. The effect on obtaining a Regents Diploma is also large and positive for New Visions and Urban Assembly; though it is not negative for any other intermediary, the significance levels vary and most effects are not precise enough to be useful. Urban Assembly schools increase PSAT taking and scores, SAT taking, and AP test taking (shown in Table A4). Effects on college, measured either by attendance, four-year college attendance, or four-year public college attendance are mostly positive, with the most consistent pattern for New Visions schools.

It bears emphasis that the sample of applicants from New Visions is the largest, and the absence of significant results for other intermediaries may simply reflect the small sample sizes. Still, none of the estimates on four-year college are negative, though some are too imprecise to be meaningful. Given the fact that differences in effects across intermediaries may be due to differences in fallback options, differences in students, and differences in school practices, it is hard to draw firm conclusions about the relative performance of particular intermediaries from this analysis alone (see, Angrist et al. (2013a), for a similar discussion of the interpretation of heterogenous charter school effects). The most noticeable pattern from Table 9 is that no single intermediary seems to be universally poor-performing on all outcomes. Understanding differences across intermediaries seems worth additional investigation.

\section{Mechanisms and Changes in School Environment}

The common denominator across the 108 schools in our sample is their small size. We'd also like to know more about other differences in the small schools' learning environment. However, defining and measuring changes in school environment tends to be a difficult task. Fortunately, starting in the 2006-07 school year, the New York City Department of Education launched the nation's largest survey effort to describe the school learning climate. The survey is completed by students, parents, and teachers, and by 2009 , $80 \%$ of eligible students and $73 \%$ of eligible 
teachers completed the survey (see the data appendix for more details).

We use information from these surveys to characterize the school environment based on student, parent, and teacher responses. In particular, we focus on describing changes in the school environment for those in our experiment. Although we do not have the survey responses made by the students in the sample, we report on the mean survey response at schools attended by the non-offered and offered compliers. In 2003, small schools advocate Thomas Toch articulated a vision for small school success (Toch, 2003, p. 13):

"Smaller schools encourage bonds between students and teachers and generate a level of genuine caring and mutual obligation between them that's found far less frequently in comprehensive high schools. Students and teachers, as a result, tend to work harder on each other's behalf. Student and teacher attendance and student involvement in extracurricular activities are higher in smaller schools. Teacher turnover and disciplinary problems are lower. [...]

The best schools have a clear sense of what they hope to achieve with their students. They are "focused." Their curricula, their teaching strategies, the way they organize their school day, even, in many instances, the design of their buildings, are aligned with their educational aims. [...]

Successful schools also have high academic expectations for every student. That is their defining characteristic."

We investigate several aspects of the small school environment motivated by this quote. The survey contains multiple questions about the school environment organized into four categories: 1) engagement, 2) safety and respect, 3) academic expectations, and 4) communications. Each response is awarded a score between 0 and 10 by the DOE, with 10 reflecting the most favorable for a school's learning environment. We use data from 2006-07 through 2008-09, which covers the most relevant years for students in our sample. To have a normalized benchmark, we standardize responses across schools to have mean zero and unit variance.

For each category, we compute the difference for the survey-reported characteristics for our enrollment compliers using methods in Abadie (2003). Researchers working with similar survey datasets often construct indices to combine multiple outcome variables and have developed inferential methods to deal with correlation across them (see, e.g., Kling, Liebman and Katz (2007)). Though this approach is parsimonious, we instead report the answers to a few specific questions to highlight the richness of the survey. For each category, we rank the survey questions by the greatest difference between the answers for non-offered and offered compliers. To illustrate the range of responses, we report the two questions for which the difference in favor of small schools' learning environment is largest and the two questions for which the difference against 
small schools is largest. We also report the fraction of questions for which the small school learning environment is favored over the counterfactual fallback school environment for those in our experiment.

Small schools are rated higher on the overwhelming majority of questions on engagement, safety and respect, academic expectations, and communications. This can be seen in Table 10, which reports survey questions based on student responses. (Parent survey responses are similar to student responses in that small schools are rated higher for the most questions in each of the four categories. They are reported in Table A7.) Small schools employ numerous strategies to increase engagement in addition to thematic programs and external partnerships. For instance, at some Urban Assembly schools, teachers make home visits (Santos, 2011). These strategies are reflected in the fact that the small school environment is associated with higher levels of engagement on 10 out of 11 questions.

The largest difference in the engagement category in favor of small schools is for the question about whether the adults that students see at the school know students. Here, non-offered compliers are at schools that are $1.0 \sigma$ worse than the typical NYC high school (which is normalized at zero). On this metric, offered small school compliers are at schools roughly $0.5 \sigma$ better than the NYC average, resulting in a $1.5 \sigma$ difference in the environment faced by non-offered and offered compliers. The second largest difference in engagement is for the question about whether adults look out for students. Here, offered compliers' schools are at $0.2 \sigma$, while non-offered compliers' schools are at $-0.8 \sigma$. These survey answers are consistent with greater monitoring and increased interaction at small schools.

Toch's quote expresses the idea that small schools will involve students in more extracurriculars. While the surveys do not capture extra-curricular participation, the largest difference against the small schools environment is for the question about the variety of classes and activities. The variety of classes and activities experienced by non-offered compliers is much greater than the NYC average, and $0.8 \sigma$ greater than that experienced by offered compliers. This finding, instead, is consistent with the view stated by Ravitch (2011, p. 205) who laments that "because of their size, they seldom have enough students or teachers to offer advanced courses in mathematics and science, elective, advanced placement courses, career and technical education, choir, band, sports teams, and other programs that many teenagers want."

The description of the small school environment is also more favorable for the three other categories. On safety and respect, offered small school compliers are at schools with a greater sense of community (measured by disagreement with the statement that most students in my school just look out for themselves). Small schools are also associated with less gang activity and outrank the untreated counterfactual school environment on 19 out of 20 questions on safety and respect. This finding is important given concerns about placing new small schools on the 
same campuses as struggling schools vulnerable to safety concerns (Miller, 2005). On academic expectations, offered compliers are at small schools that regularly complete essays and where high-achievers are treated with respect. There is little difference on college counseling, however. On communication, the environment experienced by non-offered compliers dominates by a wide margin on all five questions. Students consistently work in groups, feel comfortable talking to their instructors, and participate in hands-on activities.

Table 11 reports the results of a similar exercise based on teacher survey responses. The higher rates of teacher turnover shown in Table 3 might suggest a poor work environment at new small schools. However, based on teacher survey responses, on a large fraction of questions, offered small school compliers are at schools where teachers report greater engagement, safety and respect, academic expectations, and communication. Among the many questions, we high-

light a few where the differences are most stark. First, the contrast in the fraction of teachers who report reacting to feedback and using data to improve instructional decisions is large, but the mean level for offered compliers is near the NYC average. Second, the positive teacher's assessments on safety and respect are nearly identical to those reported in student surveys. Third, teachers report their schools have a clear vision and that there is effective communication with parents when students misbehave. For our experiment, the one dimension where the small school environment is unfavorable (as reported by teachers) is on issues related to principal supervision and management.

Overall, a consistent picture emerges about the small school environment, whether as described by student or teacher survey responses. Together with the results on truancy, many of the mechanisms present in the Toch quote appear to be validated (except extracurricular activities and teacher-principal interaction). Interestingly, many of these features where the small school environment dominates, including use of data to guide instruction, frequent teacher feedback, and high academic expectations, are shared by the high-performing charter schools studied by Angrist et al. (2013a) and Dobbie and Fryer (2013a).

\section{School Size in Education Production}

The estimates here show remarkably consistent gains for small school attendance on test scores, graduation, and college enrollment. These estimates speak to questions about the impact of Bloomberg-era reforms in the nation's largest school district. They are also relevant for policy questions such as the expansion of small schools and closing underperforming schools.

We'd also like to investigate whether there are more general lessons from our analysis of small schools. The role of school size in education production is an important question in the economics of education. Conant's (1959) original argument for large comprehensive high schools 
was mostly based on scale economies. A subsequent literature has tried to characterize optimal school sizes, with some claiming that high schools with about 600-900 students balance scale economies with the negative effects of large schools (see, e.g., Andrews, Duncombe and Yinger (2002)). Many arguments for small schools parallel those made in similar debates on small class sizes. For instance, Lazear (2001) develops a disruption-based model of learning and shows that optimal class size is larger for better-behaved students. It is possible to interpret his model as one of school size with the same underlying mechanism, with the implication that a smaller school size is preferred for harder-to-educate students. Understanding the role of school size for achievement also seems important as school choice expands, causing many traditional district schools to become smaller.

The evidence from school surveys suggests that small schools differ from other schools on many dimensions. It is clear from Table 3, however, that students who attend small schools are at schools with considerably smaller student bodies, whether measured by the number of 9 th grade classmates or the number of students at the school across all high school grades. To turn this fact into a more general statement about the effects of school size requires stronger assumptions. In particular, we must assume that small school offers affect achievement solely through changes in school size. In their context, Abdulkadiroğlu et al. (2011a) describe two sets of assumptions which justify using exam schools to study the causal effects of peers. We briefly review their arguments in a parallel effort to explore how our small school experiment identifies causal school size effects.

We begin by positing a simple model of education production, where $m_{i}$ denote a vector of education inputs measured in the small school entry grade:

$$
y_{i}=\pi^{\prime} m_{i}+\eta_{i}
$$

The mediators in $m_{i}$ include school size, measures of school quality, and teacher effects. If we partition $m_{i}$ into measures of school size $s_{i}$ and other unobserved inputs $w_{i}$ :

$$
m_{i}=\left[s_{i}^{\prime} w_{i}^{\prime}\right]^{\prime},
$$

then

$$
y_{i}=\beta^{\prime} s_{i}+\gamma^{\prime} w_{i}+\eta_{i}
$$

The first argument is based on a 2SLS version of the omitted variables bias formula (see, e.g., Angrist and Krueger (1992)). If small schools have better unmeasured inputs, then 2SLS estimates of $s_{i}$ omitting $w_{i}$ tend to be too big. The descriptive patterns in the Learning Environment Surveys described in Section VIII suggest that small schools are associated with higher levels of engagement, safety and respect, academic expectations, and communication. It is therefore plausible that the omitted variables in $w_{i}$ are beneficial for student achievement. Under this interpretation, our estimate provides an upper bound on the effect of school size. 
The second argument is based on the idea that any school input correlated with small school offers is itself caused by differences in size. That is, the relationship between unobserved school inputs $w_{i}$ is a consequence of the affect of school size (e.g., students are monitored more closely because small schools have smaller size; the ability to have frequent interactions with pupils affects teaching styles; improved communication is the result of fewer students). If we assume that the randomly generated offer affects school size, and school size in turn affects these other unmeasured inputs (i.e. a triangular structure), then 2SLS estimates treating $s_{i}$ as endogenous combine both the direct and indirect effects to capture the total effect of randomly assigned school size.

Table 12 reports estimates of two versions of 2SLS models where school size is measured either by the size of the 9 th grade class or by the number of high school classmates. The first stage estimates, shown in Panel B, are large and precise for both measures, consistent with the sharp differences in school size shown in Table 3. The estimates imply that a small school offer leads to 269 fewer 9th grade classmates or 701 fewer high school classmates. Though these estimates come from a linear model, they do not impose a linear relationship, since the 2SLS estimates can be interpreted as the weighted-average causal response to school size. ${ }^{17}$

The 2SLS estimate shown in Panel A imply that a 100 student reduction in 9th grade size causes a $0.024 \sigma$ increase in Regents math. In particular, the standard error on this estimate is 0.007 , implying that we have the power to detect small effects. For the other outcomes, the precision of the 2SLS estimates of school size are similar to that of the 2SLS estimates treating small school enrollment as endogenous reported earlier. For instance, a 100 student reduction in the number of 9th grade classmates causes a statistically significant one point increase in college attendance. Estimates of the causal effect of school size measured by grade 9-12 classmates are similar, but roughly three times smaller, as expected given the differences in the magnitude of the first stage.

Taken together, these estimates indicate that incremental changes in school size are likely to have very small effects on student achievement. Instead, dramatic changes in school sizes, such as those that occurred in New York City, would be necessary to have a significant impact on racial and socioeconomic gaps. In this context, it also helps to draw a comparison to the debates of the importance of input-based schooling policies (Hanuschek, 2003; Krueger, 2003). In particular, there are now a number of well-controlled estimates of class size effects (Angrist and Lavy, 1999; Krueger, 1999; Chetty, Friedman, Hilger, Saez and Schanzenbach, 2011; Dynarski et al., 2011; Fredriksson et al., 2013). Estimates of the effect of class size reductions of roughly 7 fewer students from Krueger (1999) imply a 0.18 standard deviation increase in Stanford

\footnotetext{
${ }^{17}$ The weights are proportional to the effect of the instrument on the cumulative distribution function of the endogenous variable (Angrist and Imbens, 1995).
} 
Achievement Tests. Here, too, one or two fewer students in a class seem likely to have small effects. On the other hand, incremental changes to either class or school size may be less policyrelevant than larger-scale changes.

\section{Conclusion}

The reconstitution of large high schools into smaller ones in New York City and elsewhere has left a lasting legacy on America's public high schools. The random variation created by NYC's high school match provides a unique opportunity to estimate the causal effects of NYC's small schools free from selection bias. We find consistent evidence that small schools boost student achievement on important graduation milestones, including on five different Regents exams, grade progression, and credit accumulation. Small school students are more likely to graduate high school and earn Regents diplomas, and are less likely to require remediation in reading and writing when they enter college. A large fraction of small school students are pushed to four-year public institutions and those within the CUNY system. The evidence, so far, also indicates that they are more likely to persist in college, as measured by matriculation for at least two academic semesters. As the cohorts in our study age, it will be possible to study longer-term measures of college persistence and college graduation.

The estimates reported here are best seen as indicating possibilities for urban small schools reform. Our lottery design necessarily requires that schools be unselective and oversubscribed. It is worth noting, however, that our sample is not isolated to a handful of schools nor do we have idiosyncratic coverage of particular schools assisted by only some intermediaries. The 108 school programs in our study represent over $70 \%$ of those eligible. Oversubscribed schools are of considerable policy interest, especially in light of Mayor Bloomberg's stated goal in 2010 to phase out the lowest performing 10 percent of city schools over the next four years (Otterman, 2010). The requirement that students are subject to lottery-based rationing also implies that special education and limited English proficient students are excluded from our lottery sample. Still, it is worth emphasizing that the students in our sample are disadvantaged by most traditional measures. More than $90 \%$ of students in our lottery sample are black or Hispanic, at least $70 \%$ obtain subsidized school lunches, and the majority have lower baseline scores than typical NYC 8th graders. Our investigation of effects across subgroups indicates that small schools are effective for a broad set of students.

Proponents argue that students are more easily monitored and safer at small schools; this in turn increases their motivation and attendance, and ultimately graduation and college attendance. The evidence on these mechanisms is borne out in our investigation of incredibly detailed data from New York City's School Learning Environment Surveys. Small schools cause 
a significant decrease in truancy. Survey respondents associate small schools with greater levels of engagement, safety and respect, academic expectations, and communication. Moreover, the consistency of the results across intermediaries, though sometimes imprecise, suggests that school size is an important common ingredient. When we channel the school effects through school size, the estimates imply that incremental changes in school size will be insufficient to have significant effects on achievement gaps, whereas large-scale changes like those that took place in New York City may be necessary.

Our findings stand out when compared to a literature with relatively few examples of successful interventions for inner-city public school students, especially for college choice and enrollment. Given this, some have argued that high school may be too late to reduce skill gaps and efforts should therefore be concentrated earlier or even before the start of a student's schooling career (see, e.g., Cunha and Heckman (2007) and Cunha, Heckman and Schennach (2010)). Moreover, interventions showing the greatest promise for urban populations have so far come from highperforming charter schools such as KIPP or Harlem's Promise Academies, which operate outside traditional district boundaries (Angrist et al., 2012; Dobbie and Fryer, 2013a). Even though the small high schools studied here had auxiliary support from foundation grants and advocacy efforts, they still operate with the same school calendar and under the same collectively-bargained work rules as other New York City high schools.

The common features of these high-performing charter schools and the small schools studied here include high expectations, close monitoring, frequent interaction, and the use of datadriven instruction. While the "No Excuses" style charter schools with these practices embody a relatively well-defined model, NYC's small schools are horizontally differentiated with themes designed to engage low-performing students. Cullen et al. (2013) and Murnane (2013) argue that increasing the variety of educational offerings at high school is a worthwhile pursuit, especially if it increases the match quality between students and schools. In future work, we intend to further explore heterogeneity across small school models and examine issues related to how the new small schools affect student sorting. 


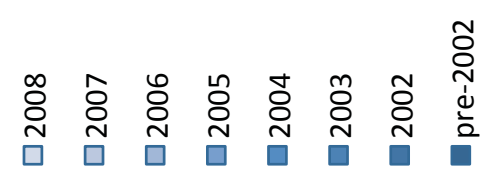

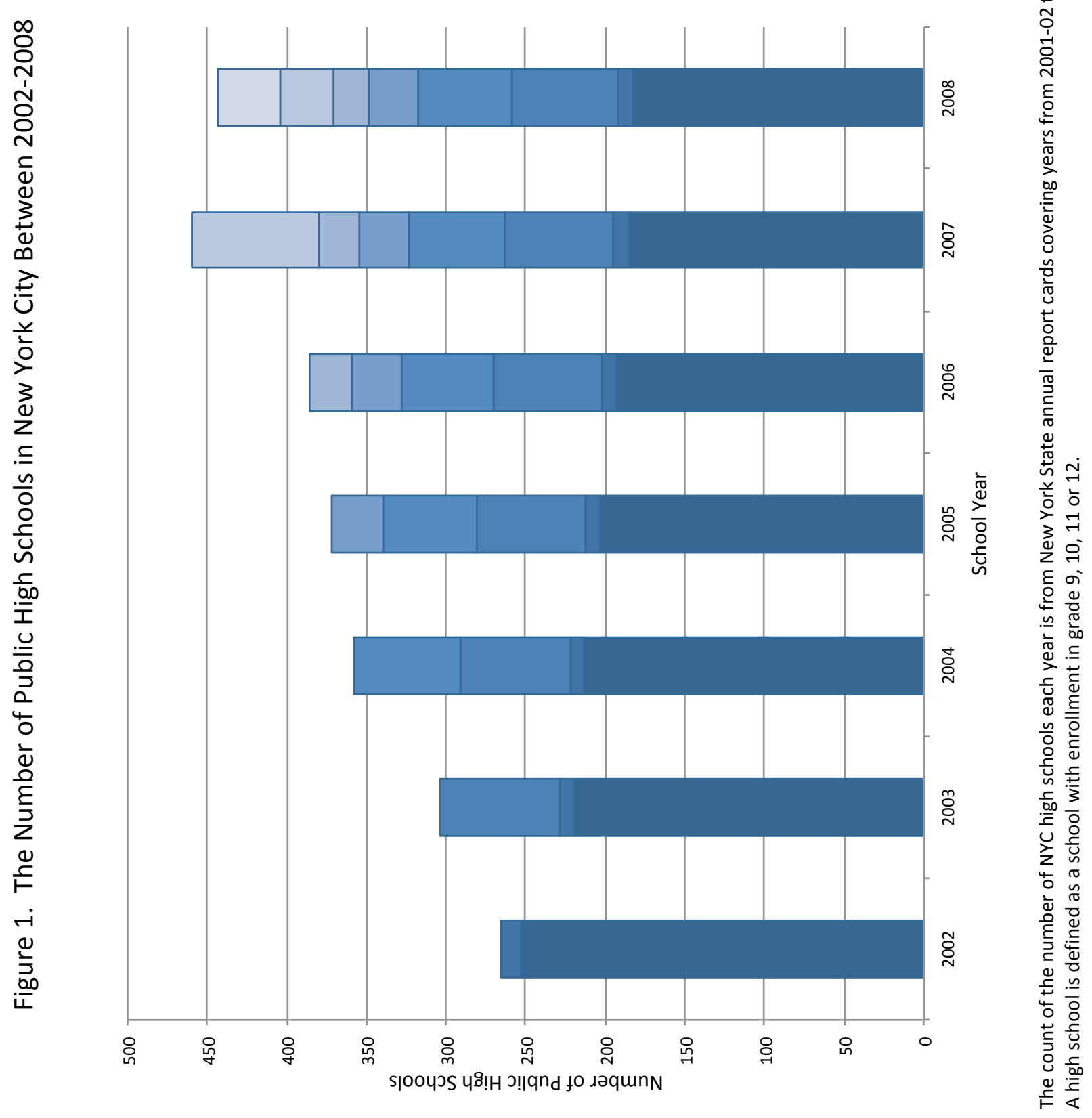




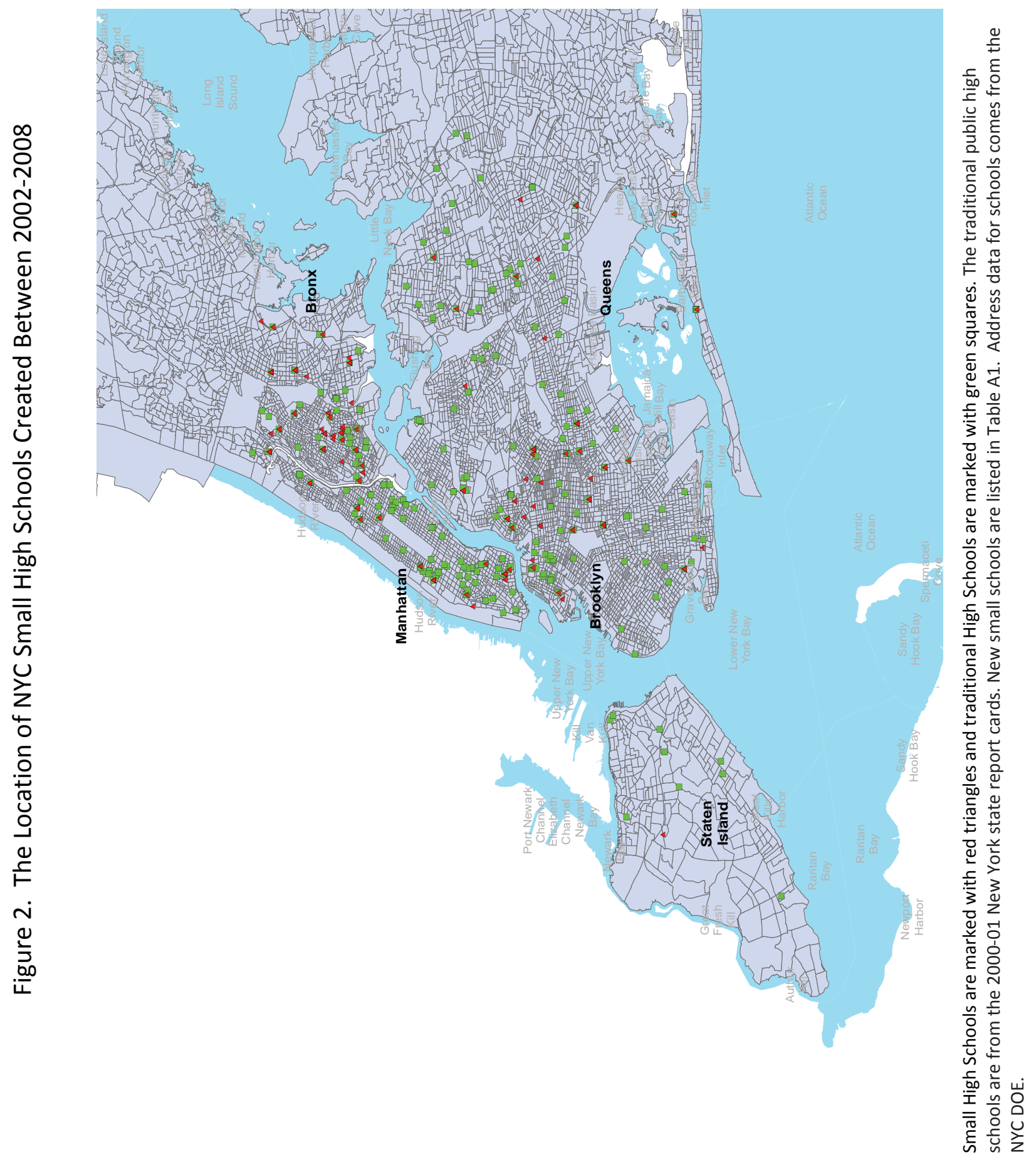




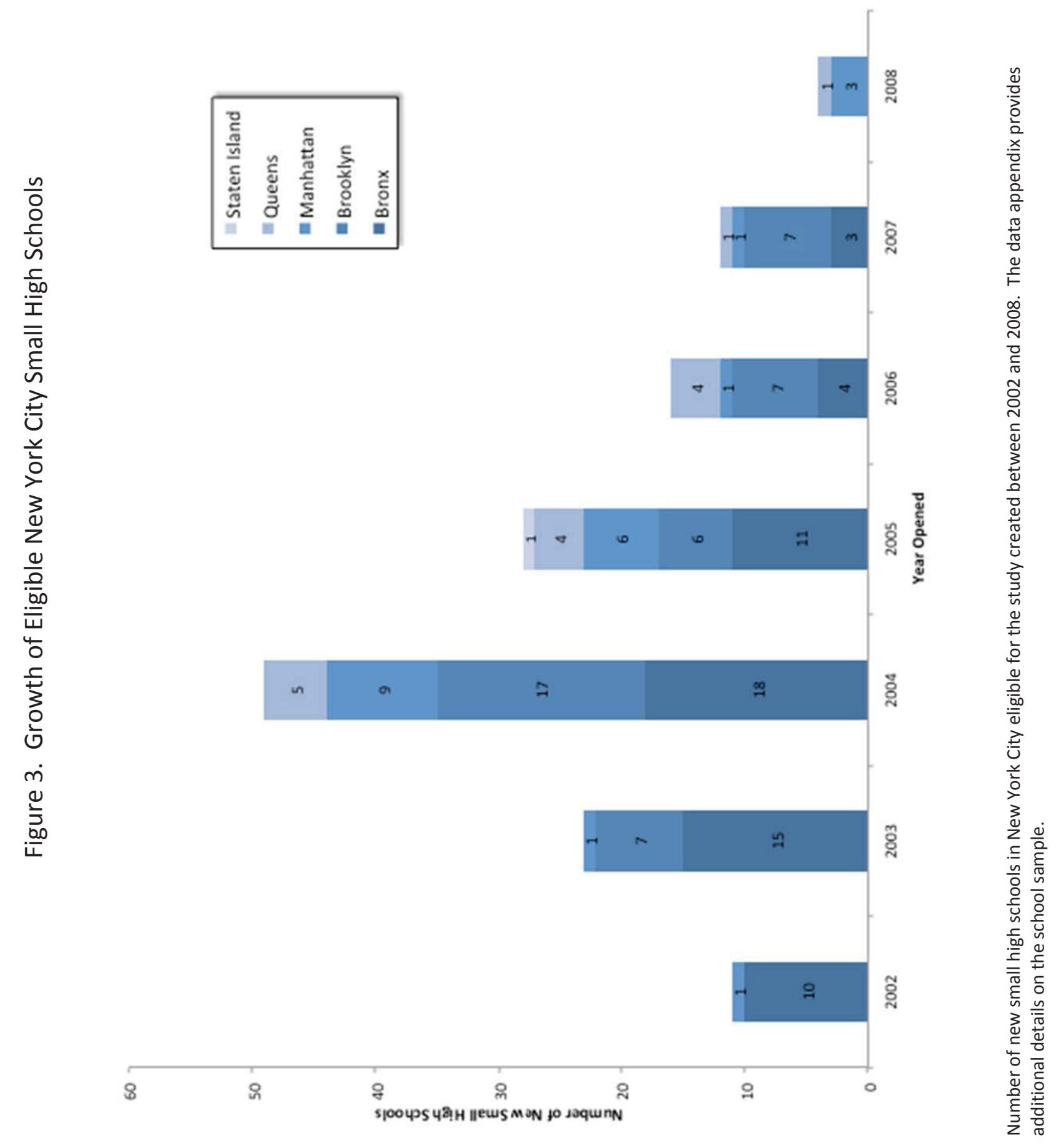




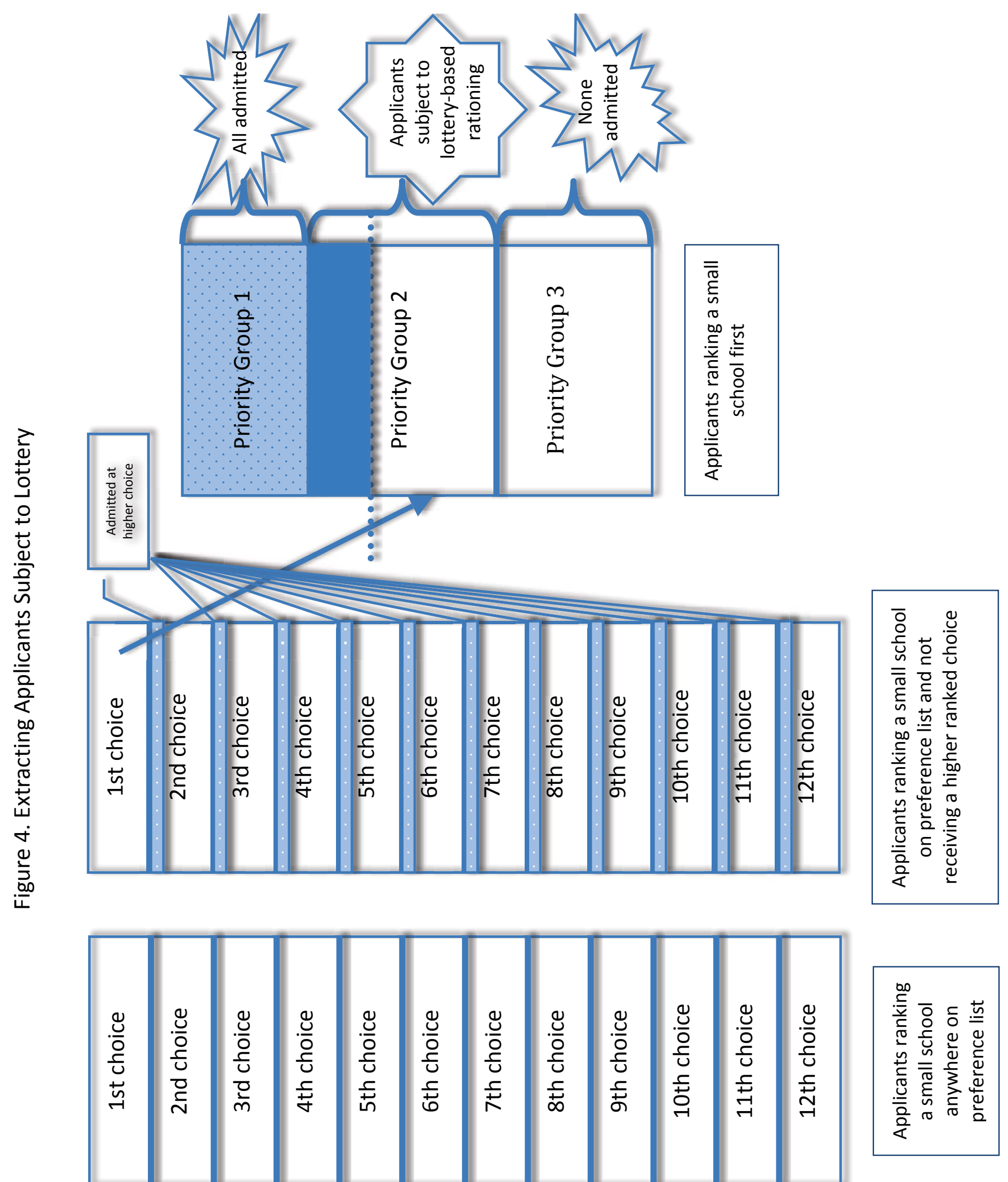


Table 1. Study Participation of NYC Small High Schools

\begin{tabular}{|c|c|c|}
\hline & $\begin{array}{c}\text { \# in lottery sample / \# } \\
\text { eligible }\end{array}$ & $\begin{array}{c}\text { \# in lottery sample / \# } \\
\text { eligible }\end{array}$ \\
\hline & (1) & (2) \\
\hline All & $108 / 151$ & $99 / 138$ \\
\hline \multicolumn{3}{|l|}{ School Intermediaries } \\
\hline New Visions & $72 / 94$ & $65 / 84$ \\
\hline Urban Assembly & $12 / 13$ & $12 / 12$ \\
\hline Replications & $8 / 12$ & $8 / 11$ \\
\hline NYC Academies & $5 / 5$ & $5 / 5$ \\
\hline Institute for Student Achievement & $7 / 15$ & $7 / 15$ \\
\hline College Board & $5 / 9$ & $5 / 9$ \\
\hline Outward Bound & $5 / 8$ & $3 / 6$ \\
\hline All Others & $11 / 15$ & $11 / 15$ \\
\hline \multicolumn{3}{|c|}{$\begin{array}{l}\text { Notes: This table reports the number of small high school programs in New York City } \\
\text { eligible for the study and the number who are in the lottery sample. A program contributes } \\
\text { to the lottery sample if it is oversubscribed and subject to rationing via lottery in at least } \\
\text { one year one year } 2003-04 \text { between } 2007-08 \text {. A school program is closed if it no longer } \\
\text { appears in the } 2012-13 \text { high school directory. Intermediary classifications are described in } \\
\text { the data appendix. Programs may belong to more than one intermediary group. }\end{array}$} \\
\hline
\end{tabular}


Table 2. Descriptive Statistics for Students

\begin{tabular}{|c|c|c|c|c|c|c|c|c|}
\hline & & & \multicolumn{4}{|c|}{ Applicants } & \multicolumn{2}{|c|}{ Covariate Balance } \\
\hline & $\begin{array}{l}\text { NYC 8th } \\
\text { graders } \\
\text { (1) }\end{array}$ & $\begin{array}{l}\text { Enrolled in a } \\
\text { Small School } \\
\text { (2) }\end{array}$ & $\begin{array}{l}\text { Ranked Small } \\
\text { School } \\
\text { Anywhere on } \\
\text { Preference } \\
\text { Form } \\
\text { (3) }\end{array}$ & $\begin{array}{l}\text { Ranked Small } \\
\text { School and } \\
\text { Did Not } \\
\text { Receive More } \\
\text { Preferred } \\
\text { Offer } \\
\text { (4) }\end{array}$ & $\begin{array}{l}\text { Ranked Small } \\
\text { School as a } \\
\text { First Choice } \\
\text { (5) }\end{array}$ & $\begin{array}{l}\text { Applicants } \\
\text { Subject to } \\
\text { Lottery } \\
\text { (6) }\end{array}$ & $\begin{array}{l}\text { Lotteried } \\
\text { Applicants } \\
\text { (7) }\end{array}$ & $\begin{array}{l}\text { Lotteried } \\
\text { Applicants } \\
\text { with Baseline } \\
\text { Scores } \\
\text { (8) }\end{array}$ \\
\hline Female & 0.49 & 0.51 & 0.51 & 0.50 & 0.48 & 0.53 & $\begin{array}{l}-0.006 \\
(0.011)\end{array}$ & $\begin{array}{c}-0.008 \\
(0.011)\end{array}$ \\
\hline Black & 0.34 & 0.46 & 0.42 & 0.42 & 0.42 & 0.44 & $\begin{array}{c}0.011 \\
(0.011)\end{array}$ & $\begin{array}{c}0.009 \\
(0.012)\end{array}$ \\
\hline Hispanic & 0.39 & 0.45 & 0.48 & 0.49 & 0.50 & 0.47 & $\begin{array}{l}-0.008 \\
(0.012)\end{array}$ & $\begin{array}{l}-0.006 \\
(0.012)\end{array}$ \\
\hline White & 0.14 & 0.04 & 0.04 & 0.04 & 0.05 & 0.05 & $\begin{array}{l}-0.005 \\
(0.005)\end{array}$ & $\begin{array}{l}-0.007 \\
(0.005)\end{array}$ \\
\hline Other/Unknown & 0.13 & 0.05 & 0.05 & 0.04 & 0.04 & 0.04 & $\begin{array}{c}0.001 \\
(0.004)\end{array}$ & $\begin{array}{c}0.004 \\
(0.004)\end{array}$ \\
\hline Subsidized lunch & 0.69 & 0.73 & 0.72 & 0.72 & 0.72 & 0.71 & $\begin{array}{c}0.011 \\
(0.011)\end{array}$ & $\begin{array}{c}0.010 \\
(0.011)\end{array}$ \\
\hline Special education & 0.10 & 0.08 & 0.09 & 0.09 & 0.10 & 0.00 & n.a & n.a \\
\hline Limited English proficiency & 0.11 & 0.10 & 0.11 & 0.11 & 0.11 & 0.00 & n.a & n.a \\
\hline Manhattan & 0.12 & 0.11 & 0.14 & 0.13 & 0.10 & 0.07 & $\begin{array}{l}-0.002 \\
(0.005)\end{array}$ & $\begin{array}{l}-0.002 \\
(0.005)\end{array}$ \\
\hline Brooklyn & 0.32 & 0.30 & 0.28 & 0.25 & 0.23 & 0.19 & $\begin{array}{l}-0.001 \\
(0.005)\end{array}$ & $\begin{array}{c}0.000 \\
(0.005)\end{array}$ \\
\hline Queens & 0.27 & 0.16 & 0.13 & 0.11 & 0.09 & 0.07 & $\begin{array}{c}0.000 \\
(0.004)\end{array}$ & $\begin{array}{c}0.000 \\
(0.004)\end{array}$ \\
\hline Bronx & 0.23 & 0.42 & 0.44 & 0.50 & 0.56 & 0.62 & $\begin{array}{c}0.003 \\
(0.005)\end{array}$ & $\begin{array}{c}0.002 \\
(0.005)\end{array}$ \\
\hline Staten Island & 0.06 & 0.01 & 0.01 & 0.02 & 0.02 & 0.04 & $\begin{array}{c}0.000 \\
(0.002)\end{array}$ & $\begin{array}{c}0.000 \\
(0.002)\end{array}$ \\
\hline Baseline Math score & 0.00 & -0.28 & -0.24 & -0.31 & -0.32 & -0.19 & & $\begin{array}{l}-0.020 \\
(0.017)\end{array}$ \\
\hline Baseline English score & 0.00 & -0.23 & -0.21 & -0.26 & -0.27 & -0.10 & & $\begin{array}{l}-0.005 \\
(0.016)\end{array}$ \\
\hline$p$-value & & & & & & & 0.963 & 0.856 \\
\hline $\mathrm{N}$ & 415,515 & 61,406 & 159,178 & 82,899 & 42,454 & 10,418 & 10,204 & 9,925 \\
\hline $\begin{array}{l}\text { Notes: This table reports de } \\
\text { Demographic information a } \\
\text { Language Arts exam, respec } \\
\text { in a small school are those } \\
\text { (3) rank a small school amor } \\
\text { a school more preferred to } \\
\text { rank a small school as their } \\
\text { the lottery. Columns (7)-(8) } \\
\text { small school. We report the } \\
\text { Regressions include risk-set } \\
\text { Proficient students do not c } \\
\text { are from tests of the hypoth }\end{array}$ & $\begin{array}{l}\text { iptive stat } \\
\text { baseline s } \\
\text { ely. NYC } 8 \\
\text { are in a s } \\
\text { one of the } \\
\text { ir highest } \\
\text { t choice, v } \\
\text { ports coef } \\
\text { estimates } \\
\text { ntrols, and } \\
\text { tribute to }\end{array}$ & $\begin{array}{l}\text { cs for the samp } \\
\text { es are taken frc } \\
\text { graders in colur } \\
\text { ll school in grac } \\
2 \text { choices on th } \\
\text { ked small scho } \\
\text { le applicants in } \\
\text { ents from regre } \\
\text { the sample wi } \\
\text { bust standard } \\
\text { lottery sample }\end{array}$ & $\begin{array}{l}\text { e of public scho } \\
\mathrm{m} \text { grade } 8 . \mathrm{Ba} \\
\mathrm{nn}(1) \text { are } 8 \text { th } \mathrm{g} \\
\mathrm{le} 9 \text { in the schoc } \\
\text { e high school ac } \\
\mathrm{l} \text {, and are ther } \\
\text { column (6) are i } \\
\text { ssions of the va } \\
\text { h all available s } \\
\text { rrors are in par } \\
\text { because of the }\end{array}$ & $\begin{array}{l}\text { ol students in } \\
\text { seline Math and } \\
\text { rade applicants } \\
\text { ol year after the } \\
\text { dmissions prefer } \\
\text { efore considere } \\
\mathrm{n} \text { a small school } \\
\text { riable in each ro } \\
\text { tudent demogr } \\
\text { enthesis. n.a. } \mathrm{m} \\
\text { were not subje }\end{array}$ & $\begin{array}{l}\text { JYC and applican } \\
\text { I English scores a } \\
\text { in the HS match } \\
\text { y participated in } \\
\text { ence form. App } \\
\text { d for admissions } \\
\text { I where there is } \\
\text { aw on an indicat } \\
\text { aphics in column } \\
\text { eeans not availat } \\
\text { ect to lottery in t }\end{array}$ & $\begin{array}{l}\text { s to small sch } \\
\text { fe from the N } \\
\text { from non-priv } \\
\text { the High Schc } \\
\text { icants in colu } \\
\text { at the small s } \\
n \text { admissions } \\
r \text { equal to on } \\
\text { (7) and also b } \\
\text { le. Special Ec } \\
\text { ee high schoo }\end{array}$ & $\begin{array}{l}\text { in columns ( } \\
\text { th grade Mat } \\
\text { schools. Stud } \\
\text { latch. Applic } \\
\text { 4) did not obt } \\
\text { l. Applicants } \\
\text { ary and also a } \\
\text { he student is } \\
\text { ine scores in } \\
\text { ion and Limit } \\
\text { nissions proc }\end{array}$ & $\begin{array}{l}\text { 1)-(6). } \\
\text { h and English } \\
\text { lents enrolled } \\
\text { ants in column } \\
\text { tain an offer at } \\
\text { in column (5) } \\
\text { re subject to } \\
\text { offered a } \\
\text { column (8). } \\
\text { ed English } \\
\text { ess. P-values }\end{array}$ \\
\hline
\end{tabular}


Table 3. NYC Enrollment Decisions, Average Per-Pupil Expenditure, and School, Teacher, Staff, and Peer Characteristics for Small High School Compliers

\begin{tabular}{|c|c|c|c|}
\hline & \multirow{3}{*}{$\begin{array}{c}\text { Non-enrollees } \\
E\left[Y_{0} \mid D=0\right] \\
(1)\end{array}$} & \multicolumn{2}{|c|}{ Small School Compliers } \\
\hline & & Non-Offered $(Z=0)$ & Offered $(Z=1)$ \\
\hline & & $(2)$ & (3) \\
\hline & \multicolumn{3}{|c|}{ Panel A. Enrollment Decisions } \\
\hline Enrolled at Small Schools & 0.00 & 0.00 & 1.00 \\
\hline Enrolled in Manhattan & 0.20 & 0.22 & 0.16 \\
\hline Enrolled in Bronx & 0.16 & 0.39 & 0.46 \\
\hline Enrolled in Brooklyn & 0.26 & 0.19 & 0.20 \\
\hline Enrolled in Queens & 0.23 & 0.11 & 0.09 \\
\hline \multirow[t]{2}{*}{ Enrolled in Staten Island } & 0.06 & 0.09 & 0.09 \\
\hline & \multicolumn{3}{|c|}{ Panel B. Average Per-Pupil Expenditure } \\
\hline Direct Services to School & 13,051 & 14,294 & 13,651 \\
\hline Classroom Funds & 7,329 & 7,890 & 7,415 \\
\hline Teachers & 6,008 & 6,421 & 6,040 \\
\hline Instructional Support Services & 1,926 & 2,249 & 1,982 \\
\hline Leadership / Supervision / Support & 1,683 & 1,921 & 1,940 \\
\hline Ancillary Support & 897 & 848 & 908 \\
\hline Building Services & 1,142 & 1,304 & 1,324 \\
\hline Field Support Costs & 326 & 354 & 300 \\
\hline System-wide Costs & 352 & 370 & 366 \\
\hline \multirow[t]{2}{*}{ System-wide Obligations } & 1,250 & 1,300 & 1,302 \\
\hline & \multicolumn{3}{|c|}{ Panel C. School, Teacher, and Staff Characteristics } \\
\hline Number of Grade 9 Students & 715 & 863 & 161 \\
\hline Number of Grade 9-12 Students & 2,117 & 2,249 & 443 \\
\hline Average English Class Size & 27 & 27 & 25 \\
\hline Average Math Class Size & 27 & 26 & 25 \\
\hline Total Number of Core Classes Taught & 428 & 446 & 107 \\
\hline Total Number of Teachers & 121 & 132 & 32 \\
\hline Percent of Teachers with Fewer than Three Years of Teaching Experience & 13 & 14 & 30 \\
\hline Percent of Teachers with Master's Degree plus 30 hours or Doctorate & 46 & 43 & 29 \\
\hline Percent of Teachers with No Valid Teaching Certificate & 4 & 5 & 6 \\
\hline Teacher Turnover Rate & 16 & 19 & 28 \\
\hline Number of Full-time Assistant Principals & 5 & 6 & 1 \\
\hline \multirow[t]{2}{*}{ Number of Full-time Non-Teaching Staff } & 9 & 12 & 3 \\
\hline & \multicolumn{3}{|c|}{ Panel D. Peer Characteristics } \\
\hline Baseline Peer Mean in Math & 0.02 & -0.28 & -0.07 \\
\hline Baseline Peer Mean in English & 0.00 & -0.28 & -0.03 \\
\hline Proportion Black or Hispanic & 0.70 & 0.85 & 0.84 \\
\hline Proportion Subsidized Lunch & 0.68 & 0.68 & 0.72 \\
\hline Proportion Female & 0.48 & 0.44 & 0.48 \\
\hline Proportion Special Education & 0.10 & 0.11 & 0.08 \\
\hline Proportion Limited English Proficient & 0.12 & 0.14 & 0.07 \\
\hline
\end{tabular}

Notes: This table shows descriptive statistics for students not enrolled at small schools, small school enrollment compliers not offered admissions $(\mathrm{Z}=0)$, and enrollment compliers offered admissions $(\mathrm{Z}=1)$. Complier attributes are computed following methods described in Abadie (2003). Baseline peer means are from 8th grade New York State Math and English and Language Arts tests for Spring 2002-2007. Teacher turnover rate is the number of teachers in that school year who were not teaching in the following school year divided by the number of teachers in the specified school year, expressed as a percentage. Non-teaching staff are staff other than teachers, principals, and assistant principals including administrators, guidance counselors, school nurses, psychologists, and other professionals who devote more than have of their time to nonteaching duties. Direct Services to Schools include Classroom Instruction, Instructional Support Services, Leadership/Supervision/Support, Ancillary Support Services, and Building Services. Classroom Funds include Teachers, Educational Paraprofessionals, Other Classroom Staff, Text Books, Libraries \& Library Books, Instructional Supplies \& Equipment, Professional Development, Contracted Instructional Services, and Summer \& Evening School. Instructional Support Services include Counseling, Attendance \& Outreach Services, Related Services, Drug Prevention Programs, Referral \& Evaluation Services, After School \& Student Activities, Parent Involvement. Leadership/Supervision/Support includes Principals, Assistant Principals, Supervisors, Secretaries, School Aids \& Other Support Staff, Supplies, Materials, Equipment and Telephone. Ancillary Support Services include Food Services, Transportation, School Safety, and Computer System Support. Building Services include Custodial Services, Building Maintenance, Leases, and Energy. School, teacher, and staff characteristics are from New York State Report Cards for the years 2006-09 available at http://reportcards.nysed.gov/index.php. Class size data is from the NYC DOE website for the years 2007-2009 available at http://schools.nyc.gov/AboutUs/data/classsize/classsize.htm. Expenditure data is from the NYC DOE website for the years 2006-2009 available at http://schools.nyc.gov/Offices/DBOR/SBER/OLD_YEARS.htm. 


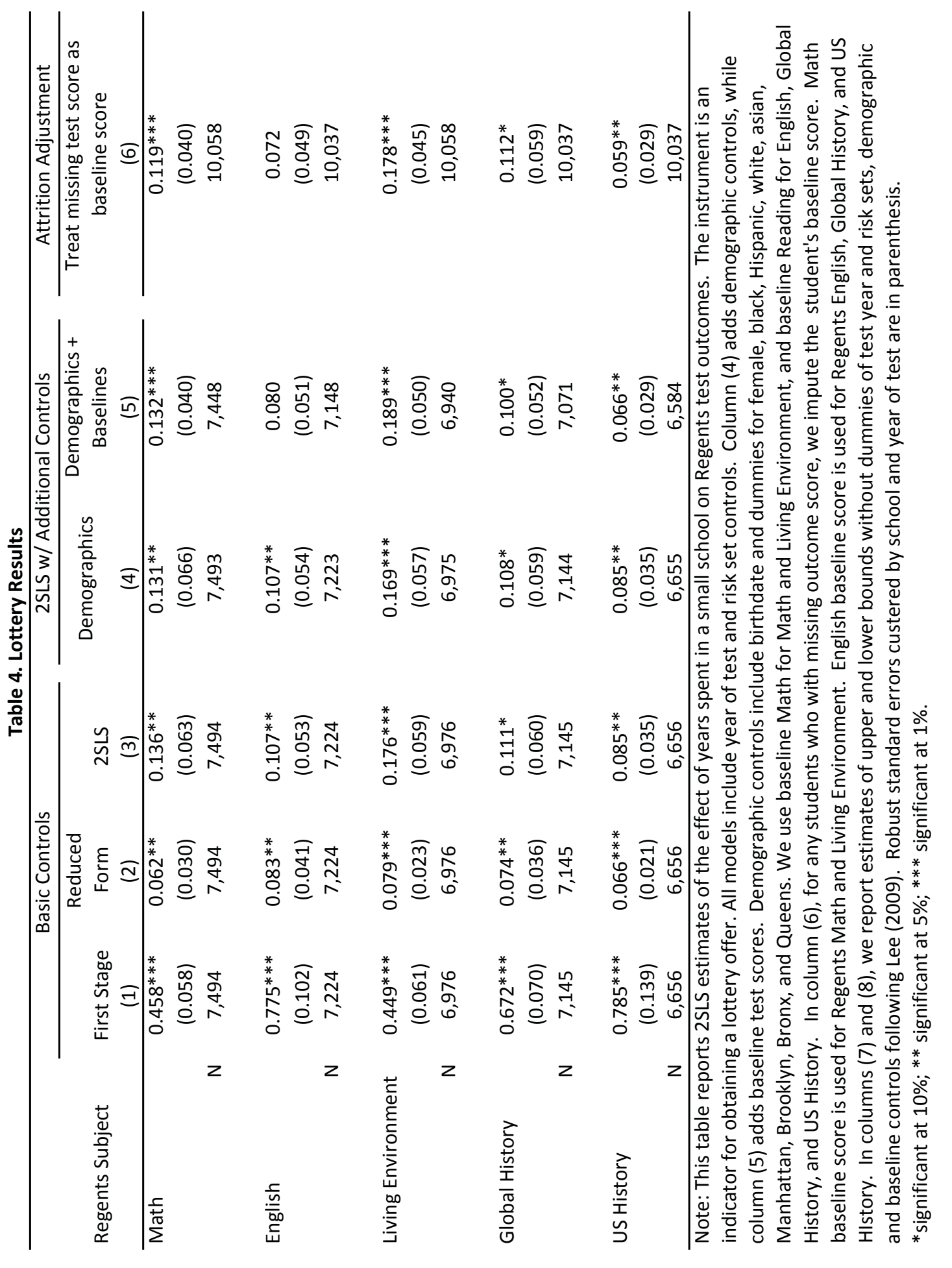


Table 5. Lottery Estimates on Credits and Attendance

\begin{tabular}{|c|c|c|c|}
\hline & & $\begin{array}{l}\text { Mean for Non-Offered } \\
\text { (1) }\end{array}$ & $\begin{array}{c}\text { All Small Schools } \\
\text { (2) }\end{array}$ \\
\hline & & \multicolumn{2}{|c|}{ Panel A. Credits } \\
\hline \multirow[t]{3}{*}{ Total Credits per Year } & & 9.433 & $1.369 * * *$ \\
\hline & & & $(0.212)$ \\
\hline & $\mathrm{N}$ & 17,867 & 34,884 \\
\hline \multirow[t]{3}{*}{ 10+ Credits per Year } & & 0.556 & $0.098 * * *$ \\
\hline & & & $(0.020)$ \\
\hline & $\mathrm{N}$ & 17,867 & 34,884 \\
\hline \multirow[t]{4}{*}{$11+$ Credits per Year } & & 0.497 & $0.096 * * *$ \\
\hline & & & $(0.020)$ \\
\hline & $\mathrm{N}$ & 17,867 & 34,884 \\
\hline & & \multicolumn{2}{|c|}{ Panel B. Grade Repetition } \\
\hline \multirow[t]{3}{*}{ Start Grade 10 on-time } & & 0.741 & $0.136 * * *$ \\
\hline & & & $(0.025)$ \\
\hline & & 5,049 & 9,752 \\
\hline \multirow[t]{3}{*}{ Start Grade 11 on-time } & & 0.587 & $0.166^{* * *}$ \\
\hline & & & $(0.029)$ \\
\hline & & 4,152 & 8,265 \\
\hline \multirow[t]{4}{*}{ Start Grade 12 on-time } & & 0.523 & $0.169 * * *$ \\
\hline & & & $(0.041)$ \\
\hline & & 2,581 & 5,180 \\
\hline & & \multicolumn{2}{|c|}{ Panel C. Attendance } \\
\hline \multirow[t]{3}{*}{ Days Absent } & & 26.56 & $-3.728 * * *$ \\
\hline & & & $(1.42)$ \\
\hline & $\mathrm{N}$ & 15,871 & 31,298 \\
\hline
\end{tabular}

Notes: This table reports 2SLS estimates of small school attendance on measures of credits per year and attendance, where the endogenous variable is 9th grade small school enrollment and the instrument is an indicator for offer. The sample is restricted to students in our lottery sample with demographics and baseline scores. All models include controls for risk sets, demographics, and baseline scores. Robust standard errors clustered at the student level are in parenthesis for Panel A and C. Robust standard errors are reported for Panel B. Since enrollment data only covers 2005-2010, we include applicants from 2004-2007 for "Start Grade 11 on-time." For "Start Grade 12 on-time," we include applicants from 2004-2006. If a student is not matched with the credits or attendance files, they are treated as having 0 credits and 0 attendance. ${ }^{*}$ significant at $10 \%$; ${ }^{* *}$ significant at $5 \% ; * * *$ significant at $1 \%$. 
Table 6. Lottery Estimates for High School Graduation and College Remediation

\begin{tabular}{|c|c|c|c|}
\hline & & $\begin{array}{c}\text { Mean for } \\
\text { Non-Offered } \\
\text { (1) }\end{array}$ & $\begin{array}{c}\text { All Small Schools } \\
(2)\end{array}$ \\
\hline & \multicolumn{3}{|c|}{ Panel A. Graduation } \\
\hline \multirow[t]{2}{*}{ Received a HS diploma } & & 0.533 & $\begin{array}{c}0.093 * * * \\
(0.031)\end{array}$ \\
\hline & $\mathrm{N}$ & 5,146 & 9,925 \\
\hline \multirow[t]{2}{*}{ Received a Local HS diploma } & & 0.148 & $\begin{array}{c}0.001 \\
(0.022)\end{array}$ \\
\hline & $\mathrm{N}$ & 5,146 & 9,925 \\
\hline \multirow[t]{2}{*}{ Received a Regents diploma } & & 0.341 & $\begin{array}{c}0.101^{* * *} \\
(0.035)\end{array}$ \\
\hline & $\mathrm{N}$ & 5,146 & 9,925 \\
\hline \multirow[t]{2}{*}{ Received an Advanced Regents Diploma } & & 0.044 & $\begin{array}{l}-0.009 \\
(0.013)\end{array}$ \\
\hline & $\mathrm{N}$ & 5,146 & 9,925 \\
\hline & & \multicolumn{2}{|c|}{ Panel B. Remediation } \\
\hline \multirow[t]{2}{*}{ Not CUNY Remedial for Math } & & 0.185 & $\begin{array}{c}0.030 \\
(0.026)\end{array}$ \\
\hline & & 4,963 & 9,597 \\
\hline \multirow[t]{2}{*}{ Not CUNY Remedial for Reading } & & 0.315 & $\begin{array}{c}0.086 * * * \\
(0.030)\end{array}$ \\
\hline & & 4,963 & 9,597 \\
\hline \multirow[t]{2}{*}{ Not CUNY Remedial for Writing } & & 0.313 & $\begin{array}{c}0.090 * * * \\
(0.031)\end{array}$ \\
\hline & & 4,963 & 9,597 \\
\hline
\end{tabular}

Notes: The table reports 2SLS estimates of small school attendance on high school graduation. The endogenous variable is an indicator for whether a student attends a small school in grade 9. The instrument is an indicator for obtaining an offer at a small school. If a student is coded as receiving both a Local HS diploma and Regents or Advanced Regents diploma, we count the student as receiving a Regents or Advanced Regents diploma. The sample is restricted to students with baseline scores and demographic characteristics. Remediation benchmarks are based on CUNY thresholds. Students who are not remedial for math either score 510 or higher on SAT Math or 75 or higher on Regents math. Students who are not remedial for reading either score 510 or higher on SAT Reading or 75 or higher on Regents English. Students who are not remedial for writing either score 510 or higher for SAT Writing or 75 or higher on Regents English. All models include risk set dummies, demographic controls, and baseline test controls. Robust standard errors clustered on 9th grade school are reported in parenthesis. *significant at $10 \%$; ${ }^{* *}$ significant at $5 \%$; $* * *$ significant at $1 \%$. 
Table 7. Lottery Estimates on College Choice,

Enrollment, and Persistence

\begin{tabular}{|c|c|c|c|}
\hline & & $\begin{array}{l}\text { Mean for Non-Offered } \\
\text { (1) }\end{array}$ & $\begin{array}{c}\text { All Small Schools } \\
(2)\end{array}$ \\
\hline & & \multicolumn{2}{|c|}{ Panel A. College Choice and Enrollment } \\
\hline \multirow[t]{3}{*}{ Ever attend college } & & 0.365 & $0.071 * *$ \\
\hline & & & $(0.028)$ \\
\hline & $\mathrm{N}$ & 4,633 & 8,573 \\
\hline \multirow[t]{3}{*}{ Attend within four years } & & 0.283 & $0.069 * * *$ \\
\hline & & & $(0.026)$ \\
\hline & $\mathrm{N}$ & 4,633 & 8,573 \\
\hline \multirow[t]{3}{*}{ Attend within six years } & & 0.379 & $0.064 * *$ \\
\hline & & & $(0.032)$ \\
\hline & $\mathrm{N}$ & 3,740 & 7,095 \\
\hline \multirow[t]{3}{*}{ Ever attend a 2 year college } & & 0.196 & 0.036 \\
\hline & & & $(0.028)$ \\
\hline & $\mathrm{N}$ & 4,633 & 8,573 \\
\hline \multirow[t]{3}{*}{ Ever attend a 4 year college } & & 0.205 & $0.060 * * *$ \\
\hline & & & $(0.020)$ \\
\hline & $\mathrm{N}$ & 4,633 & 8,573 \\
\hline \multirow[t]{3}{*}{ Ever attend a 4-year public college } & & 0.135 & $0.066 * * *$ \\
\hline & & & $(0.021)$ \\
\hline & $\mathrm{N}$ & 4,633 & 8,573 \\
\hline \multirow[t]{3}{*}{ Ever attend a 4-year private college } & & 0.087 & 0.007 \\
\hline & & & $(0.019)$ \\
\hline & $\mathrm{N}$ & 4,633 & 8,573 \\
\hline \multirow[t]{3}{*}{ Ever attend CUNY } & & 0.247 & $0.070 * *$ \\
\hline & & & $(0.028)$ \\
\hline & $\mathrm{N}$ & 4,633 & 8,573 \\
\hline & & \multicolumn{2}{|c|}{ Panel B. College Persistence } \\
\hline \multirow[t]{3}{*}{ At least 2 academic semesters attempted } & & 0.243 & $0.049 *$ \\
\hline & & & $(0.025)$ \\
\hline & $\mathrm{N}$ & 4,633 & 8,573 \\
\hline \multirow[t]{3}{*}{ At least 4 academic semesters attempted } & & 0.157 & 0.035 \\
\hline & & & $(0.023)$ \\
\hline & $\mathrm{N}$ & 3,740 & 7,095 \\
\hline
\end{tabular}

Notes: This table reports 2SLS estimates of small school attendance on measures of credits per year and attendance, where the endogenous variable is attend small school in 9th grade and instrument is an indicator for offer. We drop applicants in the 2003-04 cohort because we have few observations in the NSC file for this cohort. We code "attend college" as 1 if students could be matched with the NSC file and their college name and enrollment dates are not missing. An academic semester is enrollment between January and May or enrollment between August and December. The attend within six years and persistence results for 4 academic semesters are only for application cohorts from 2004-05, 2005-06, and 2006-07. Robust standard errors clustered on 9 th grade school are reported in parenthesis. *significant at $10 \%$; ${ }^{*}$ significant at $5 \%$; $* * *$ significant at $1 \%$. 


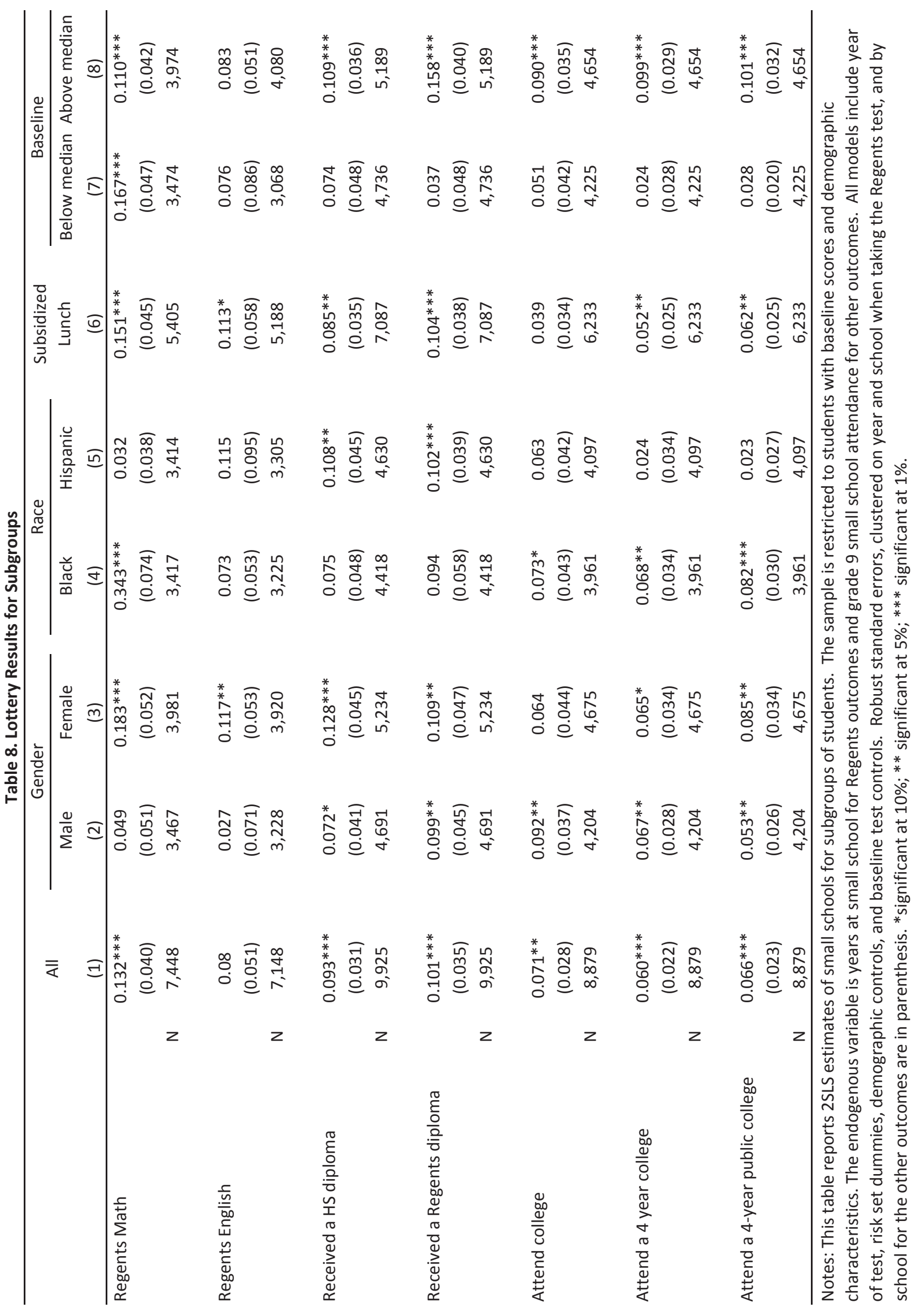




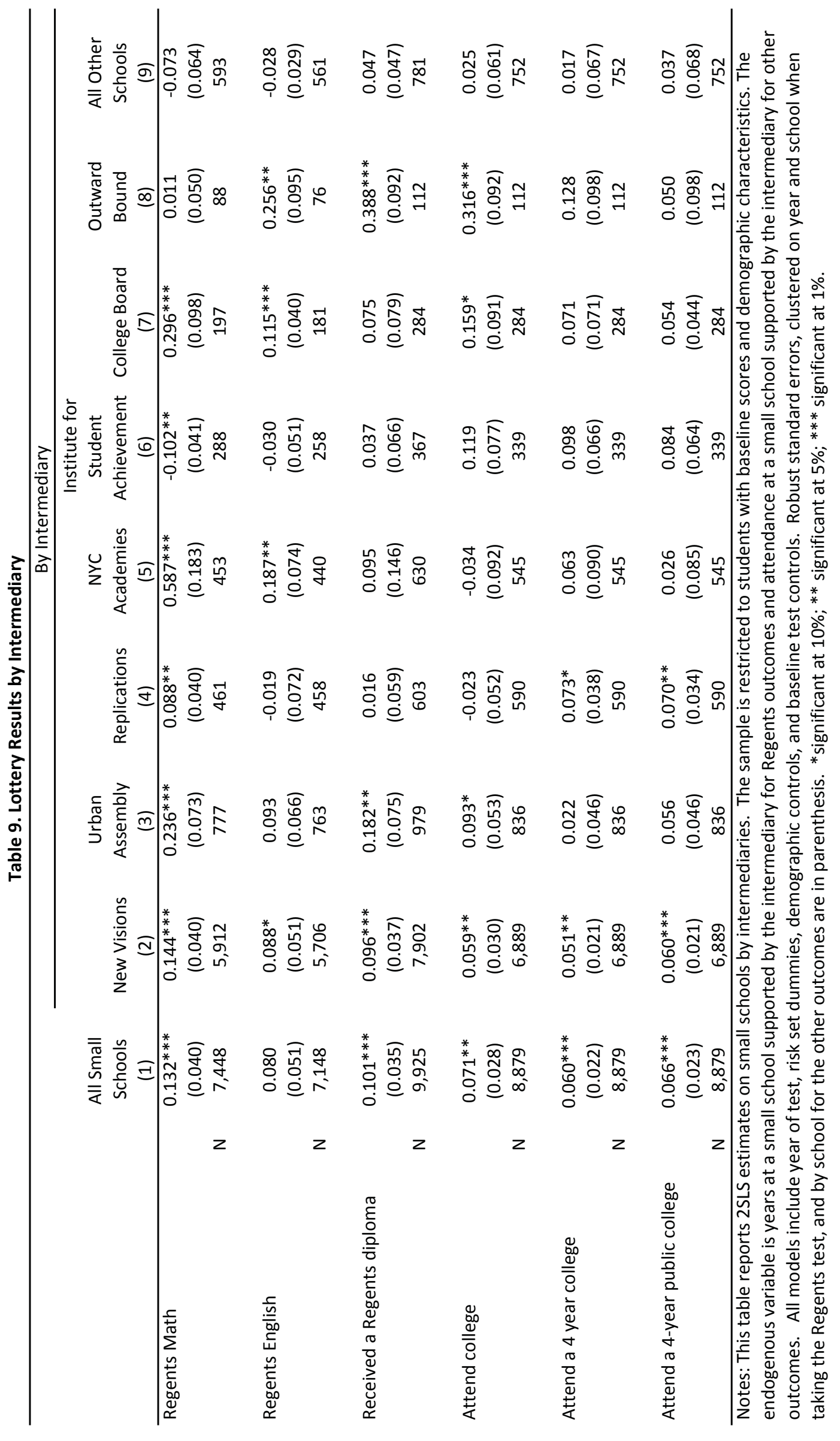




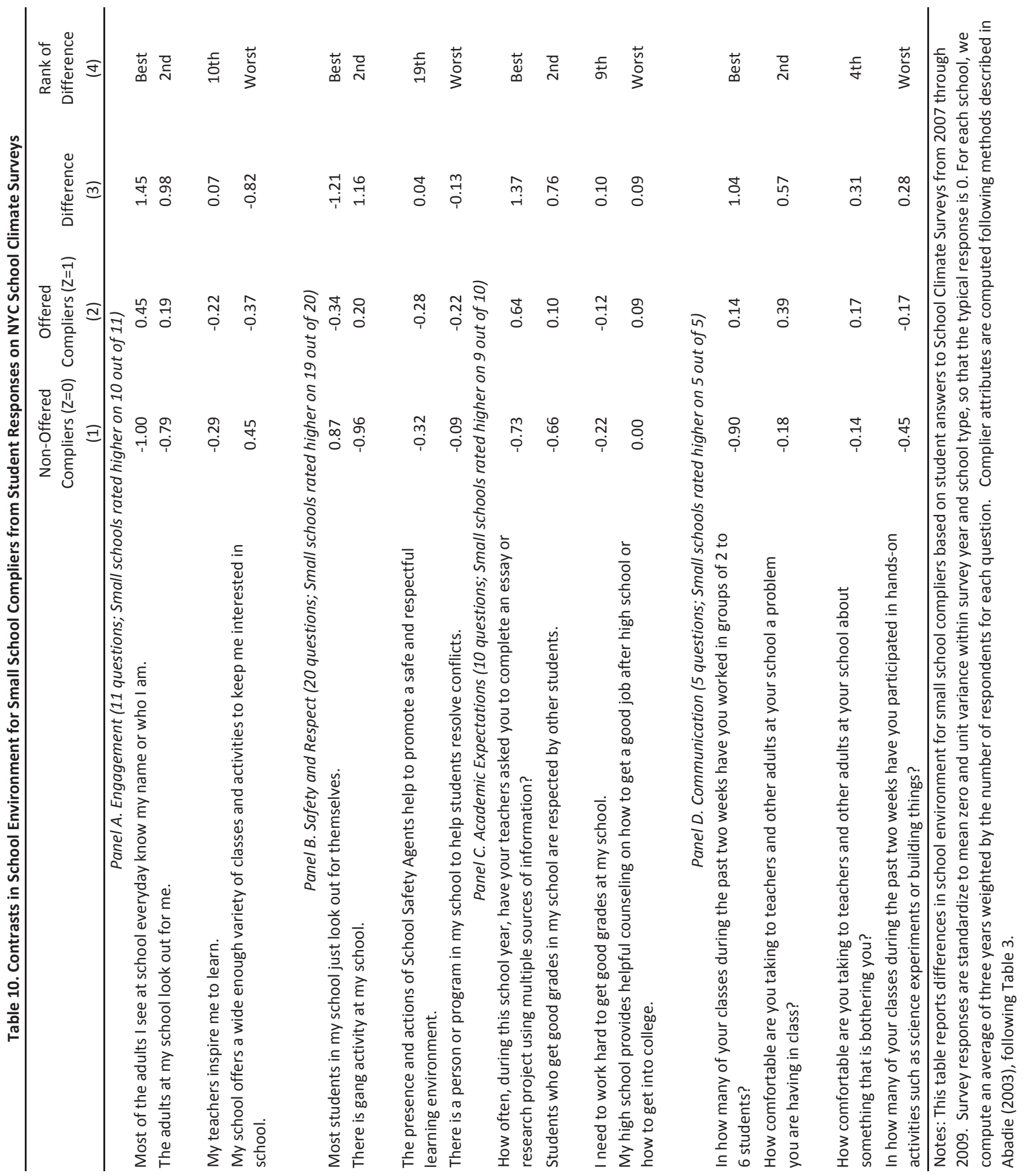




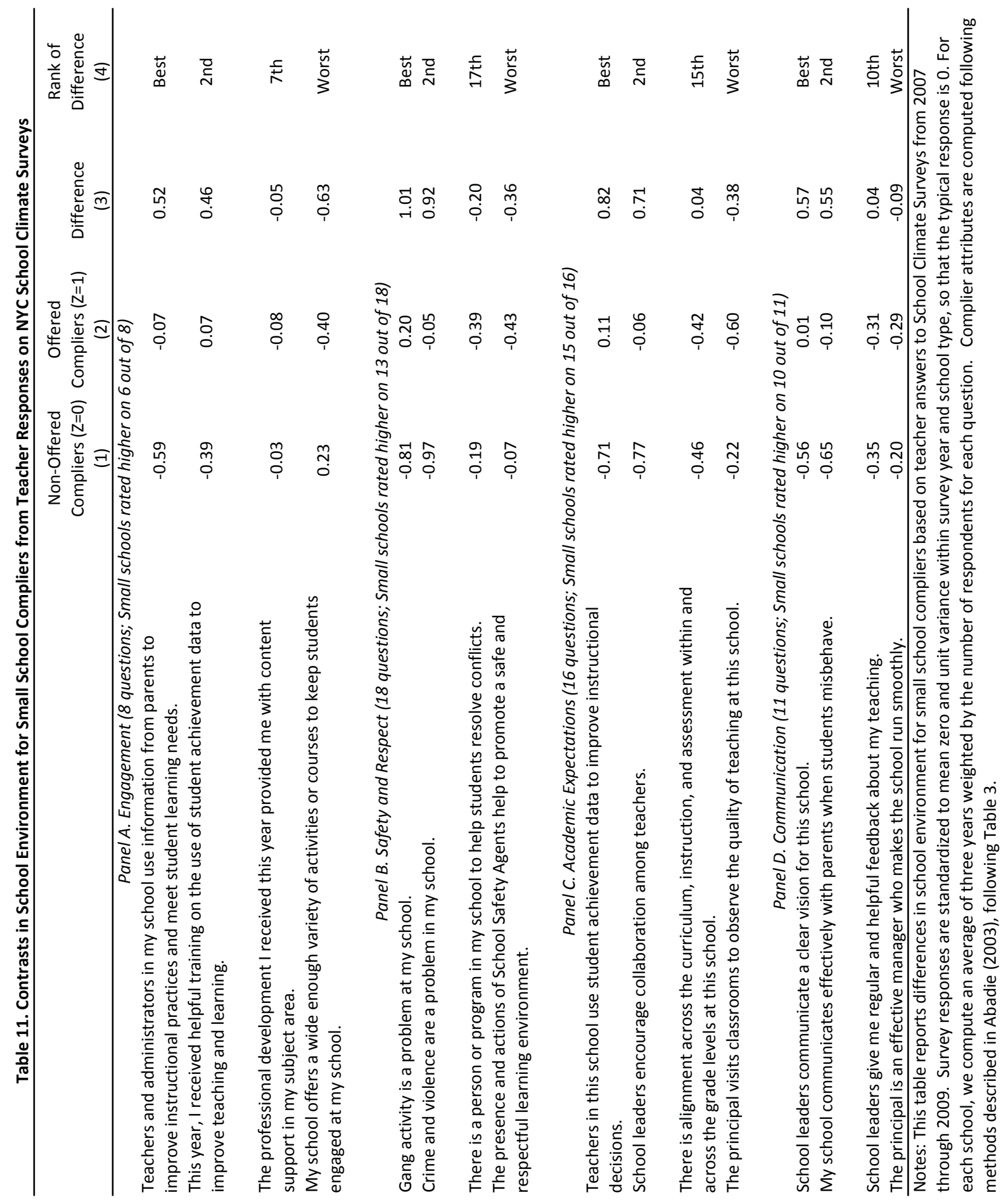


Table 12. 2SLS Estimates of School Size

$$
\text { Endogenous Variable }
$$

School Size in Grade 9 (100s) School Size in Grades 9-12 (100s)

(1)

\begin{tabular}{|c|c|c|c|}
\hline \multirow{3}{*}{ Regents Math } & \multicolumn{3}{|c|}{ Panel A. 2SLS } \\
\hline & & $-0.024 * * *$ & $-0.009 * * *$ \\
\hline & & $(0.007)$ & $(0.003)$ \\
\hline \multirow{4}{*}{ Regents English } & $\mathrm{N}$ & 7,197 & 7,197 \\
\hline & & $-0.023 *$ & $-0.009 *$ \\
\hline & & $(0.013)$ & $(0.005)$ \\
\hline & $\mathrm{N}$ & 6,962 & 6,962 \\
\hline \multirow[t]{3}{*}{ HS Graduation } & & $-0.011^{* *}$ & $-0.004 * * *$ \\
\hline & & $(0.004)$ & $(0.002)$ \\
\hline & $\mathrm{N}$ & 9,416 & 9,416 \\
\hline \multirow[t]{3}{*}{ College Attendance } & & $-0.010 * *$ & $-0.004 * *$ \\
\hline & & $(0.005)$ & $(0.002)$ \\
\hline & $\mathrm{N}$ & 8,410 & 8,410 \\
\hline & & \multicolumn{2}{|c|}{ Panel B. First Stage Estimates } \\
\hline \multirow[t]{3}{*}{ Small School Offer } & & $-2.693 * * *$ & $-7.007 * * *$ \\
\hline & & $(0.369)$ & (0.939) \\
\hline & $\mathbf{N}$ & 7,197 & 7,197 \\
\hline
\end{tabular}

Notes: This table reports two-stage least squares (2SLS) estimates of the effects of school size on Regents test scores, graduation and college attendance. The first-stage in Panel B is for the Regents Math outcome and includes demographics and baseline scores. The unreported other first-stages are similar. The sample includes students with demographics and baseline scores and the application cohorts vary for each outcome following the appropriate outcome table. Robust standard errors, clustered on year and school when taking the Regents test, and by school for the other outcomes are in parenthesis.

${ }^{*}$ significant at $10 \% ;{ }^{* *}$ significant at $5 \% ;{ }^{* * *}$ significant at $1 \%$. 


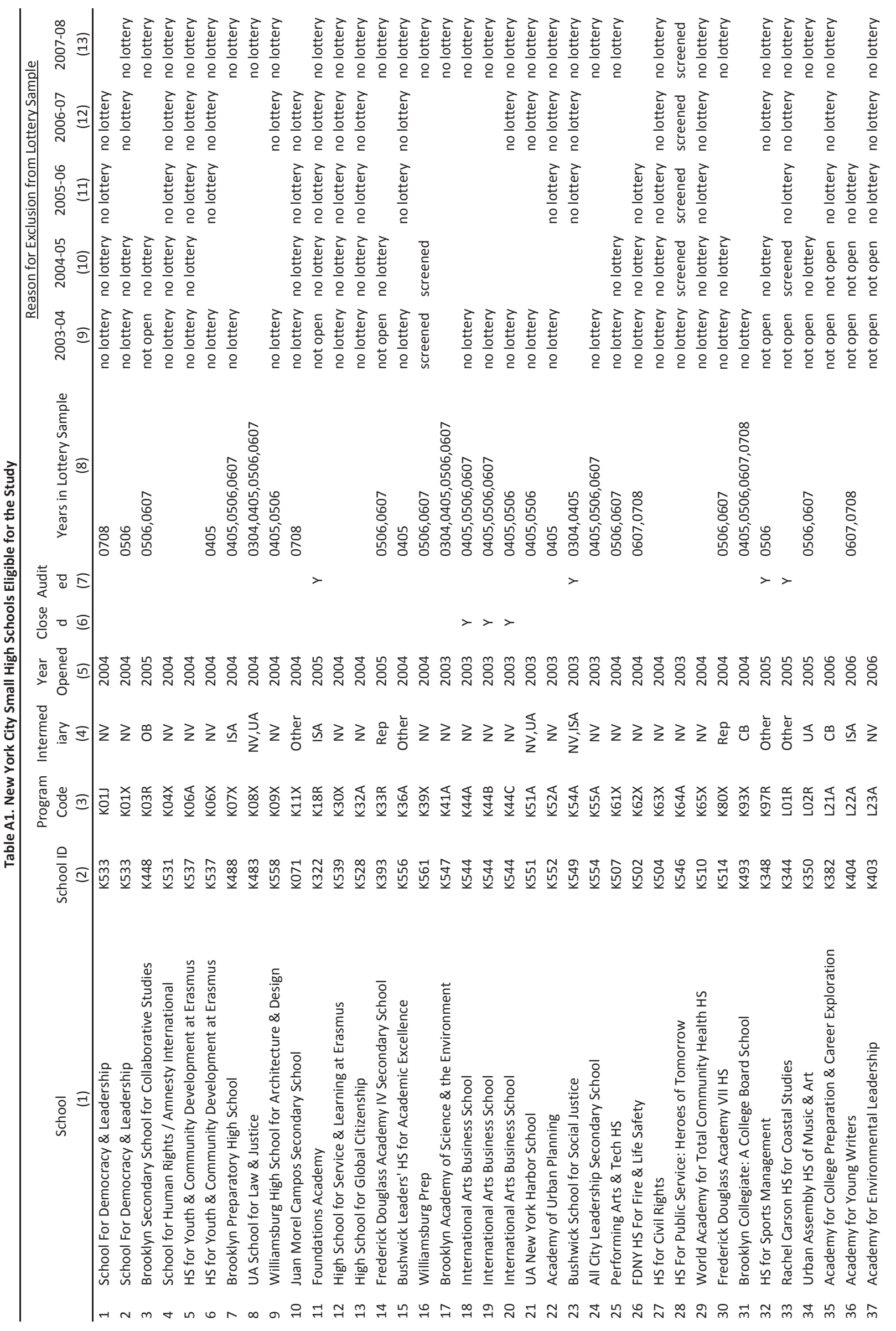




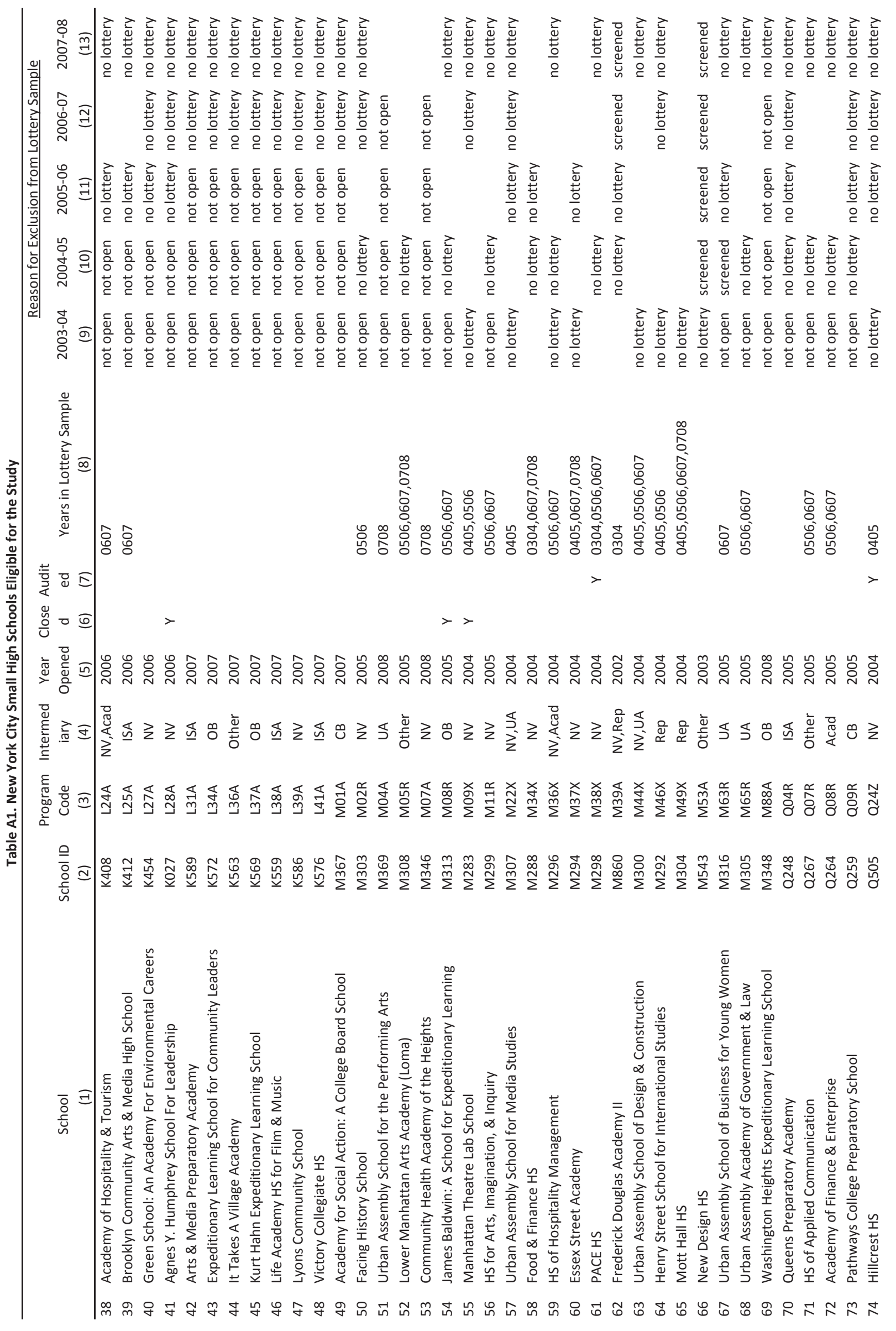




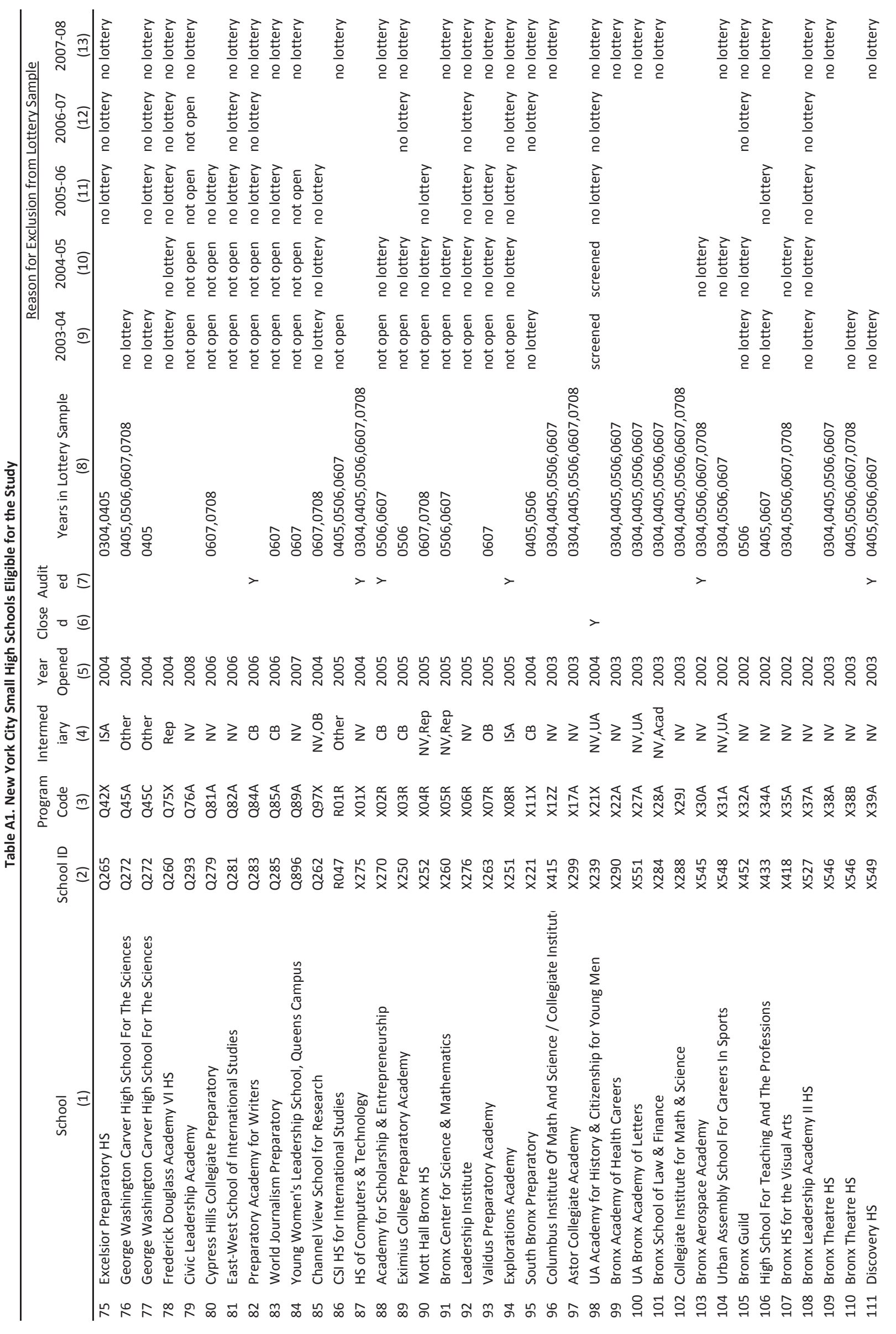




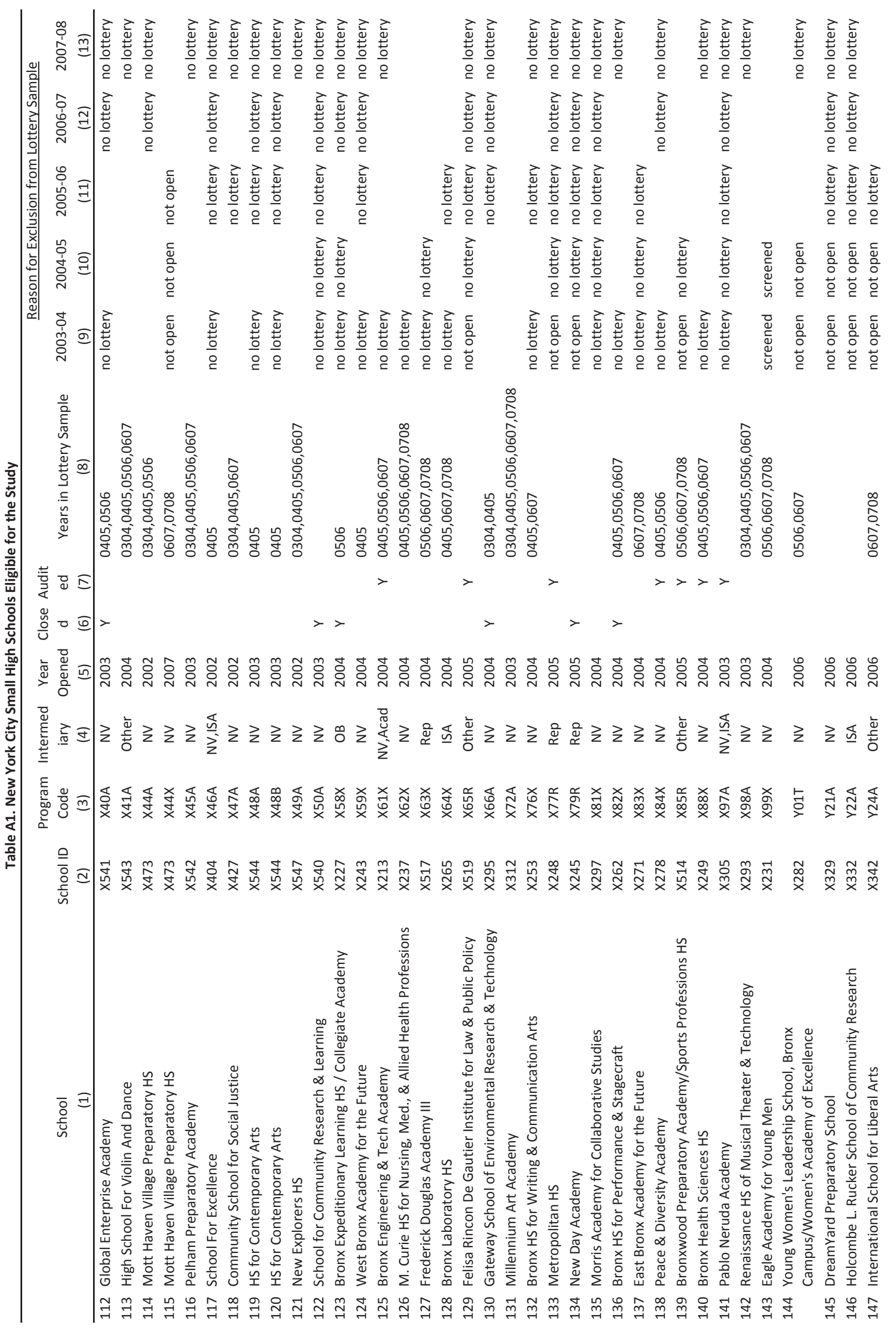




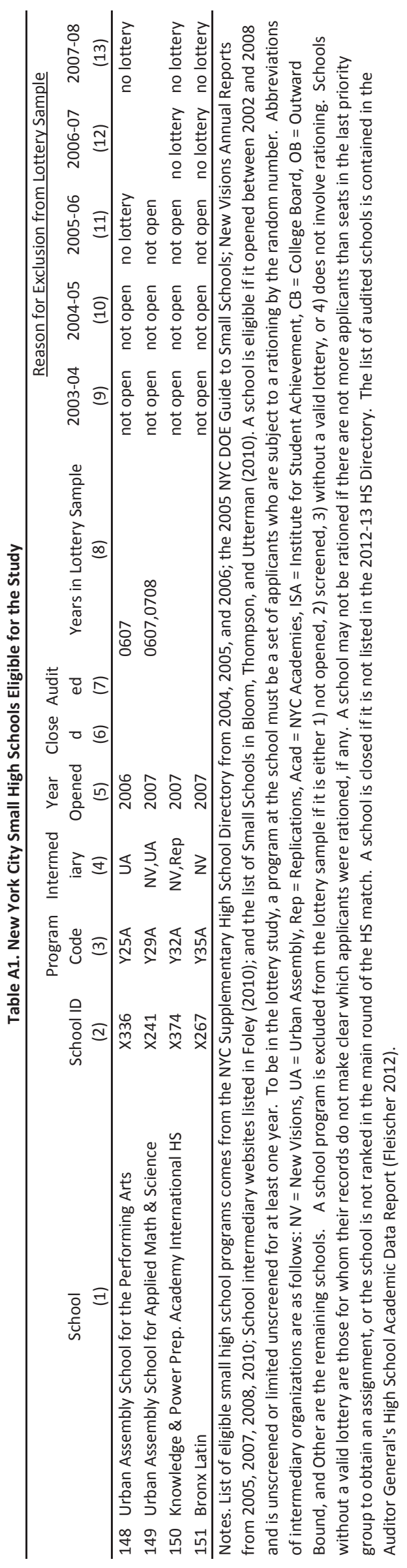




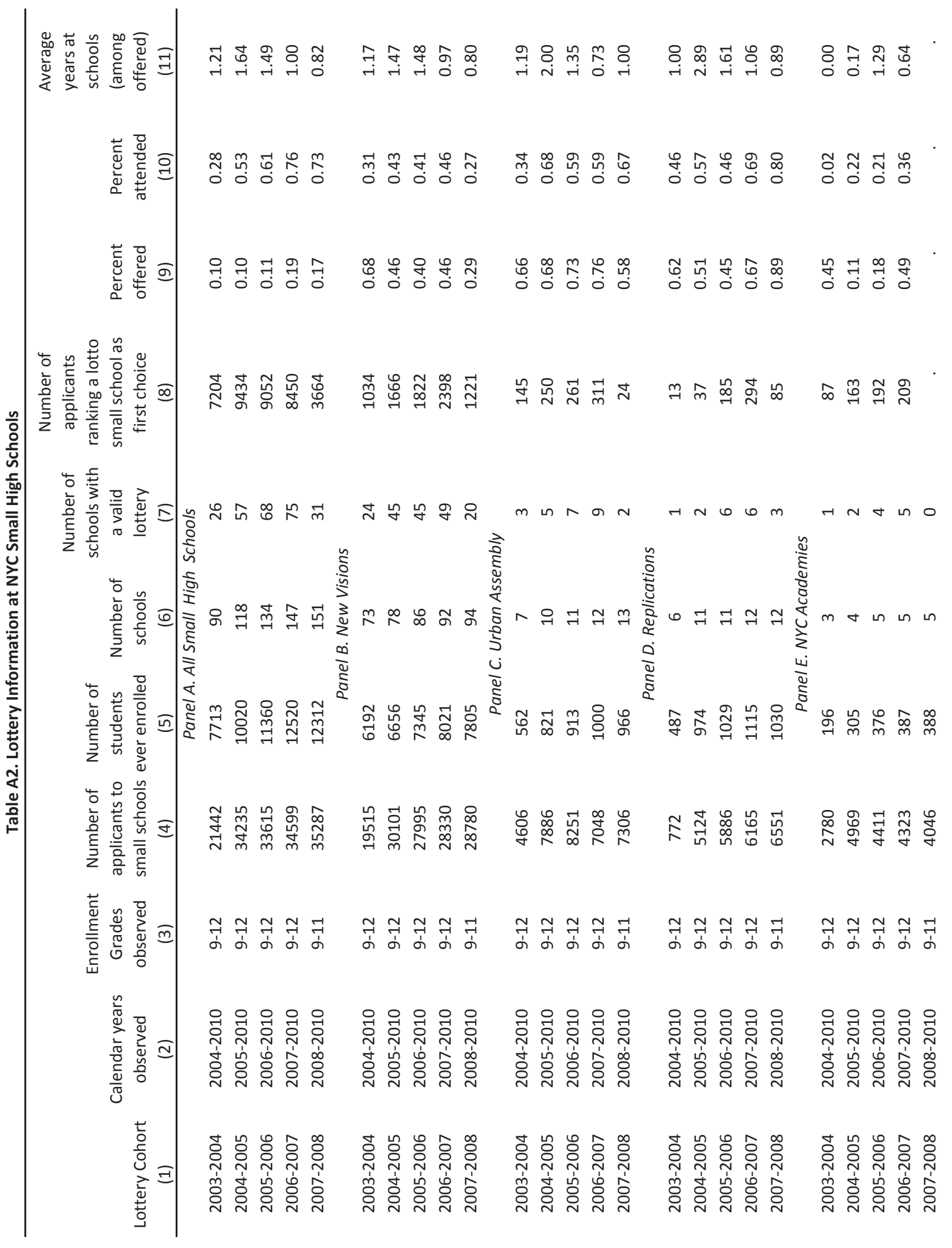




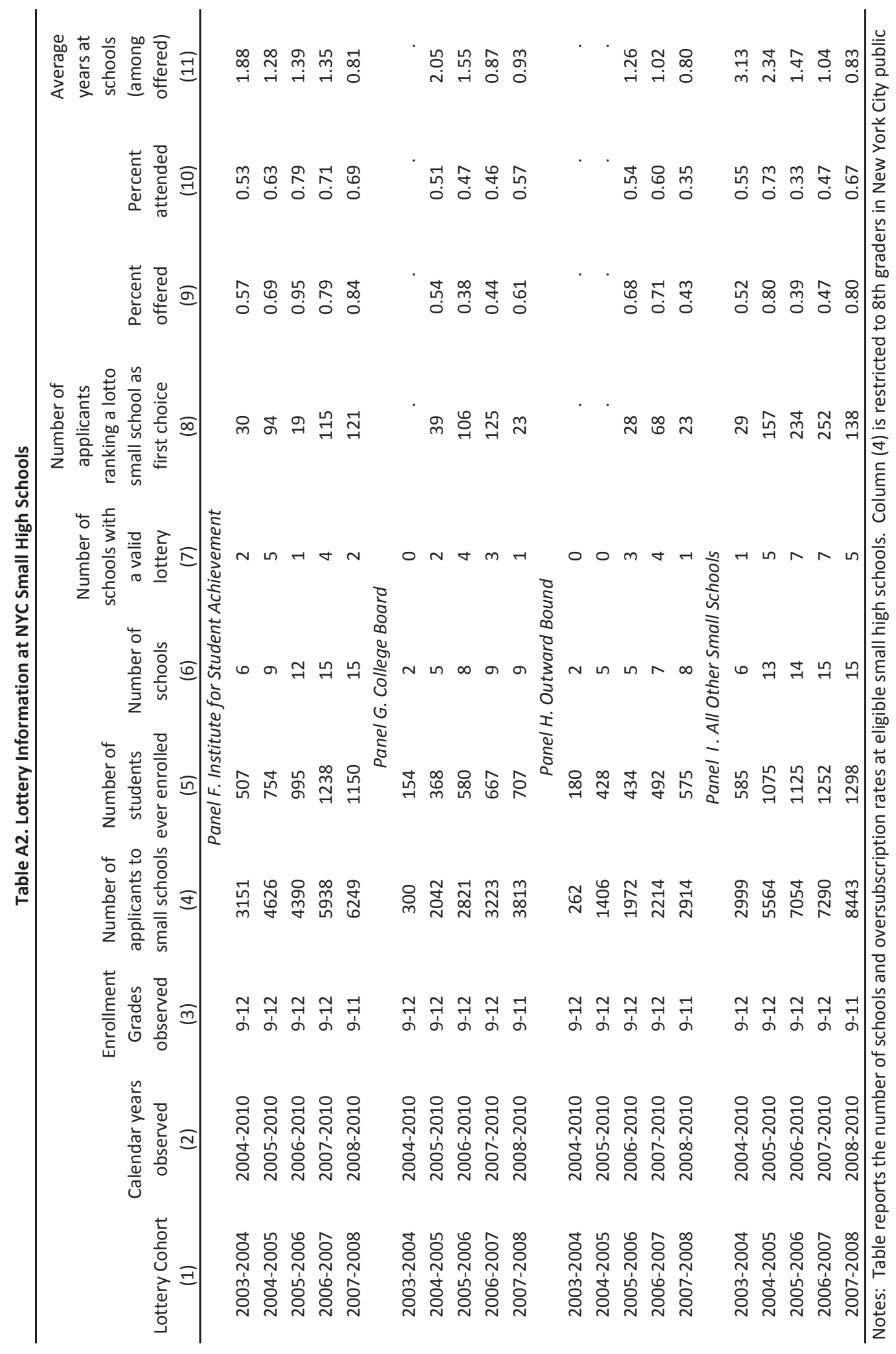


Table A3. Attrition

\begin{tabular}{|c|c|c|c|c|}
\hline \multirow{3}{*}{ Regents Subject } & & \multirow[b]{2}{*}{$\begin{array}{l}\text { Eraction of Non- } \\
\text { Offered with } \\
\text { Regents }\end{array}$} & \multicolumn{2}{|c|}{ Attrition Differentials } \\
\hline & & & Demographics & $\begin{array}{l}\text { Demographics+ } \\
\text { Baseline Scores }\end{array}$ \\
\hline & & (1) & (2) & (3) \\
\hline \multirow[t]{3}{*}{ Math } & & 0.717 & 0.016 & 0.016 \\
\hline & & & $(0.011)$ & $(0.011)$ \\
\hline & $\mathrm{N}$ & 3,809 & 10,204 & 10,058 \\
\hline \multirow[t]{3}{*}{ English } & & 0.684 & $0.023 * *$ & $0.025 * *$ \\
\hline & & & $(0.011)$ & $(0.011)$ \\
\hline & $\mathrm{N}$ & 3,634 & 10,204 & 10,037 \\
\hline \multirow[t]{3}{*}{ Living Environment } & & 0.655 & $0.044 * * *$ & $0.046 * * *$ \\
\hline & & & $(0.011)$ & $(0.011)$ \\
\hline & $\mathrm{N}$ & 3,482 & 10,204 & 10,058 \\
\hline \multirow[t]{3}{*}{ Global History } & & 0.672 & $0.027 * *$ & $0.029 * *$ \\
\hline & & & $(0.011)$ & $(0.011)$ \\
\hline & $\mathrm{N}$ & 3,569 & 10,204 & 10,037 \\
\hline \multirow[t]{2}{*}{ US History } & & 0.616 & $\begin{array}{c}0.044^{* * *} \\
(0.012)\end{array}$ & $\begin{array}{c}0.046 * * * \\
(0.012)\end{array}$ \\
\hline & $\mathrm{N}$ & 3,275 & 10,204 & 10,037 \\
\hline
\end{tabular}

Notes: Table reports coefficients from regressions of an indicator variable equal to 1 if the outcome test score is non-missing on offer. Models for columns (2) and (3) include risk-set controls and demographic variables. In column (3), we add baseline test scores as controls. The sample includes lottery participants for whom we expect to observe follow-up scores. Robust standard errors in parenthesis. ${ }^{*}$ significant at $10 \%$; ${ }^{* *}$ significant at $5 \%$; ${ }^{* * *}$ significant at $1 \%$ 


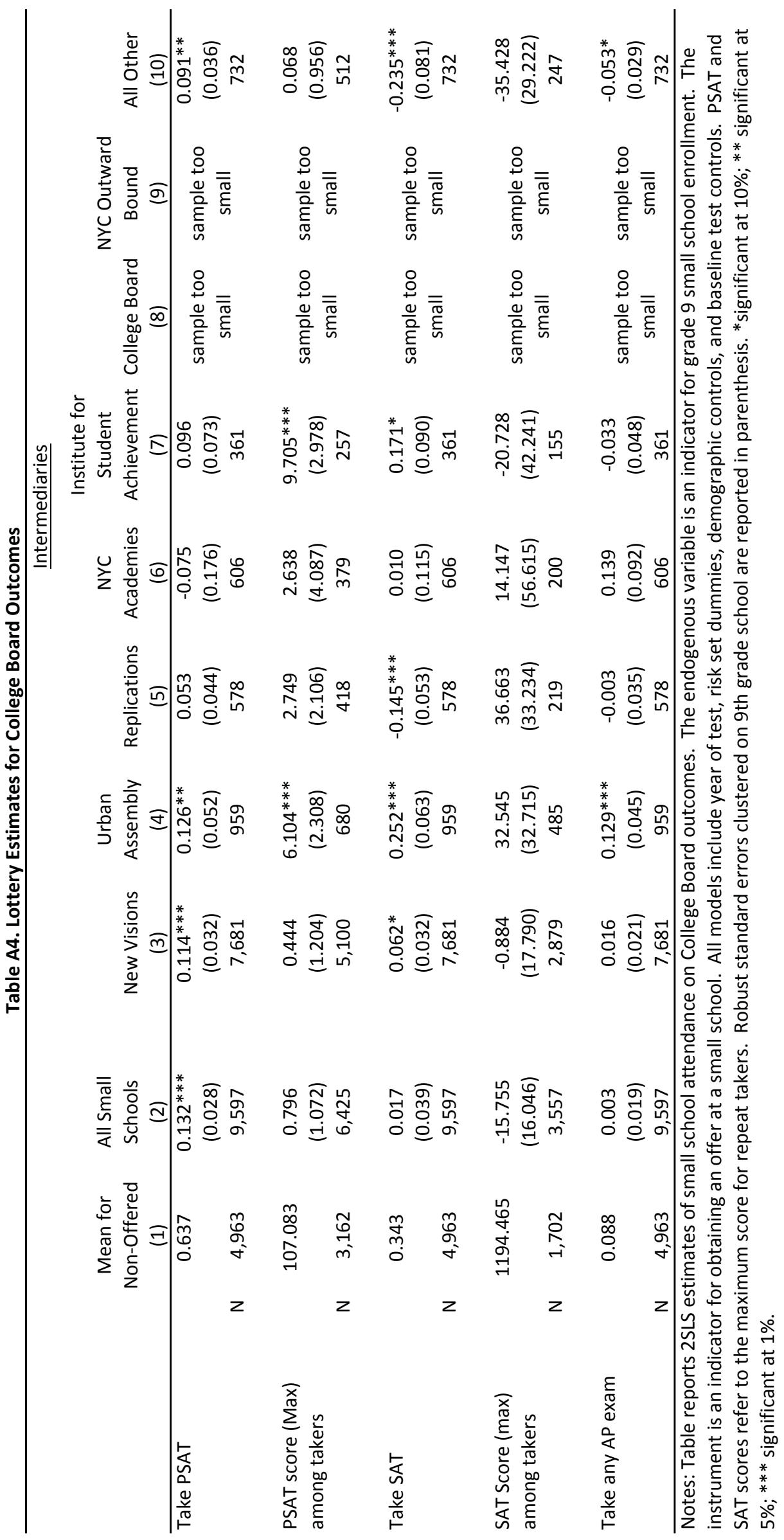




\begin{tabular}{|c|c|c|c|c|c|c|c|c|}
\hline & \multicolumn{8}{|c|}{ Compliers at Intermediaries } \\
\hline & \multicolumn{2}{|c|}{ New Visions } & \multicolumn{2}{|c|}{$\underline{\text { Urban Assembly }}$} & \multicolumn{2}{|c|}{$\underline{\text { Replications }}$} & \multicolumn{2}{|c|}{$\underline{\text { NYC Academies }}$} \\
\hline & $\begin{array}{l}\text { Not-Offered } \\
(Z=0) \\
(1)\end{array}$ & $\begin{array}{l}\text { Offered }(Z=1) \\
\text { (2) }\end{array}$ & $\begin{array}{l}\text { Not-Offered } \\
(Z=0) \\
(3)\end{array}$ & $\begin{array}{c}\text { Offered }(Z=1) \\
\text { (4) }\end{array}$ & $\begin{array}{l}\text { Not-Offered } \\
(\mathrm{Z}=0) \\
(5)\end{array}$ & $\begin{array}{c}\text { Offered }(Z=1) \\
(6)\end{array}$ & $\begin{array}{l}\text { Not-Offered } \\
(\mathrm{Z}=0) \\
(7)\end{array}$ & $\begin{array}{c}\text { Offered }(Z=1) \\
\text { (8) }\end{array}$ \\
\hline & \multicolumn{8}{|c|}{ Panel A. Enrollment Decisions } \\
\hline Enrolled at small schools & 0.17 & 1.00 & 0.46 & 1.00 & 0.37 & 1.00 & 0.51 & 1.00 \\
\hline Enrolled in Manhattan & 0.24 & 0.19 & 0.19 & 0.16 & 0.28 & 0.22 & 0.25 & 0.27 \\
\hline Enrolled in Bronx & 0.51 & 0.59 & 0.32 & 0.34 & 0.56 & 0.60 & 0.45 & 0.37 \\
\hline Enrolled in Brooklyn & 0.17 & 0.18 & 0.45 & 0.50 & 0.19 & 0.18 & 0.03 & 0.00 \\
\hline Enrolled in Queens & 0.07 & 0.05 & 0.05 & 0.00 & 0.00 & 0.00 & 0.34 & 0.35 \\
\hline \multirow[t]{2}{*}{ Enrolled in Staten Island } & 0.01 & 0.00 & 0.00 & 0.00 & 0.00 & 0.00 & 0.00 & 0.00 \\
\hline & \multicolumn{8}{|c|}{ Panel B. Average Per-Pupil Expenditure } \\
\hline Direct Services to School & 14,491 & 13,801 & 14,026 & 13,723 & 14,439 & 12,909 & 16,391 & 14,495 \\
\hline Classroom Funds & 7,938 & 7,520 & 7,702 & 7,305 & 7,814 & 7,242 & 8,419 & 7,522 \\
\hline Teachers & 6,410 & 6,073 & 6,286 & 5,833 & 6,369 & 5,628 & 6,664 & 6,132 \\
\hline Instructional Support Services & 2,252 & 2,046 & 2,070 & 2,119 & 2,120 & 1,822 & 3,071 & 1,501 \\
\hline Leadership / Supervision / Support & 1,994 & 1,963 & 2,095 & 1,926 & 2,083 & 1,732 & 2,049 & 2,062 \\
\hline Ancillary Support & 838 & 901 & 746 & 874 & 845 & 890 & 970 & 843 \\
\hline \multirow[t]{2}{*}{ Building Services } & 1,386 & 1,285 & 1,326 & 1,390 & 1,487 & 1,137 & 1,784 & 2,500 \\
\hline & \multicolumn{8}{|c|}{ Panel C. School, Teacher, and Staff Characteristics } \\
\hline Number of Grade 9 Students & 790 & 173 & 517 & 106 & 481 & 131 & 883 & 135 \\
\hline Number of Grade 9-12 Students & 1,955 & 484 & 1,335 & 314 & 1,311 & 314 & 2,157 & 315 \\
\hline Average English Class Size & 26 & 25 & 25 & 24 & 27 & 28 & 24 & 24 \\
\hline Average Math Class Size & 25 & 24 & 25 & 23 & 27 & 27 & 25 & 24 \\
\hline Total Number of Core Classes Taught & 388 & 109 & 273 & 66 & 262 & 79 & 384 & 77 \\
\hline Total Number of Teachers & 117 & 34 & 82 & 24 & 82 & 26 & 128 & 24 \\
\hline $\begin{array}{l}\text { Percent of Teachers with Fewer than Three Years of } \\
\text { Teaching Experience }\end{array}$ & 18 & 30 & 18 & 36 & 26 & 45 & 15 & 32 \\
\hline $\begin{array}{l}\text { Percent of Teachers with Master's Degree plus } 30 \\
\text { Hours or Doctorate }\end{array}$ & 39 & 29 & 39 & 23 & 36 & 21 & 45 & 28 \\
\hline $\begin{array}{l}\text { Percent of Teachers with No Valid Teaching } \\
\text { Certificate }\end{array}$ & 16 & 15 & 13 & 21 & 18 & 19 & 18 & 14 \\
\hline Teacher Turnover Rate & 21 & 28 & 21 & 25 & 24 & 31 & 29 & 31 \\
\hline Number of Full-time Assistant Principals & 5 & 1 & 4 & 1 & 3 & 0 & 6 & 1 \\
\hline \multirow[t]{2}{*}{ Number of Full-time Non-Teaching Staff } & 11 & 3 & 8 & 1 & 7 & 2 & 13 & 1 \\
\hline & \multicolumn{8}{|c|}{ Panel D. Peer Characteristics } \\
\hline Baseline Peer Mean in Math & -0.33 & -0.13 & -0.31 & -0.03 & -0.21 & 0.11 & -0.42 & -0.06 \\
\hline Baseline Peer Mean in English & -0.33 & -0.10 & -0.31 & -0.02 & -0.20 & 0.15 & -0.49 & -0.13 \\
\hline Proportion Black or Hispanic & 0.91 & 0.91 & 0.93 & 0.96 & 0.94 & 0.95 & 0.89 & 0.85 \\
\hline Proportion Subsidized Lunch & 0.69 & 0.72 & 0.74 & 0.79 & 0.74 & 0.75 & 0.65 & 0.67 \\
\hline Proportion Female & 0.44 & 0.46 & 0.44 & 0.43 & 0.50 & 0.52 & 0.41 & 0.48 \\
\hline Proportion Special Education & 0.11 & 0.09 & 0.09 & 0.06 & 0.08 & 0.06 & 0.14 & 0.06 \\
\hline Proportion Limited English Proficient & 0.15 & 0.08 & 0.12 & 0.07 & 0.12 & 0.06 & 0.21 & 0.13 \\
\hline \multicolumn{9}{|c|}{$\begin{array}{l}\text { Notes: This table shows descriptive statistics for students not enrolled at small schools, small school enrollment compliers not offered admissions (Z=0), and } \\
\text { enrollment compliers offered admissions (Z=1). Complier attributes are computed following methods described in Abadie (2003). Baseline peer means are from 8th } \\
\text { grade New York State Math and English and Language Arts tests for Spring 2002-2007. Teacher turnover rate is the number of teachers in that school year who were } \\
\text { not teaching in the following school year divided by the number of teachers in the specified school year, expressed as a percentage. Non-teaching staff are staff other } \\
\text { than teachers, principals, and assistant principals including administrators, guidance counselors, school nurses, psychologists, and other professionals who devote } \\
\text { more than have of their time to non-teaching duties. Direct Services to Schools include Classroom Instruction, Instructional Support Services, } \\
\text { Leadership/Supervision/Support, Ancillary Support Services, and Building Services. Classroom Funds include Teachers, Educational Paraprofessionals, Other Classroom } \\
\text { Staff, Text Books, Libraries \& Library Books, Instructional Supplies \& Equipment, Professional Development, Contracted Instructional Services, and Summer \& Evening } \\
\text { School. Instructional Support Services include Counseling, Attendance \& Outreach Services, Related Services, Drug Prevention Programs, Referral \& Evaluation } \\
\text { Services, After School \& Student Activities, Parent Involvement. Leadership/Supervision/Support includes Principals, Assistant Principals, Supervisors, Secretaries, } \\
\text { School Aids \& Other Support Staff, Supplies, Materials, Equipment and Telephone. Ancillary Support Services include Food Services, Transportation, School Safety, and } \\
\text { Computer System Support. Building Services include Custodial Services, Building Maintenance, Leases, and Energy. School, teacher, and staff characteristics are from } \\
\text { New York State Report Cards for the years 2006-09 available at http://reportcards.nysed.gov/index.php. Class size data is from the NYC DOE website for the years } \\
\text { 2007-2009 available at http://schools.nyc.gov/AboutUs/data/classsize/classsize.htm. Expenditure data is from the NYC DOE website for the years 2006-2009 available } \\
\text { at http://schools.nyc.gov/Offices/DBOR/SBER/OLD_YEARS.htm. }\end{array}$} \\
\hline
\end{tabular}


Table A5.b NYC Enrollment Decisions, School Characteristics, and Peers Characteristics for Compliers by Intermediary

Compliers at Intermediaries

\begin{tabular}{|c|c|c|c|c|c|c|c|c|}
\hline & \multicolumn{8}{|c|}{ Compliers at Intermediaries } \\
\hline & \multicolumn{2}{|c|}{$\frac{\text { Institute for Student }}{\text { Achievement }}$} & \multicolumn{2}{|c|}{ College Board } & \multicolumn{2}{|c|}{ Outward Bound } & \multicolumn{2}{|c|}{ All Others } \\
\hline & $\begin{array}{l}\text { Not-Offered } \\
(Z=0) \\
(1)\end{array}$ & $\begin{array}{l}\text { Offered }(\mathrm{Z}=1) \\
\text { (2) }\end{array}$ & $\begin{array}{l}\text { Not-Offered } \\
\qquad(\mathrm{Z}=0) \\
(3)\end{array}$ & $\begin{array}{l}\text { Offered }(\mathrm{Z}=1) \\
\text { (4) }\end{array}$ & $\begin{array}{l}\text { Not-Offered } \\
\qquad(\mathrm{Z}=0) \\
(5)\end{array}$ & $\begin{array}{c}\text { Offered }(Z=1) \\
\text { (6) }\end{array}$ & $\begin{array}{l}\text { Not-Offered } \\
\quad(Z=0) \\
(7)\end{array}$ & $\begin{array}{c}\text { Offered }(Z=1) \\
\text { (8) }\end{array}$ \\
\hline & \multicolumn{8}{|c|}{ Panel A. Enrollment Decisions } \\
\hline Enrolled at small schools & 0.38 & 1.00 & 0.35 & 1.00 & 0.34 & 1.00 & 0.21 & 1.00 \\
\hline Enrolled in Manhattan & 0.09 & 0.00 & 0.08 & 0.00 & 0.03 & 0.08 & 0.08 & 0.03 \\
\hline Enrolled in Bronx & 0.21 & 0.24 & 0.38 & 0.39 & 0.37 & 0.28 & 0.35 & 0.39 \\
\hline Enrolled in Brooklyn & 0.60 & 0.72 & 0.34 & 0.39 & 0.42 & 0.34 & 0.02 & 0.01 \\
\hline Enrolled in Queens & 0.08 & 0.05 & 0.20 & 0.22 & 0.30 & 0.29 & 0.10 & 0.10 \\
\hline \multirow[t]{2}{*}{ Enrolled in Staten Island } & 0.00 & 0.00 & 0.00 & 0.00 & 0.01 & 0.00 & 0.43 & 0.47 \\
\hline & \multicolumn{8}{|c|}{ Panel B. Average Per-Pupil Expenditure } \\
\hline Direct Services to School & 13,744 & 14,126 & 15,126 & 14,766 & 15,263 & 14,659 & 13,473 & 13,805 \\
\hline Classroom Funds & 7,593 & 7,689 & 8,348 & 7,746 & 8,521 & 8,103 & 7,406 & 7,401 \\
\hline Teachers & 6,084 & 6,016 & 6,781 & 6,410 & 6,803 & 6,659 & 6,117 & 6,206 \\
\hline Instructional Support Services & 2,023 & 2,115 & 2,210 & 2,135 & 2,182 & 2,117 & 2,155 & 1,958 \\
\hline Leadership / Supervision / Support & 1,874 & 2,121 & 2,123 & 2,027 & 2,019 & 1,796 & 1,776 & 2,080 \\
\hline Ancillary Support & 811 & 848 & 879 & 1,104 & 966 & 1,030 & 970 & 913 \\
\hline \multirow[t]{2}{*}{ Building Services } & 1,363 & 1,261 & 1,482 & 1,659 & 1,493 & 1,530 & 1,085 & 1,380 \\
\hline & \multicolumn{8}{|c|}{ Panel C. School, Teacher, and Staff Characteristics } \\
\hline Number of Grade 9 Students & 383 & 129 & 510 & 106 & 469 & 108 & 700 & 116 \\
\hline Number of Grade 9-12 Students & 1,161 & 334 & 1,454 & 251 & 1,243 & 274 & 2,153 & 281 \\
\hline Average English Class Size & 26 & 22 & 29 & 29 & 28 & 27 & 28 & 25 \\
\hline Average Math Class Size & 26 & 24 & 29 & 29 & 28 & 26 & 27 & 24 \\
\hline Total Number of Core Classes Taught & 248 & 92 & 299 & 90 & 253 & 123 & 443 & 87 \\
\hline Total Number of Teachers & 69 & 27 & 87 & 33 & 84 & 42 & 123 & 22 \\
\hline $\begin{array}{l}\text { Percent of Teachers with Fewer than Three Years of } \\
\text { Teaching Experience }\end{array}$ & 24 & 25 & 25 & 33 & 22 & 32 & 18 & 34 \\
\hline $\begin{array}{l}\text { Percent of Teachers with Master's Degree plus } 30 \text { Hours or } \\
\text { Doctorate }\end{array}$ & 33 & 19 & 38 & 25 & 38 & 24 & 44 & 30 \\
\hline Percent of Teachers with No Valid Teaching Certificate & 16 & 16 & 17 & 15 & 17 & 14 & 14 & 18 \\
\hline Teacher Turnover Rate & 22 & 26 & 24 & 35 & 22 & 19 & 15 & 23 \\
\hline Number of Full-time Assistant Principals & 3 & 1 & 4 & 1 & 3 & 1 & 5 & 1 \\
\hline \multirow[t]{2}{*}{ Number of Full-time Non-Teaching Staff } & 6 & 2 & 7 & 3 & 8 & 3 & 10 & 1 \\
\hline & \multicolumn{8}{|c|}{ Panel D. Peer Characteristics } \\
\hline Baseline Peer Mean in Math & -0.32 & -0.35 & -0.20 & -0.16 & -0.30 & -0.16 & -0.17 & -0.07 \\
\hline Baseline Peer Mean in English & -0.29 & -0.24 & -0.21 & -0.05 & -0.24 & -0.04 & -0.12 & -0.01 \\
\hline Proportion Black or Hispanic & 0.93 & 0.97 & 0.86 & 0.86 & 0.97 & 0.89 & 0.68 & 0.62 \\
\hline Proportion Subsidized Lunch & 0.75 & 0.80 & 0.72 & 0.71 & 0.76 & 0.80 & 0.66 & 0.68 \\
\hline Proportion Female & 0.51 & 0.56 & 0.51 & 0.54 & 0.55 & 0.56 & 0.50 & 0.56 \\
\hline Proportion Special Education & 0.10 & 0.06 & 0.09 & 0.07 & 0.08 & 0.07 & 0.10 & 0.06 \\
\hline Proportion Limited English Proficient & 0.11 & 0.10 & 0.11 & 0.05 & 0.08 & 0.08 & 0.10 & 0.08 \\
\hline
\end{tabular}

Notes: This table shows descriptive statistics for students not enrolled at small schools, small school enrollment compliers not offered admissions ( $\mathrm{Z}=0$ ), and enrollment compliers offered admissions ( $Z=1$ ). Complier attributes are computed following methods described in Abadie (2003). Baseline peer means are from 8th grade New York State Math and English and Language Arts tests for Spring 2002-2007. Teacher turnover rate is the number of teachers in that school year who were not teaching in the following school year divided by the number of teachers in the specified school year, expressed as a percentage. Non-teaching staff are staff other than teachers, principals, and assistant principals including administrators, guidance counselors, school nurses, psychologists, and other professionals who devote more than have of their time to nonteaching duties. Direct Services to Schools include Classroom Instruction, Instructional Support Services, Leadership/Supervision/Support, Ancillary Support Services, and Building Services. Classroom Funds include Teachers, Educational Paraprofessionals, Other Classroom Staff, Text Books, Libraries \& Library Books, Instructional Supplies \& Equipment, Professional Development, Contracted Instructional Services, and Summer \& Evening School. Instructional Support Services include Counseling, Attendance \& Outreach Services, Related Services, Drug Prevention Programs, Referral \& Evaluation Services, After School \& Student Activities, Parent Involvement.

Leadership/Supervision/Support includes Principals, Assistant Principals, Supervisors, Secretaries, School Aids \& Other Support Staff, Supplies, Materials, Equipment and Telephone. Ancillary Support Services include Food Services, Transportation, School Safety, and Computer System Support. Building Services include Custodial Services, Building Maintenance, Leases, and Energy. School, teacher, and staff characteristics are from New York State Report Cards for the years 2006-09 available at http://reportcards.nysed.gov/index.php. Class size data is from the NYC DOE website for the years 2007-2009 available at

http://schools.nyc.gov/AboutUs/data/classsize/classsize.htm. Expenditure data is from the NYC DOE website for the years 2006-2009 available at

http://schools.nyc.gov/Offices/DBOR/SBER/OLD_YEARS.htm. 
Table A6. Lottery Results by School Subsamples

\begin{tabular}{|c|c|c|c|c|c|c|}
\hline & & \multirow{3}{*}{$\begin{array}{l}\text { All Small } \\
\text { Schools } \\
(1)\end{array}$} & \multicolumn{2}{|c|}{ Year school opened } & \multirow{3}{*}{$\begin{array}{c}\text { Excluding } \\
\text { closed schools } \\
\text { (4) }\end{array}$} & \multirow{3}{*}{$\begin{array}{c}\text { Excluding } \\
\text { audited } \\
\text { schools } \\
\text { (5) }\end{array}$} \\
\hline & & & $2002-2005$ & $2006-2008$ & & \\
\hline & & & $(2)$ & (3) & & \\
\hline \multirow[t]{3}{*}{ Regents Math } & & $0.132 * * *$ & $0.108 * * *$ & $0.282^{* *}$ & $0.135^{* * *}$ & $0.114 * * *$ \\
\hline & & $(0.040)$ & $(0.040)$ & $(0.112)$ & $(0.036)$ & $(0.042)$ \\
\hline & $\mathrm{N}$ & 7,448 & 7,024 & 424 & 7,110 & 6,541 \\
\hline \multirow[t]{3}{*}{ Regents English } & & 0.080 & 0.073 & $0.081^{* * *}$ & $0.087^{*}$ & 0.049 \\
\hline & & $(0.051)$ & $(0.051)$ & $(0.017)$ & $(0.048)$ & $(0.045)$ \\
\hline & $\mathrm{N}$ & 7,148 & 6,761 & 387 & 6,830 & 6,304 \\
\hline \multirow[t]{3}{*}{ Total Credits } & & $1.369 * * *$ & $1.266^{* * *}$ & $1.037^{* *}$ & $1.486^{* * *}$ & $1.218^{* * *}$ \\
\hline & & $(0.212)$ & $(0.208)$ & $(0.496)$ & $(0.204)$ & $(0.213)$ \\
\hline & $\mathrm{N}$ & 34,884 & 33022 & 1,862 & 33,228 & 30,400 \\
\hline \multirow[t]{3}{*}{ Received a HS diploma } & & $0.093 * * *$ & $0.081 * * *$ & $0.137^{* *}$ & $0.099 * * *$ & $0.100 * * *$ \\
\hline & & $(0.031)$ & $(0.029)$ & $(0.068)$ & $(0.030)$ & $(0.032)$ \\
\hline & N & 9,925 & 9,344 & 581 & 9,472 & 8,711 \\
\hline \multirow[t]{3}{*}{ Received a Regents diploma } & & $0.101 * * *$ & $0.095 * * *$ & 0.064 & $0.107^{* * *}$ & $0.120 * * *$ \\
\hline & & $(0.035)$ & $(0.033)$ & $(0.073)$ & $(0.033)$ & $(0.033)$ \\
\hline & $\mathrm{N}$ & 9,925 & 9,344 & 581 & 9,472 & 8,711 \\
\hline \multirow[t]{3}{*}{ Attend college } & & $0.071 * *$ & $0.058^{* *}$ & $0.135^{*}$ & $0.076 * * *$ & $0.066^{* *}$ \\
\hline & & $(0.028)$ & $(0.027)$ & $(0.071)$ & $(0.027)$ & $(0.029)$ \\
\hline & $N$ & 8,879 & 8,298 & 581 & 8,447 & 7,788 \\
\hline \multirow[t]{3}{*}{ Attend a 4 year college } & & $0.060 * * *$ & $0.049 * *$ & $0.106^{*}$ & $0.063 * * *$ & $0.055^{* *}$ \\
\hline & & $(0.022)$ & $(0.021)$ & $(0.061)$ & $(0.022)$ & $(0.023)$ \\
\hline & N & 8,879 & 8,298 & 581 & 8,447 & 7,788 \\
\hline \multirow[t]{3}{*}{ Attend a 4-year public college } & & $0.066^{* * *}$ & $0.059 * * *$ & 0.077 & $0.074 * * *$ & $0.056 * *$ \\
\hline & & $(0.023)$ & $(0.022)$ & $(0.048)$ & $(0.022)$ & $(0.024)$ \\
\hline & $\mathrm{N}$ & 8,879 & 8,298 & 581 & 8,447 & 7,788 \\
\hline
\end{tabular}

Notes: This table reports 2SLS estimates for different sets of small schools. The endogenous variable is years at small school for Regents outcomes and grade 9 small school attendance for other outcomes. The sample is restricted to students with baseline scores and demographic characteristics. All models include year of test, risk set dummies, demographic controls, and baseline test controls. Robust standard errors, clustered on year and school when taking the Regents test, and by school for the other outcomes are in parenthesis. The standard error of English in Column (3) is clustered on the year of test. The last row reports 2SLS estimates on effects of enrollment at any small schools in grade 9. Robust standard errors clustered at the student level are reported. ${ }^{*}$ significant at $10 \%$; ${ }^{* *}$ significant at $5 \%$; $* *$ significant at $1 \%$. 


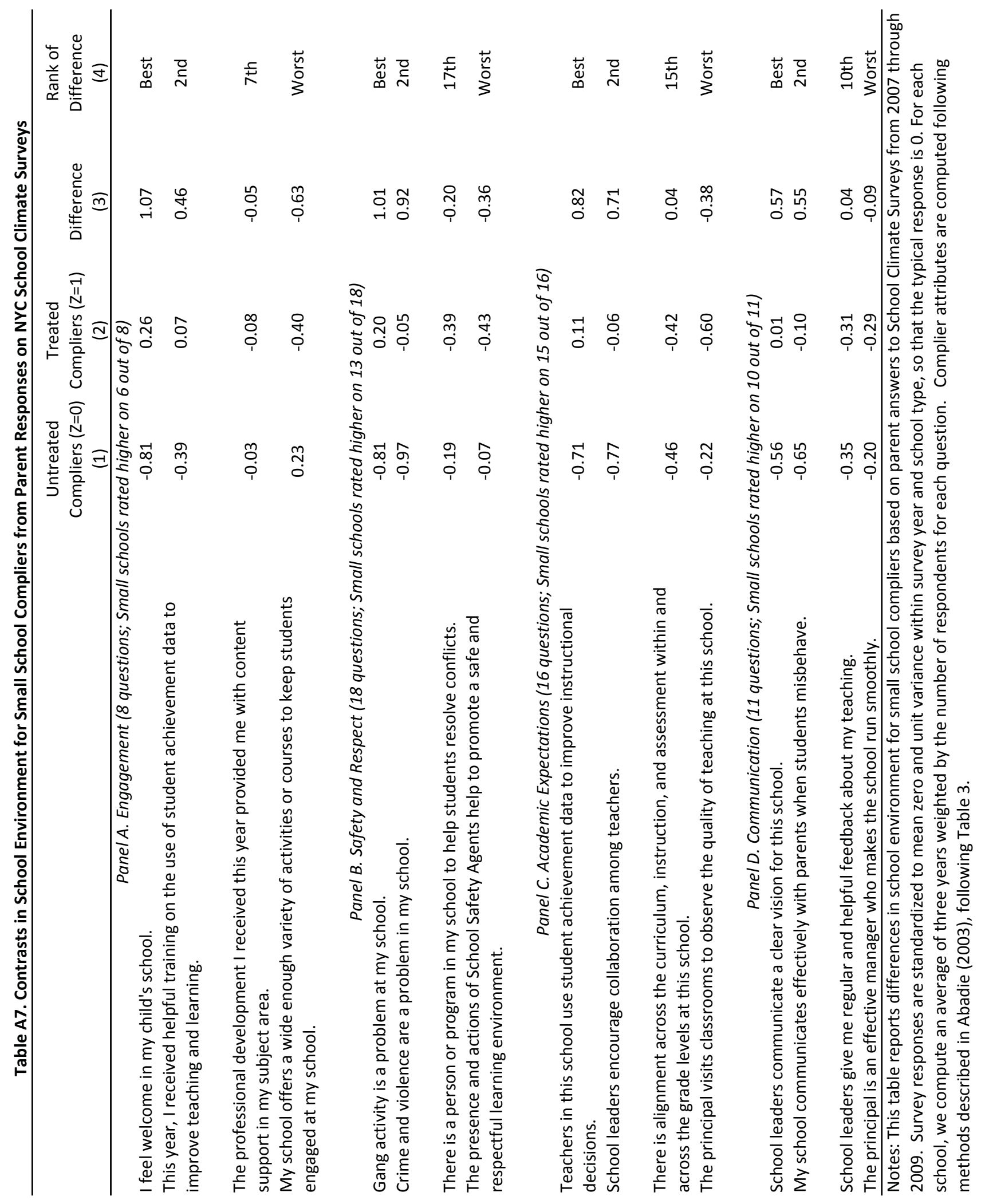




\section{A Data Appendix}

\section{A.1 Constructing List of Small High Schools \\ Data Sources for School Sample}

There is no comprehensive list of new small high schools created during school years 2002-03 and 2007-08. We assembled a master list of small schools from the following sources:

\section{1) NYC Department of Education Publications}

- Directory of NYC Public High Schools 2002-2003

This directory indicates on the top of each page whether a school is new. 44 school programs are listed as new in the directory, three of them are exam schools. The remaining 41 school are in the master list.

- Supplementary Directory of NYC Public High Schools, 2004, 2005, 2006

These directories were distributed to participants in the High School (HS) Match to provide information on new small schools, which were not included in the HS Directory. 50 schools are listed in the 2004 directory, 30 schools are listed in the 2005 directory, and 18 schools are listed in the 2006 directory. These 98 schools are in the master list.

\section{2) New Visions Publications}

- 2005-06 Guide to NYC Small High Schools

In 2005, the New Visions for the Public Schools published a separate guide to NYC small high schools listing 220 small schools. 115 of these schools are not in the 20022003 directory or Supplementary Directories, and are therefore added to the master list.

- Annual Reports from New Visions for Public Schools, 2005, 2007, 2008, 2010

The appendix of the Annual Reports of the New Visions for Public Schools includes a list of small schools supported by New Visions. We collected all annual reports available online, covering years 2005, 2007, 2008 and 2010. 109 schools are in the 2005 report, but each is already in the master list. 120 schools are in the 2007 report, 4 of which are not yet in the master list. 98 schools are in the 2008 report, 43 of which are not yet in the master list. 98 schools are in the 2010 report, 8 of which are not yet in the master list. 
- The Fund for Teachers list of New Visions-Affiliated New York City Public Schools

The Fund for Teachers, a group supporting teacher training, assembled a list of 194 New Visions affiliated New York City Public Schools. 10 of these schools are not yet in the master list.

\section{3) Other Outside Reports}

- New Century High Schools and the Small Schools Movement in New York City Interim Report

There are 81 schools in this report, all of which are already in the master list.

- Approaches of Bill \&5 Melinda Gates Foundation-Funded Intermediary Organizations to Structuring and Supporting Small High Schools in New York City (Foley et al., 2010)

We visit each intermediary organization's website to collect the list of schools they support. We visited websites of the following organizations: Asia Society, Big Picture Learning, City University of New York (CUNY), Coalition of Essential Schools, College Board, Diploma Plus, Good Shepherd Services, Institute for Student Achievement, Internationals Network for Public Schools, Johns Hopkins University (JHU), National Academy Foundation, National Council of La Raza (NCLR), New Visions for Public Schools, New York City Outward Bound Center, Replications, The Urban Assembly, Woodrow Wilson National Fellowship Foundation (WWNFF), and Young Women's Leadership Network. The Early College High School Initiative lists CUNY, NCLR and WWNFF schools at their website. We identify a total of 324 schools from these 18 Intermediary websites, 147 of which are not yet in the master list. Many of these additional schools admit students at 6th grade, are screened, or are created after 2008 and therefore will be ineligible. Diploma Plus and Good Shepherd Services are primarily involved in transfer schools serving over-age students with difficulty in fulfilling graduation requirements, so these schools are excluded from the sample. Johns Hopkins Talent Development High Schools operate schools which are not necessarily small high schools and therefore excluded.

- Transforming the High School Experience: How New York City's New Small Schools Are Boosting Student Achievement and Graduation Rates? (Bloom et al., 2010)

There are a total of 109 schools in this report, 1 of which is not yet in the master list. 


\section{Eligible Unscreened Small Schools}

There can be multiple school programs at a school, and applicants rank programs in the HS match. The HS match files (further described below) include the correspondence between program code and school building code (DBN code). If a program code is not linked to a school building code, we look up the building code in subsequent year's high school directories.

Combining the list of schools identified above, there are a total of 466 school programs. To be an eligible small school, we impose two additional restrictions. First, we require that a school is created in or after 2002 and is created before or in 2008. New programs in the 2002-03 Directory of the NYC Public High Schools are founded in 2002. We identify the opening years for the other remaining programs by using the opening year listed in the 2005-06 Guide to NYC Small High Schools, if available. If the opening year of a program cannot be identified from these sources, we define the opening year based on the enrollment and ranking year as follows: First, we exclude programs at schools that have students enrolled in grade 12 in 2004, inferring that the school was open before 2002. Second, we include any school for which the first year a program at their school is listed as a choice is a year between 2004-05 through 2007-08.

Next, we eliminate any small schools that screen applicants. Schools with Audition, Educational Option, Screened, and Test admissions types are excluded, while Unscreened, Limited Unscreened, or Zoned schools are included.

Table A1 lists 151 programs in 143 schools that form our eligible small school program sample.

\section{A.2 Data Sources for Student Applications, Outcomes, and School Surveys}

The New York City Department of Education is the source for four datasets: 1) high school match and student enrollment office files containing student rankings, eligibility and priorities for each school as well as demographic information on applicants at the time of application, 2) registration and enrollment files which contains school attendance information from the Office of School Performance and Accountability, 3) outcome files for baseline tests, Regents tests, graduation, credits, attendance, College Board (PSAT, SAT, and AP) assessments, and National Student Clearinghouse college information and 4) School Climate Surveys. We describe these data sets in turn and provide details on the procedures used to construct the analysis sample.

\section{High School Match and Student files}

The High School Application Processing System (HSAPS) is maintained by the Student Enrollment Office (formerly the Office of Student Enrollment and Planning Operations, OSEPO), which oversees the high school admissions process. The Student Enrollment office provided us 
access to files used in the HS match for five school years 2003-04 through 2007-08, for initial placement of students into high school in school years 2004-05 through 2008-09.

All students interested in attending a New York City high school participate by submitting a rank order list of up to 12 schools. The high school match files contain students' choice schools in preference order, the priority that a student obtains at each school, and the high school assignments at the end of the main round of the match (the main round follows the assignment of Specialized High Schools).

In addition to the match files, the student file has demographic information such as gender, race, home language code, and borough of residence for each student. These files also include a student's LEP and SPED status for application years 2003-04 through 2006-07. LEP and SPED status for 2007-08 are provided in enrollment files (see below). Each file for a given application year contains a unique student ID number, which allows us to merge the files together.

\section{Registration and Enrollment files}

The registration file is from the Office of School Performance and Accountability and is available as part of data underlying school progress reports. The registration and enrollment cover all public school students in grades 9 to 12 for school years 2002-2003 through 2009-2010.

This data set includes each student's ID, grade, and current school as of October in the school year. The registration data are used to determine whether and for how many years a student enrolls in a small school, where a student who is enrolled in October is counted as enrolling for the entire year. Starting in 2004-05, there is a separate file which contains a list of all students who obtain a subsidized school lunch in that year. This variable is used to code subsidized lunch status for applicants using the application year. For applicants in 2003-04, 2004-05, and 2005-06, we used the lunch status record from 2004-05. For application cohort in 2006-07, we used the lunch status record from 2005-06. For application cohort in 2007-08, we used the lunch status record from 2006-07. Table B1 indicates the steps involved in processing the high school application file and merging it with the Student Enrollment files.

From the file of high school applicants, we eliminated 9th grade applicants (since the main entry point is the 8th grade), private school applicants (based on whether their ID starts with the letter "A") and those who do not submit a New York City Public School Admissions Application (based on the Main Round HS ranking file). These correspond to columns 2-4 in Table B1. Further sample restrictions to identify the applicants subject to lotteries are described below. 


\section{Identifying Admissions Lotteries}

Table B1 describes additional steps involved towards identifying admissions lotteries from the high school application file. In the first few years of the high school match, the enrollment office had discretion on the placement of limited English proficient and special education students, so we exclude them from the lottery sample. We also exclude students who are rated top $2 \%$ performers in a standardized English Language Arts exam since they are guaranteed a seat if their first choice is an Educational Option school.

The next step is to eliminate students who do not rank a small school program as their first choice. A student's priority at a program is determined by two variables: priority_group and hs_rank. priority_group is an integer that is determined by factors such as students' borough of residence. hs_rank is an integer entered by schools, which may be determined by eligibility, whether the student visited school open house, etc. Programs that screen students also enter their ranking of students via hs_rank. A finer hs_rank indicates that the program is screening applicants. Therefore, if the maximum hs_rank is greater than 10 for a program in a given year, the program is likely screening applicants and is not part of the lotteried set.

A program may give precedence to either the priority_group variable or the hs_rank variable in determining a student's final priority. For example, consider a school that gives precedence to priority_group. A student has higher (i.e. better) priority if he has a lower priority_group number. Among two students who have the same priority_group number, the one with the lower hs_rank has higher priority. We identify the "lotteried priority" at a school as the priority_grouphs_rank cell where some students who rank the school first are offered a seat, and others are not. We only include lotteried priority (given by priority_group-hs_rank cells) where 1) some of the students in the priority_group-hs_rank cell are not assigned the school, 2) no student with priority_group-hs_rank cell higher than the lotteried priority at the school is assigned a lower school in her choice list, and 3) no student in a priority_group-hs_rank lower than the lotteried priority at the school receives an offer from the program.

Among students within the lotteried priority, a student's offer variable is coded as 1 if he is assigned to the school program; it is coded 0 otherwise.

\section{Outcomes: Baseline test files}

The baseline test file has 8th grade scores on New York State Education Department Math and English Language Arts for each student indexed by student ID and spans years 2003 through 2008. Each year, we standardized scores to have mean zero and standard deviation one for each test among all test takers in New York City. These serve as our baseline math and English scores. 


\section{Outcomes: Regents test file}

The NYC Regents test file contains the date and raw score for each tested student from 2004 to 2010. Regents exams are mandatory state examinations where performance determines whether a student is eligible for a Regents high school diploma in New York. There are Regents examinations in English, Global History, US History, and multiple exams in math and Science. A Regents exam typically has a multiple choice section and a long answer or essay component, and each exam usually lasts for three hours. The English exam, however, consists of two three-hour pieces over two days. The exam has a locally graded component and Dee, Jacob, McCrary, and Rockoff (2011) illustrate how test scores bunch near performance thresholds.

The New York State Board of Regents governs and designs the Regents exams. Starting in 2005, they started to modify the math exams. At the beginning of our sample, the two math exams were Elementary Algebra and Planar Geometry (Math A) and Intermediate Algebra and Trigonometry (Math B). Two new math exams, Integrated Algebra I (Math E) and Geometry (Math G), have since been phased in. Since students typically either take Math A or Math E, we focus on the score on the test taken first, taking the Math A score when both are contemporaneous. There are Regents science exams in Earth Science, Living Environment, Chemistry, and Physics. The science outcome we focus on is Living Environment because it is the most commonly taken Regents science exam. English and US History Regents exams are typically taken in 11th grade. In Table B2, for each test, we report the number of applicants and the number of test scores we observe.

Since students may take Regents exams multiple times, there can be multiple test scores per student in the Regents test file. Table B2 presents the number of students who have taken each exam more than once among small school applicant sample. The Regents file does not have the test date, and instead only has a variable indicating the term ("termcd"). Based on discussions with the DOE, we either convert term to fall, if the termcd is "1", "5", "a", or "A" and to spring if the termcd is "2", "3", "4", "6", or "7". The DOE indicated that there are exceptions at the following school DBNs where the termcd of "2" refers to the fall semester: 79M573, 79M612, 32K564, 02M560, 10X319, 02M575, 22K585, 12X480, 03M505, 02M570, 21K525, 21K540, 19K409, 17K489, 15K698, 14K454, 14K640, 07X379, 11X265, 15K529, 08X377, 05M285, 21K728, 02M303, 25Q792, 18K578, 24Q520, and 19K431. If a student takes the test more than once after 9 th grade, we used the test score from the earliest date. There are a small number of cases where there is more than one score on the same date, and this date is the first date after entering 9 th grade. In some of these cases, there are two different test codes, where one code ends with a "2." We used the score corresponding to the test that does not end with a "2." Otherwise, we treated the score as missing. 
Some students may also take Regents exams before exam school enrollment. Table B2 shows the fraction of students who take exams before enrolling in an exam school. With the exception of Math where the fraction is small, almost no students take a Regents exam before entering high school. Students who have scores before the 9 th grade are omitted for that outcome because they tested prior to potential small school enrollment.

Most Regents exams are offered in January, June, and August, with most students usually taking tests in June. The exact number of students who take the exam before 9 th grade, the number who take the exam more than once after 9th grade, and the number who take the exam on a date other than the most common test date are presented in Table B2.

For each subject, we standardized scores to have mean zero and standard deviation one within year-term-subject among all subject test takers among the cohort of applicants in the HS match for years 2003-04 to 2007-08.

\section{Outcomes: Credits}

The Credit file indicates the total number of high school credits a student earned in a given year covering years 2005-2011. We study three measures of credits: 1) total credits per year, 2) an indicator if credit requirement for promotion is met, i.e. credit is greater than or equal 10, and 3) an indicator if credit requirement for graduation is met, i.e. credit greater than or equal 11.

\section{Outcomes: Attendance}

The Attendance file contains information on student absences for each school year and term. The file covers school years from 2003-04 to 2008-09. If a student switches schools, there are multiple observations within the year for the student. We total the days of absence in these cases within the year.

\section{Outcomes: High School Graduation}

The Graduation file contains the discharge status of all public school students from 2005 to the Spring 2012. For application cohorts 2003-04, 2004-05, 2005-06, 2006-07 and 2007-08, students should start school in Fall 2004, Fall 2005, Fall 2006, Fall 2007 and Fall 2008 and graduate on-time in Spring 2008, Spring 2009, Spring 2010, Spring 2011 and Spring 2012, respectively. We do not report graduation in 5 years or 6 years.

To code graduation type, we use the following discharge codes:

a) 26, 30, and 61 (discharge codes for a local diploma)

b) 27,46 , and 60 (discharge codes for a Regents diploma) 
c) 28, 47, and 62 (discharge codes for an Advanced Regents diploma)

It is possible for students to have graduated with several different discharge files. In such cases, we take the highest ranking diploma received. For instance, if a student received both a local and Regents diploma, then we code her as obtaining a Regents diploma. Similarly, if a student is listed as receiving a Regents and an Advanced Regents diploma, we code her as receiving Advanced Regents. Consequently, there is a unique graduation outcome for each student.

\section{Outcomes: College Board (PSAT, SAT, and APs)}

The College Board provides NYC DOE with reports on the test performance of all NYC testtakers from 2006 through 2012. The match rates of our application cohorts is shown in Table B3. When there is more than one test score available for applicants, we use the maximum test score.

\section{Outcomes: National Student Clearinghouse}

The NYC Department of Education matches data on seniors to National Student Clearinghouse (NSC) files, which record information on enrollment at over 90 percent of American 4-year colleges and universities. The data were submitted by the NYC DOE for students based on graduation or GED cohorts for a 4 or 6 year cycle. The file we have is from the list of students in a graduation cohort in 2009-2012, and was submitted to the NSC in January 2013. A college is coded as a four year college if the highest degree offered by the college is 4 years, even if a student is enrolled in a 2 year program. In 2011 and 2012, parents could opt out of the National Student Clearinghouse. The DOE estimates that only roughly 100 parents opted out. Table B3 shows the number of applicants we observe with NSC outcomes.

The NYC DOE reports that the following colleges with more than 1,000 students are not in the National Student Clearinghouse. The two main colleges are Rutgers and Columbia University. Other colleges which are not in the NSC are ASA Institute of Business and Computer Technology, the United States Military Academy, Bard College, St. Thomas Aquinas College, Briar Cliffe College in Bethpage, United Talmudical Seminar, Art Institute of New York City, UTA Mesivta or Kiryas Joel, Boricua College, the American Musical and Dramatic Academy, and the Mildred Elley School.

The most common colleges attended in our lottery sample are CUNY Borough of Manhattan, CUNY Bronx Community College, CUNY New York City College of Technology, CUNY Lehman College, CUNY LaGuardia Community College, CUNY College of Staten Island, CUNY 
Kingsborough Community College, CUNY Hostos CMTY College, CUNY Queensborough Community College, and CUNY John Jay College of Criminal Justice.

\section{NYC School Climate Surveys}

In the 2006-07 school year, the NYC Department of Education initiated a Learning Environment Survey to collect information from students in grades 6-12, parents, and teachers about school practices. The survey is administered every year and the response rate for the years we use are as follows:

\begin{tabular}{c|cccc} 
& Parent & Teacher & Students & Total \\
\hline $2006-07$ & $216,914(26 \%)$ & $31,592(44 \%)$ & $338,201(65 \%)$ & $586,707(40 \%)$ \\
$2007-08$ & $347,829(40 \%)$ & $48,002(61 \%)$ & $410,708(73 \%)$ & $806,539(55 \%)$ \\
$2008-09$ & $381,543(45 \%)$ & $57,822(73 \%)$ & $410,299(80 \%)$ & $849,664(59 \%)$
\end{tabular}

We use data on school surveys obtained online at http://schools.nyc.gov/Accountability/tools/ survey/default.htm (last accessed, July 2013). Even though response rates have increased over time, we only use data from surveys for three years from 2007-2009 because our goal is to characterize the school environment experienced by the students in our sample.

The school survey contains four parts: engagement, safety and respect, communication, and academic expectations. Though there is some overlap between these categories, the DOE defines them as follows:

1) Engagement: engage all parents, teachers, and students in an active and vibrant partnership to promote student learning.

2) Safety and Respect: ensure that all members of the school community feel physically and emotionally secure, allowing everyone to focus on student learning.

3) Communication: provide information about school's educational goals and offer appropriate feedback on each student's learning outcomes.

4) Academic Expectations: encourage students to do their best by developing rigorous and meaningful academic goals.

Students, parents, and teachers are asked to fill out questions related to each of these aspects of schooling. Each question response is awarded a score between 0 and 10, with 10 reflecting the score most favorable to a school's learning environment. The DOE converts each question into a score using a school survey model (DOE, 2012d). Scores on surveys contribute to a school's progress reports, representing 10-15\% of school's grade. Rockoff and Speroni (2008) provide 
further analysis of the comparability of survey responses from students, teachers, and parents from 2008.

The survey classifies schools into nine groups: Early Childhood Center, Elementary School, Elementary/Middle School, K-12 School, Middle School, Middle/High School, High School, Transfer School, and YABC. We standardize scores with zero mean and unit variance within

survey year and school type. For each school, we compute an average of three years weighted by the number of respondents for each question. We merge school survey attributes to enrollment by school (not program).

\section{Matching Datasets and the Analysis Sample}

We merged high school match files and the student file, then matched the merged file to the registration file for grade 8 . Next, we merged baseline scores for students for whom they are available. Finally, we merged the dataset of cleaned Regents outcome scores. For each test, we compute the implied years of small school attendance based on the test date and enrollment status. If a student took a Regents test in the fall semester, we computed years assuming the exam date is January 31st. Otherwise, we compute years assuming the exam date is June 1st. The resulting file is our analysis sample for the Regents outcomes. We follow a similar approach for credit, attendance, and graduation outcomes. We compute grade progression from enrollment files. The NYC DOE's College Board and National Student Clearinghouse files are matched to the set of lotteried small school applicants. 


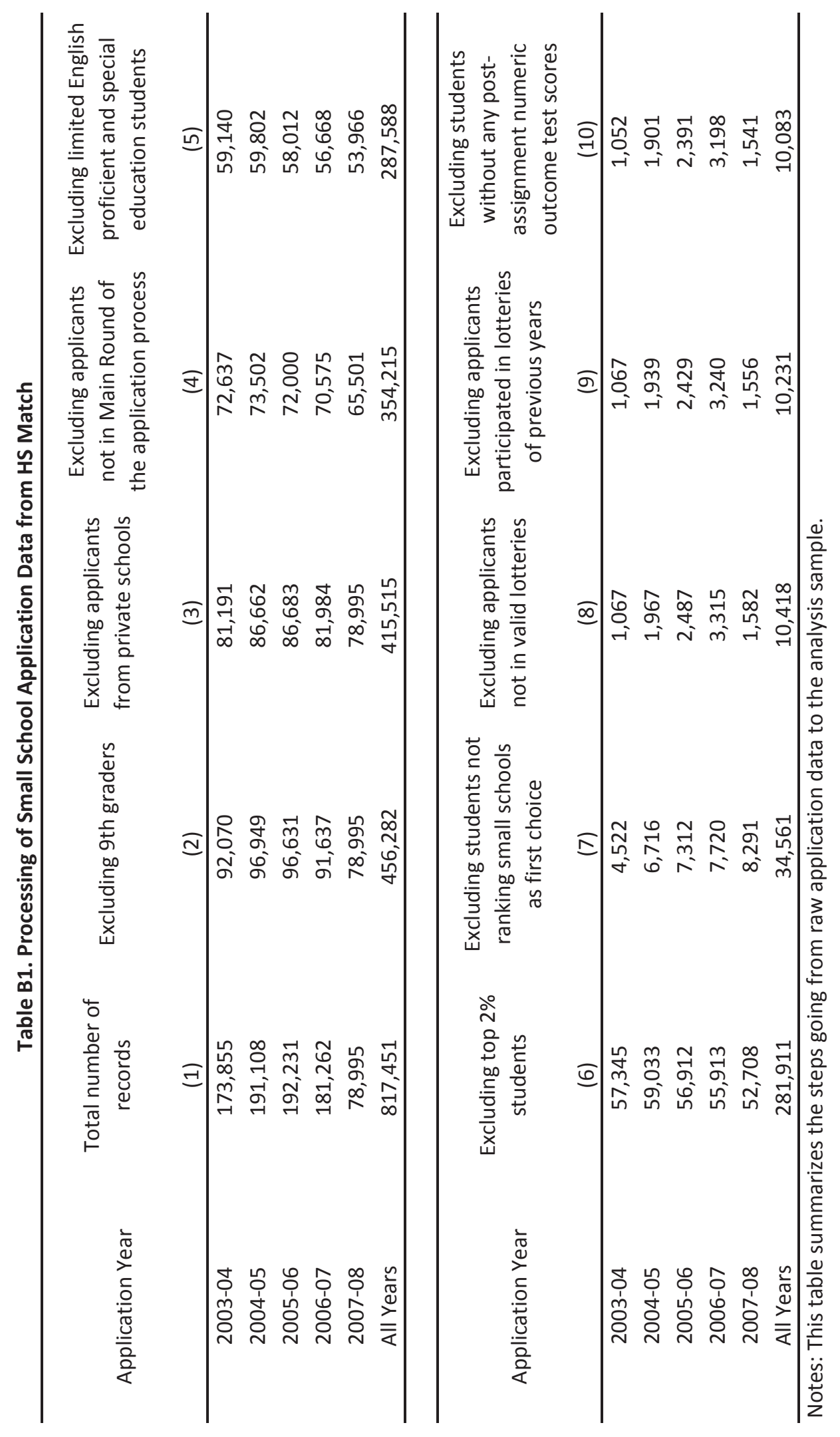


Table B2. Match from Small School Applicants to Regents Test Score Outcomes

\begin{tabular}{|c|c|c|c|c|c|c|}
\hline \multirow[b]{2}{*}{ Record Availability } & \multicolumn{6}{|c|}{ Application School Year } \\
\hline & $\begin{array}{c}2003-04 \\
(1)\end{array}$ & $\begin{array}{c}\text { 2004-05 } \\
(2)\end{array}$ & $\begin{array}{c}2005-06 \\
(3)\end{array}$ & $\begin{array}{c}2006-07 \\
(4)\end{array}$ & $\begin{array}{c}\text { 2007-08 } \\
(5)\end{array}$ & $\begin{array}{c}\text { All Years } \\
(6)\end{array}$ \\
\hline & \multicolumn{6}{|c|}{ Panel A. Math } \\
\hline Number of applicants & 1,067 & 1,939 & 2,429 & 3,240 & 1,556 & 10,231 \\
\hline Number with score observed before application & 29 & 20 & 53 & 149 & 64 & 315 \\
\hline Number with score observed after application & 802 & 1,415 & 1,745 & 2,393 & 1,169 & 7,524 \\
\hline Number with different multiple scores observed after application & 247 & 644 & 808 & 1,164 & 534 & 3,397 \\
\hline Number with different multiple scores observed after application, on first date & 1 & 5 & 0 & 2 & 2 & 10 \\
\hline Number with score observed on most common date & 498 & 662 & 720 & 1,435 & 678 & 3,993 \\
\hline Number with score observed before most common date & 194 & 507 & 753 & 179 & 47 & 1,680 \\
\hline \multirow[t]{2}{*}{ Number with score observed after most common date } & 109 & 241 & 272 & 777 & 442 & 1,841 \\
\hline & \multicolumn{6}{|c|}{ Panel B. English } \\
\hline Number of applicants & 1,067 & 1,939 & 2,429 & 3,240 & 1,556 & 10,231 \\
\hline Number with score observed before application & 0 & 0 & 0 & 0 & 1 & 1 \\
\hline Number with score observed after application & 778 & 1,353 & 1,709 & 2,331 & 1,091 & 7,262 \\
\hline Number with different multiple scores observed after application & 223 & 458 & 650 & 701 & 352 & 2,384 \\
\hline Number with different multiple scores observed after application, on first date & 0 & 1 & 1 & 15 & 5 & 22 \\
\hline Number with score observed on most common date & 310 & 549 & 674 & 993 & 456 & 2,982 \\
\hline Number with score observed before most common date & 168 & 278 & 394 & 455 & 291 & 1,586 \\
\hline \multirow[t]{2}{*}{ Number with score observed after most common date } & 300 & 525 & 640 & 868 & 339 & 2,672 \\
\hline & \multicolumn{6}{|c|}{ Panel C. Global History } \\
\hline Number of applicants & 1,067 & 1,939 & 2,429 & 3,240 & 1,556 & 10,231 \\
\hline Number with score observed before application & 0 & 0 & 0 & 0 & 0 & 0 \\
\hline Number with score observed after application & 797 & 1,365 & 1,673 & 2,276 & 1,069 & 7,180 \\
\hline Number with different multiple scores observed after application & 254 & 640 & 692 & 823 & 371 & 2,780 \\
\hline Number with different multiple scores observed after application, on first date & 0 & 5 & 2 & 9 & 1 & 17 \\
\hline Number with score observed on most common date & 475 & 809 & 933 & 1,315 & 723 & 4,255 \\
\hline Number with score observed before most common date & 26 & 62 & 151 & 165 & 85 & 489 \\
\hline \multirow[t]{2}{*}{ Number with score observed after most common date } & 296 & 489 & 587 & 787 & 260 & 2,419 \\
\hline & \multicolumn{6}{|c|}{ Panel D. US History } \\
\hline Number of applicants & 1,067 & 1,939 & 2,429 & 3,240 & 1,556 & 10,231 \\
\hline Number with score observed before application & 0 & 0 & 0 & 0 & 0 & 0 \\
\hline Number with score observed after application & 716 & 1,256 & 1,608 & 2,163 & 933 & 6,676 \\
\hline Number with different multiple scores observed after application & 215 & 399 & 492 & 494 & 174 & 1,774 \\
\hline Number with different multiple scores observed after application, on first date & 0 & 0 & 1 & 2 & 2 & 5 \\
\hline Number with score observed on most common date & 393 & 624 & 887 & 1,180 & 641 & 3,725 \\
\hline Number with score observed before most common date & 240 & 403 & 468 & 572 & 214 & 1,897 \\
\hline \multirow[t]{2}{*}{ Number with score observed after most common date } & 83 & 229 & 252 & 409 & 76 & 1,049 \\
\hline & \multicolumn{6}{|c|}{ Panel E. Living Environment } \\
\hline Number of applicants & 1,067 & 1,939 & 2,429 & 3,240 & 1,556 & 10,231 \\
\hline Number with score observed before application & 0 & 0 & 0 & 0 & 0 & 0 \\
\hline Number with score observed after application & 788 & 1,326 & 1,645 & 2,189 & 1,046 & 6,994 \\
\hline Number with different multiple scores observed after application & 157 & 447 & 511 & 598 & 232 & 1,945 \\
\hline Number with different multiple scores observed after application, on first date & 0 & 1 & 0 & 2 & 1 & 4 \\
\hline Number with score observed on most common date & 307 & 473 & 749 & 1,050 & 491 & 3,070 \\
\hline Number with score observed before most common date & 2 & 7 & 42 & 123 & 39 & 213 \\
\hline Number with score observed after most common date & 479 & 845 & 854 & 1,014 & 515 & 3,707 \\
\hline
\end{tabular}

Notes: This table summarizes the match between Regents test score outcomes and lotteried small school applicants. The sample is restricted to students in column (10) of Table B1. 
Table B3. Match from Small School Applicants to Outcome Data

\begin{tabular}{|c|c|c|c|c|c|c|}
\hline \multirow{2}{*}{ Application Cohort } & \multirow{2}{*}{$\begin{array}{l}\text { Number of } \\
\text { Students in } \\
\text { Sample }\end{array}$} & \multirow{2}{*}{ Years Observed } & \multirow{2}{*}{$\begin{array}{l}\text { Most Common } \\
\text { Years Observed }\end{array}$} & \multicolumn{3}{|c|}{ Matching Rate } \\
\hline & & & & Total & Offered & Not Offered \\
\hline & \multicolumn{6}{|c|}{ Panel A. Credits } \\
\hline $2003-2004$ & 1,067 & $2005-2011$ & $2005-2008$ & 0.922 & 0.926 & 0.914 \\
\hline $2004-2005$ & 1,939 & $2005-2011$ & $2006-2009$ & 0.943 & 0.949 & 0.937 \\
\hline $2005-2006$ & 2,429 & $2005-2011$ & $2007-2010$ & 0.929 & 0.942 & 0.920 \\
\hline $2006-2007$ & 3,240 & $2005-2011$ & $2008-2011$ & 0.921 & 0.932 & 0.911 \\
\hline \multirow[t]{2}{*}{$2007-2008$} & 1,556 & $2005-2011$ & $2009-2011$ & 0.939 & 0.927 & 0.947 \\
\hline & \multicolumn{6}{|c|}{ Panel B. Attendance } \\
\hline $2003-2004$ & 1,067 & $2005-2010$ & $2005-2008$ & 0.988 & 0.986 & 0.991 \\
\hline $2004-2005$ & 1,939 & $2006-2010$ & $2006-2009$ & 0.985 & 0.986 & 0.984 \\
\hline $2005-2006$ & 2,429 & $2007-2010$ & $2007-2010$ & 0.978 & 0.984 & 0.974 \\
\hline $2006-2007$ & 3,240 & $2008-2010$ & $2008-2010$ & 0.970 & 0.973 & 0.968 \\
\hline \multirow[t]{2}{*}{$2007-2008$} & 1,556 & $2009-2010$ & $2009-2010$ & 0.993 & 0.985 & 0.998 \\
\hline & \multicolumn{6}{|c|}{ Panel C. Graduation } \\
\hline $2003-2004$ & 1,067 & $2008-2012$ & 2010 & 0.799 & 0.799 & 0.797 \\
\hline $2004-2005$ & 1,939 & $2009-2012$ & 2011 & 0.812 & 0.836 & 0.788 \\
\hline $2005-2006$ & 2,429 & 2010-2012 & 2012 & 0.798 & 0.823 & 0.780 \\
\hline $2006-2007$ & 3,240 & 2011-2012 & 2012 & 0.815 & 0.826 & 0.803 \\
\hline \multirow[t]{2}{*}{$2007-2008$} & 1,556 & 2012 & 2012 & 0.814 & 0.803 & 0.821 \\
\hline & \multicolumn{6}{|c|}{ Panel D. PSAT } \\
\hline $2003-2004$ & 1,067 & $2004-2008$ & $2005-2006$ & 0.604 & 0.631 & 0.550 \\
\hline $2004-2005$ & 1,939 & $2002-2010$ & $2006-2007$ & 0.624 & 0.660 & 0.588 \\
\hline $2005-2006$ & 2,429 & $2005-2011$ & $2007-2008$ & 0.636 & 0.679 & 0.604 \\
\hline 2006-2007 & 3,240 & $2007-2011$ & 2008-2009 & 0.660 & 0.705 & 0.616 \\
\hline \multirow[t]{2}{*}{$2007-2008$} & 1,556 & $2008-2012$ & $2009-2010$ & 0.673 & 0.687 & 0.664 \\
\hline & \multicolumn{6}{|c|}{ Panel E. SAT } \\
\hline $2003-2004$ & 1,067 & $2006-2010$ & 2007 & 0.425 & 0.450 & 0.372 \\
\hline $2004-2005$ & 1,939 & $2007-2011$ & 2008 & 0.326 & 0.331 & 0.321 \\
\hline $2005-2006$ & 2,429 & $2008-2012$ & 2009 & 0.297 & 0.342 & 0.264 \\
\hline $2006-2007$ & 3,240 & $2009-2012$ & 2010 & 0.374 & 0.399 & 0.350 \\
\hline \multirow[t]{2}{*}{$2007-2008$} & 1,556 & $2010-2012$ & 2011 & 0.393 & 0.423 & 0.374 \\
\hline & \multicolumn{6}{|c|}{ Panel F. Advanced Placement } \\
\hline $2003-2004$ & 1,067 & $2006-2008$ & $2007-2008$ & 0.070 & 0.058 & 0.095 \\
\hline $2004-2005$ & 1,939 & 2007-2009 & $2008-2009$ & 0.054 & 0.051 & 0.056 \\
\hline $2005-2006$ & 2,429 & $2007-2011$ & $2009-2010$ & 0.091 & 0.111 & 0.076 \\
\hline $2006-2007$ & 3,240 & $2008-2012$ & $2010-2011$ & 0.123 & 0.147 & 0.100 \\
\hline \multirow[t]{2}{*}{$2007-2008$} & 1,556 & $2009-2012$ & 2011-2012 & 0.107 & 0.132 & 0.089 \\
\hline & \multicolumn{6}{|c|}{ Panel G. National Student Clearinghouse } \\
\hline $2003-2004$ & 1,067 & $2009-2012$ & n.a & 0.004 & 0.001 & 0.009 \\
\hline $2004-2005$ & 1,939 & $2009-2013$ & $2009-2012$ & 0.401 & 0.444 & 0.359 \\
\hline $2005-2006$ & 2,429 & $2009-2013$ & $2010-2012$ & 0.395 & 0.439 & 0.363 \\
\hline $2006-2007$ & 3,240 & $2009-2013$ & 2011-2012 & 0.400 & 0.431 & 0.370 \\
\hline $2007-2008$ & 1,556 & $2010-2013$ & 2012 & 0.293 & 0.316 & 0.277 \\
\hline
\end{tabular}

Notes: This table summarizes the match between credit, attendance, graduation, College Board, and National Student Clearinghouse outcomes and lotteried small school applicants. The sample is restricted to students in column (10) of Table B1. 


\section{References}

Abadie, Alberto, "Semiparametric Instrumental Variables Estimation of Treatment Response Models," Journal of Econometrics, 2003, 113(2), 231-263.

Abdulkadiroğlu, Atila, Josh Angrist, and Parag Pathak, "The Elite Illusion: Achievement Effects at Boston and New York Exam Schools," 2011. forthcoming, Econometrica.

, Yusuke Narita, and Parag Pathak, "Research Design meets Market Design," 2013. Unpublished working paper, MIT.

, Joshua D. Angrist, Susan Dynarski, Thomas J. Kane, and Parag A. Pathak,

"Accountability and Flexibility in Public Schools: Evidence from Boston's Charters and Pilots," Quarterly Journal of Economics, 2011, 126(2), 699-748.

, Parag A. Pathak, and Alvin E. Roth, "The New York City High School Match," American Economic Review, Papers and Proceedings, 2005, 95, 364-367.

_ _ _ _ and _ _ _ "Strategy-proofness versus Efficiency in Matching with Indifferences: Redesigning the New York City High School Match," American Economic Review, 2009, 99(5), 1954-1978.

Anderson, Michael, "Multiple Inference and Gender Differences in the Effects of Early Intervention: A Reevaluation of the Abecedarian, Perry Preschool and Early Training Projects," Journal of the American Statistical Association, 2008, 103, 1481-1495.

Andrews, M., W. Duncombe, and J. Yinger, "Revisiting Economies of Size in American Education: Are We Any Closer to a Consensus?," Economics of Education Review, 2002, 21(3), 245262.

Angrist, Joshua D. and Alan Krueger, "Estimating the Payoff to Schooling Using the Vietnam-Era Draft Lottery," 1992. NBER Working Paper 4067.

and Guido Imbens, "Two-Stage Least Squares Estimation of Average Causal Effects in Models with Variable Treatment Intensity," Journal of the American Statistical Association: Applications and Case Studies, 1995, 90, 431-442.

and Victor Lavy, "Using Maimonides' Rule to Estimate the Effect of Class Size on Student Achievement," Quarterly Journal of Economics, 1999, 114(2), 533-575.

, Parag Pathak, and Christopher R. Walters, "Explaining Charter School Effectiveness," American Economic Journal: Applied Economics, 2013, 5(4), 1-27. 
Sarah R. Cohodes, Susan Dynarski, Parag A. Pathak, and Christopher Walters, "Stand and Deliver: Effects of Boston's Charter High Schools on College Preparation, Entry and Choice," 2013. NBER Working paper, 19275.

— Susan Dynarski, Thomas J. Kane, Parag A. Pathak, and Christopher Walters, "Who Benefits from KIPP?," Journal of Policy Analysis and Management, 2012.

Barrow, Lisa, Amy Claessens, and Diane Whitmore Schanzenbach, "The Impact of Chicago's Small High School Initiative," 2013. NBER Working Paper, 18889.

Bloom, Howard S. and Rebecca Unterman, "Sustained Positive Effects on Graduation Rates Produced by New York City's Small Public High Schools of Choice," 2012. MDRC Policy Brief.

and _ _ "Sustained Progress: New Findings about the Effectiveness and Operation of Small Public High Schools of Choice in New York City," 2013. MDRC Policy Brief, August 26.

Bloom, Howard, Saskia-Levy Thompson, and Rebecca Unterman, "Transforming the High School Experience: How New York City's New Small Schools are Boosting Student Achievement and Graduation Rates," 2010. MDRC.

Bloomfield, David C., "Small Schools: Myth and Reality," in "NYC Schools Under Bloomberg and Klein: What Parents, Teachers, and Policymakers Need to Know" 2006, pp. $49-56$.

Bowen, William, Mathew Chingos, and Mike McPherson, Crossing the Finish Line: Completing College at America's Public Universities, Princeton University Press, Princeton NJ, 2009.

Brynes, Susan, "\$51 Million Grant from Bill \& Melinda Gates Foundation to Support Small Dynamic High Schools to Boost Student Achievement," 2003. Press Release, Bill \& Melinda Gates Foundation, September. Available at: http://www.gatesfoundation.org/MediaCenter/Press-Releases/2003/09/New-York-City-Department-of-Education-ReceivesGrant.

Chetty, Raj, John N. Friedman, Nathaniel Hilger, Emmanuel Saez, and Diane Whitmore Schanzenbach, "How Does Your Kindergarten Classroom Affect Your Earnings? Evidence from Project Star," Quarterly Journal of Economics, 2011, 126(4), 1593-1660.

Conant, James B., The American High School Today: A First Report to Interested Citizens, New York: McGraw-Hill, 1959. 
Cullen, Julie B., Brian Jacob, and Steve Levitt, "The Effect of School Choice on Participants: Evidence from Randomized Lotteries," Econometrica, 2006, 75, 1191-1230.

—, Steven D. Levitt, Erin Robertson, and Sally Sadoff, "What Can Be Done to Improve Struggling High Schools?," Journal of Economic Perspectives, 2013, 27(2), 133152.

Cunha, Flavio and James Heckman, "The Technology of Skill Formation," American Economic Review, 2007, 97(2), 31-47.

_ _ _ _ and Susanne Schennach, "Estimating the Technology of Cognitive and Noncognitive Skill Formation," Econometrica, 2010, 78(3), 883-931.

Dee, Thomas S., Brian A. Jacob, Justin McCrary, and Jonah Rockoff, "Rules and Discretion in the Evaluation of Students and Schools: The Case of the New York Regents Examinations," 2011. Work in progress, Columbia University.

Deming, David J. and Susan Dynarski, "Into College, Out of Poverty? Policies to Increase the Postsecondary Attainment of the Poor," in Philip Levine and David Zimmerman, eds., Targeting Investments in Children: Fighting Poverty When Resources are Limited, University of Chicago Press, 2010.

— , Justine S. Hastings, Thomas J. Kane, and Douglas O. Staiger, "School Choice, School Quality and Postsecondary Attainment," 2011. forthcoming, American Economic Review.

Dobbie, William and Roland J. Fryer, "Are High Quality Schools Enough to Close the Achievement Gap? Evidence from a Social Experiment in Harlem," American Economic Journal: Applied Economics, 2011, 3(3), 158-187. and __ , "Getting Beneath the Veil of Effective Schools: Evidence from New York City," American Economic Journal: Applied Economics, 2013, 5(4), 28-60.

_ and _ _ "The Medium-Term Impacts of High-Achieving Charter Schools on Non-Test Score Outcomes," 2013. Working paper, Princeton University.

DOE, "Empowerment School Performance Agreement for 2006-07," 2007. Available at: http://www.crpe.org/portfolio/external-resources/nyc-performance-contract, Last accessed: September 2013. 
, "New York City Department of Education, Office of Labor Relations, Frequently Asked Questions," 2007. http://schools.nyc.gov/NR/rdonlyres/7E50C743-72E1-4BDC8F40-E8DDED86570A/0/LaborFAQs200742407.pdf, Last accessed: September 2013.

_ , "ChildrenFirst: A Bold, Common-Sense Plan to Create Great Schools for All New York City Children," 2009. New York City Department of Education, Available at: http://schools.nyc.gov/NR/rdonlyres/51C61E8F-1AE9-4D37-88814D688D4F843A/0/cf_corenarrative.pdf, Last accessed: September 2013.

—, "Mayor Bloomberg and Chancellor Walcott Announce 54 New Schools Will Open Next Fall," 2012. DOE Press Release, April 17, Available at: http://schools.nyc.gov/Offices/mediarelations/NewsandSpeeches/20112012/54_New_Schools, Last accessed: September 2013.

_ , "New York City Graduation Rates: Class of 2011 (2007 Cohort)," 2012. Available at: http://www.nyc.gov/html/om/pdf/2012/2011_grad_deck_presentation.pdf, Last accessed: August 2013.

_ "New York City Graduation Requirements," $2012 . \quad$ Available at: http://schools.nyc.gov/RulesPolicies/GraduationRequirements/default.htm, Last accessed: August 2013.

— "NYC School Survey 2011-2012," $2012 . \quad$ Available at: http://schools.nyc.gov/Accountability/tools/survey/default.htm, Last accessed: August 2013.

Dur, Umut, Scott D. Kominers, Parag A. Pathak, and Tayfun Sönmez, "The Demise of Walk Zones in Boston: Priorities vs. Precedence in School Choice," 2013. NBER Working Paper 18981.

Dynarski, Susan M., Joshua Hyman, and Diane Schanzenbach, "Experimental Evidence on the Effect of Childhood Investments on Postsecondary Attainment and Degree Completion," 2011. NBER Working Paper, w17533.

Epstein, Marc, "Small Schools: Miracle or Mirage?," 2013. Huffington Post, Blog, Available at: http://www.huffingtonpost.com/marc-epstein/small-schools-miracleor_b_2641400.html?utm_hp_ref=new-york, Last accessed: September 2003.

Fleischer, Brian, "High School Academic Data Audit Report," 2012. Report from Office of Auditor General Commissioned by the New York City Department of Education, February 23. 
Foderaro, Lisa, "CUNY Adjusts Amid Tide of Remedial Students," 2011. New York Times, N.Y. / Region, March 3.

Foley, Eileen and Elizabeth Reisner, "The New Century High Schools in New York City," in Becky A. Smerdon and Kathryn M. Borman, eds., Saving America's High Schools, Urban Institute Press, 2009, pp. 85-111.

, Erickson Arcaira, Stephen Coleman, Elizabeth Reisner, Troy Scott, Tandra Turner, and Yvonne Woods, "Approaches of Bill \& Melinda Gates Foundation-Funded Intermediary Organizations to Structuring and Supporting Small High Schools in New York City," 2010. Policy Studies Associates.

Fredriksson, Peter, Björn Öckert, and Hessel Oosterbeek, "Long-Term Effects of Class Size," Quarterly Journal of Economics, 2013, 128(1), 249-285.

Gates, Bill, "Prepared remarks by Bill Gates at National Education Summit on High Schools," 2005. Available at: http://www.gatesfoundation.org/media-center/speeches/2005/02/billgates-2005-national-education-summit, Last accessed: July 2013.

_ "Annual Letter of the Bill and Melinda Gates Foundation," 2009. http://www.gatesfoundation.org/who-we-are/resources-and-media/annual-letterslist/annual-letter-2009.

Gewertz, Catherine, "Federal Officials to Probe Complaint Against N.Y.C. Small High Schools," Education Week, July 12, 2006.

__ , "Small Schools Under Big Fire," Education Week, March 22, 2006.

Goertz, M., S. Loeb, and J. Wyckoff, "Recruiting, Evaluating and Retaining teachers: The Children First Strategy to Improve New York City's Teachers," in J. O'Day, C. Bitter, and L. Gomez, eds., Education Reform in New York City: Ambitious Change in the Nation's Most Complex School System, Cambridge MA: Harvard Education Press, 2011, pp. 157-177.

Gootman, Elisa, "Early Gains at City's Themed Schools," 2005. New York Times, Metropolitan Desk, January 4.

—_ "Annenberg Grant to Help Smaller Schools," 2006. New York Times, NY/Region Section, April 28.

— "City's New Small Schools are Focus of a Bias Inquiry," 2006. New York Times, NY/Region Section, June 16. 
and Sharona Coutts, "Lacking Credits, Some Students Learn a Shortcut," 2008. New York Times, NY/Region Section, April 11.

Hanuschek, Eric A., "The Failure of Input-Based Schooling Policies," Economic Journal, 2003, 113, F64-F98.

Hemphill, Clara and Kim Nauer, "The New Marketplace: How Small-School Reforms and School Choice have Reshaped New York City's High Schools," 2009. Center for New York City Affairs, Milano the New School for Management and Urban Policy.

_ and _ _ "Managing by the Numbers: Empowerment and Accountability in New York City's Schools," 2010. Center for New York City Affairs, Milano the New School for Management and Urban Policy.

Hoxby, Caroline and Christopher Avery, "The Missing "One-offs": The Hidden Supply of High-Achieving, Low-Income Students," 2012. NBER Working Paper, 18586.

Iatarola, P., A. Schwartz, L. Stiefel, and Colin Chellman, "Small Schools, Large Districts: Small School Reform and New York City's Students," Teachers College Record, 2008, 110(9), 1837-1878.

Imbens, Guido W. and Joshua D. Angrist, "Identification and Estimation of Local Average Treatment Effects," Econometrica, 1994, 62, 467-475.

Klein, Joel I., "Cover Letter," in Laura Kurgan and New Visions for Public Schools, eds., From Large School Buildings to Small School Campuses: Orchestrating the Shift, 2005, p. 2.

_ _ "Empowerment Schools FAQ," 2006. New York City Department of Education, Available at: http://schools.nycenet.edu/region6/midwood/empowerment.html, Last accessed: September 2013.

Kling, Jeffrey R., Jeffrey B. Liebman, and Lawrence F. Katz, "Experimental Analysis of Neighborhood Effects," Econometrica, 2007, 75(1), 83-119.

Kominers, Scott D. and Tayfun Sönmez, "Designing for Diversity in Matching," 2012. Working paper, Boston College.

Krueger, Alan, "Experimental Estimates of Education Production Functions," Quarterly Journal of Economics, 1999, 114(2), 497-532.

Krueger, Alan B., "Economic Considerations and Class Size," Economic Journal, 2003, 113, $34-63$. 
Kuziemko, Ilyana, "Using Shocks to School Enrollment to Estimate the Effect of School Size on Student Achievement," Economics of Education Review, 2006, 25, 63-75.

Lawrence, Barbara, "Dollars and Sense: The Cost Effectiveness of Small Schools," 2002. Together with: Steven Bingler and Barbara Diamond and Bobbie Hill and Jerry Hoffman and Craig Howley and Stacy Mitchell and David Rudolph and Elliot Washor, KnowledgeWorks Foundation.

Lazear, Edward P., "Educational Production," Quarterly Journal of Economics, 2001, 116(3), 777-803.

Miller, Gifford, "Sharing Space: Rethinking the Implementation of Small High School Reform in New York City," 2005. Council of the City of New York, Available at: http://www.nyc.gov/html/records/pdf/govpub/2130small_schools_final3.pdf, last accessed: September 2013.

Murnane, Richard J., "U.S. High School Graduation Rates: Patterns and Explanations," 2013. NBER Working Paper, 18701.

Nadelstern, Eric, "Inteview with Horace editor Jill Davidson," 2005. Available at: http://www.essentialschools.org/resources/312, Last accessed: September 2013.

NCES, "Digest of Education Statistics, National Center for Education Statistics," 2010. http://nces.ed.gov/fastfacts/, Last accessed: July 2012.

NVPS, "Reforming High Schools: Lessons from the New Century High Schools Initiative," 2006. Publication of New Visions for Public Schools.

NYSED, "New York State Education Department, 100.5 Diploma Requirements," 2010. Available at: http://www.p12.nysed.gov/part100/pages/1005.html, Last accessed: August 2013.

Otterman, Sharon, "Big Schools Fall Hard in City Plan," 2010. NY Times, Metropolitan Desk, January 26.

Phillips, Anna, "In a First, City Plans to End Contract with a Support Organization," 2011. GothamSchools, April 19th, http://gothamschools.org/2011/04/19/in-a-first-city-plans-toend-contract-with-a-support-organization/, Last accessed: September 2013.

Pop-Eleches, Cristian and Miguel Urquiola, "Going to a Better School: Effects and Behavioral Responses," American Economic Review, 2013, 4, 1289-1324.

Ravitch, Diane, The Death and Life of the Great American School System: How Testing and Choice are Undermining Education, Basic Books, 2011. 
Robelen, Eric, "Gates High Schools get Mixed Review in Study," 2005. Education Week, November 16.

Rockoff, Jonah and Cecilia Speroni, "Reliability, Consistency, and Validity of the NYC DOE Environmental Surveys: A Preliminary Analysis," 2008. Unpublished note, Columbia University.

Rodriguez-Planas, Nuria, "Longer-Terms Impacts of Mentoring, Educational Services, and Learning Incentives: Evidence from a Randomized Trial in the United States," American Economic Journal: Applied Economics, 2012, 4(4), 121-139.

Santos, Fernanda, "Before the School Bell, Teachers in Bronx Make House Calls," 2011. NY Times, N.Y. Region, September 2.

Schwartz, Amy E., L. Stiefel, and Matthew Wiswall, "Do Small Schools Improve Performance in a Large, Urban District? Causal Evidence from New York City," 2013. Unpublished manuscript, Institute for Education and Social Policy, NYU.

Shear, Linda, Barbara Means, Karen Mitchell, Ann House, Torie Gorges, Aasha Joshi, Becky Smerdon, and Jamie Shkolnik, "Contrasting Paths to Small-School Reform: Results of a 5-year Evaluation of the Bill \& Melinda Gates Foundation's National High Schools Initiative," Teachers College Volume, 2008, 110(9), 1986-2039.

Toch, Thomas, High Schools on a Human Scale: How Small Schools Can Transform American Education, Beacon Press, 2003.

_ , "Small is Still Beautiful," Washington Monthly, 2010, July/August.

UFT, "Report of the United Federation of Teachers Small School Task Force," 2005. Available at: http://www.uft.org/files/attachments/uft-report-2005-06-small-schools.pdf, Last accessed: September 2013. 